\title{
Global maps of soil temperature
}

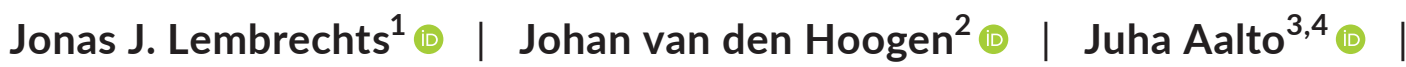

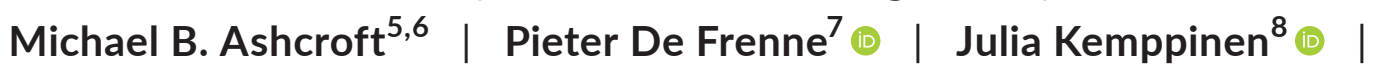

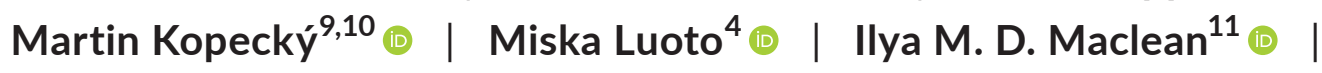

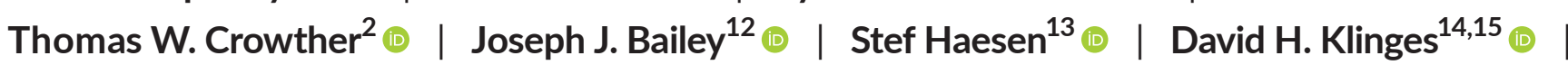

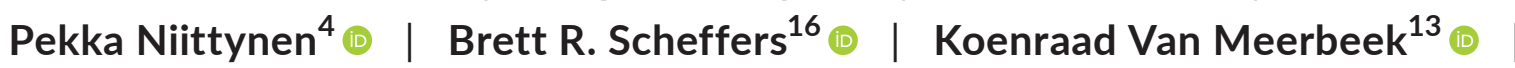

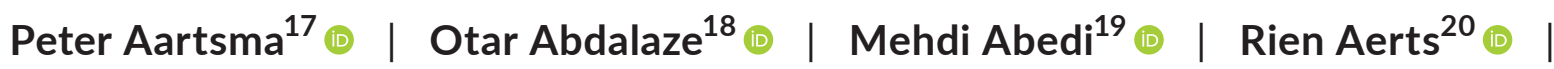

Negar Ahmadian ${ }^{19}{ }_{\infty}$ | Antje Ahrends ${ }^{21}$ A $_{\text {| Juha M. Alatalo }}^{22}{ }^{2}$ |

Jake M. Alexander ${ }^{23}{ }_{(0)}$ | Camille Nina Allonsius ${ }^{24}$ C $_{\text {| Jan Altman }}{ }^{9,10}{ }_{\odot}$ |

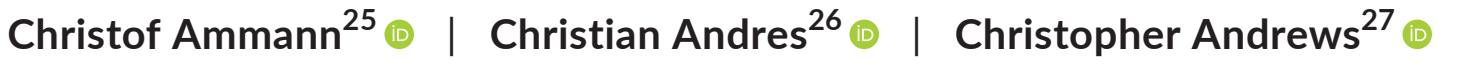

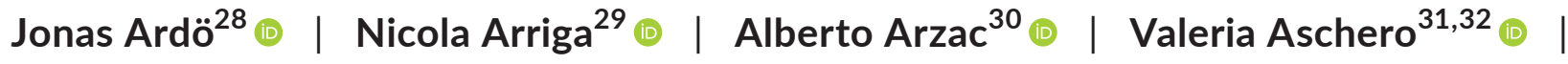

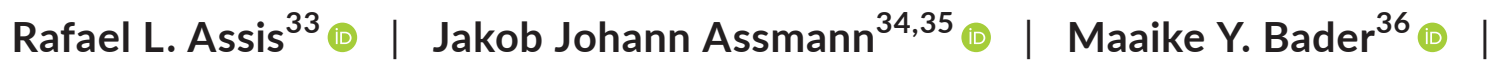

Khadijeh Bahalkeh $^{19}$ (] | Peter Barančok ${ }^{37}$ (1) | Isabel C. Barrio ${ }^{38}$ (i)

Agustina Barros $^{32} \odot$ | Matti Barthel ${ }^{26}$ | Edmund W. Basham ${ }^{14} \odot$ | Marijn Bauters ${ }^{39} \odot$ |

Manuele Bazzichetto $^{40}$ (i) | Luca Belelli Marchesini ${ }^{41}$ (ㅇ | Michael C. Bell ${ }^{42}$ (ㅇ |

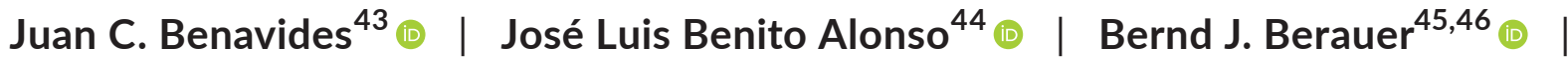

Jarle W. Bjerke ${ }^{47}$ (1) | Robert G. Björk ${ }^{48,49}$ (1) Mats P. Björkman ${ }^{48,49}$

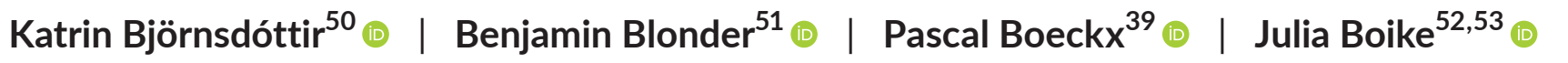

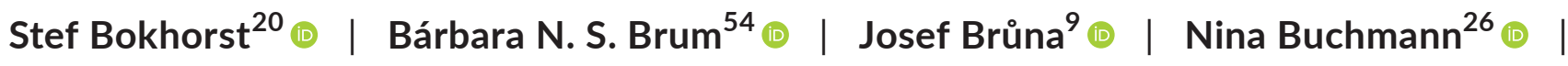

Pauline Buysse $^{55}$ | José Luís Camargo ${ }^{56}$ | Otávio C. Campoe ${ }^{57}$ @ | Onur Candan ${ }^{58}{ }_{\infty}$

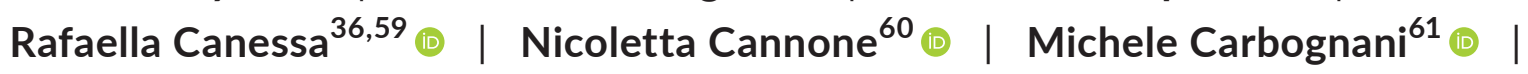

Jofre Carnicer ${ }^{62,63}$ (1) | Angélica Casanova-Katny ${ }^{64}$ @ | Simone Cesarz ${ }^{65,66}$ (

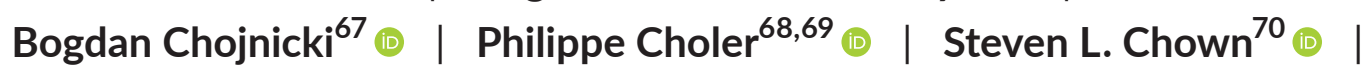

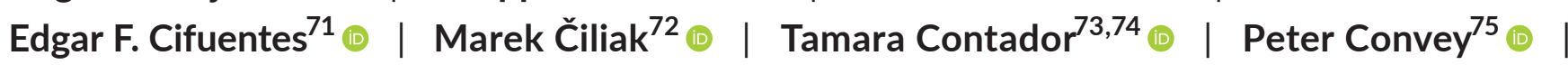

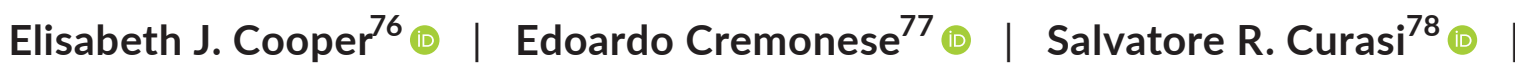

Robin Curtis $^{11}$ | Maurizio Cutini ${ }^{79}$ ( ) | C. Johan Dahlberg ${ }^{80,81} \odot$ | Gergana N. Daskalova ${ }^{82} \odot$ |

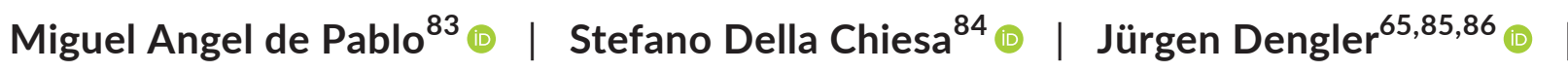

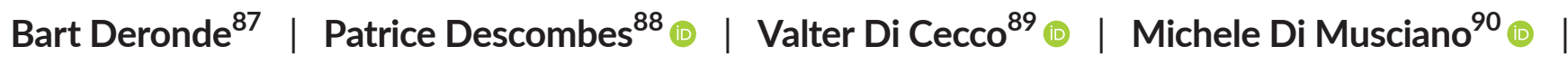

Jan Dick $^{27}$ (1) | Romina D. Dimarco ${ }^{91,92}$ | Jiri Dolezal ${ }^{9,93}$ | Ellen Dorrepaal $^{94}$ (ㅇ | 


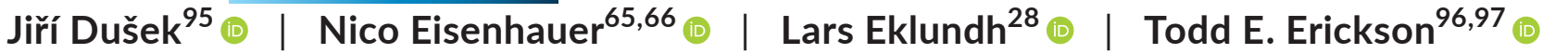

Brigitta Erschbamer $^{98}$ @ | Werner Eugster ${ }^{26}$ ( ) | Robert M. Ewers ${ }^{99}$ |

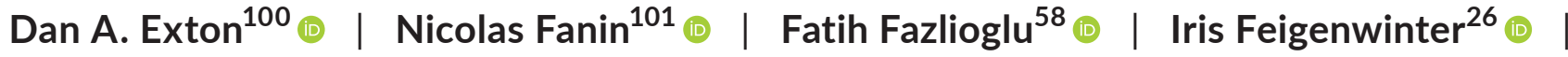

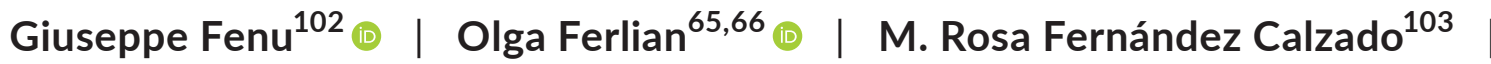

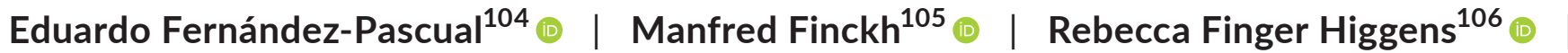

T'ai G. W. Forte ${ }^{61}$ (i) | Erika C. Freeman ${ }^{107}$ ( $\mid$ Esther R. Frei ${ }^{108,109,110}$

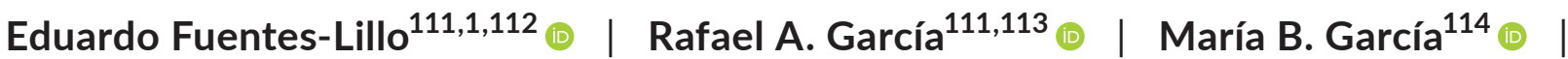

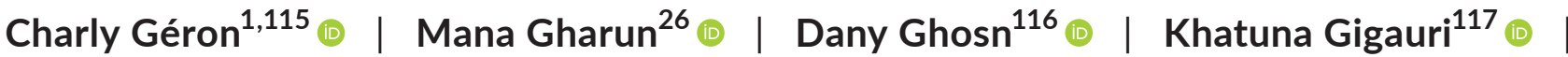

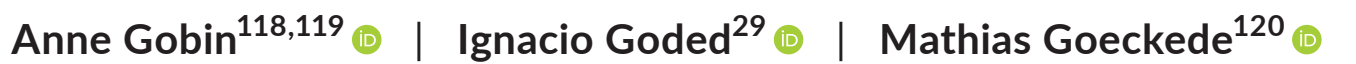

Felix Gottschall $^{65,66}$ ( ) | Keith Goulding ${ }^{121}$ ( ) | Sanne Govaert ${ }^{7}$ ( ) |

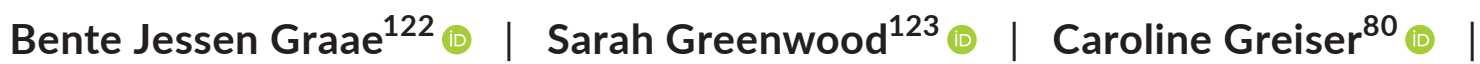

Achim Grelle $e^{124}$ @ | Benoit Guénard ${ }^{125}$ @ | Mauro Guglielmin ${ }^{126}$

Joannès Guillemot ${ }^{127,128}$ @ | Peter Haase ${ }^{129,130}$ @ | Sylvia Haider ${ }^{131,65}$ (

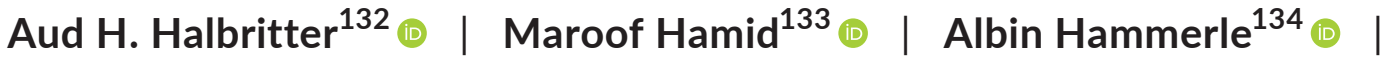

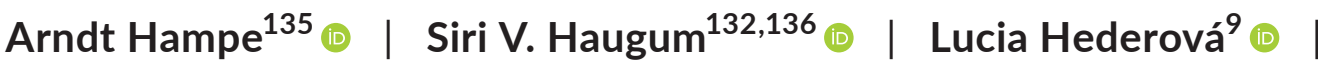

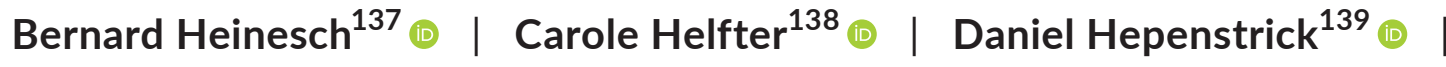

Maximiliane Herberich $^{140}$ (] | Mathias Herbst ${ }^{141}$ | Luise Hermanutz $^{142}$ (ㅇ |

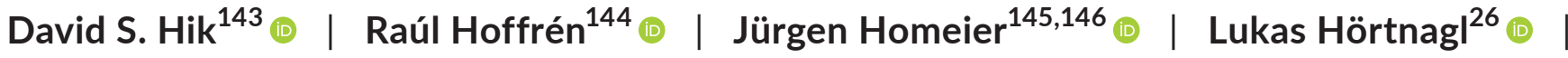

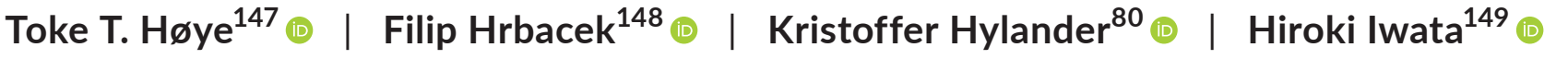

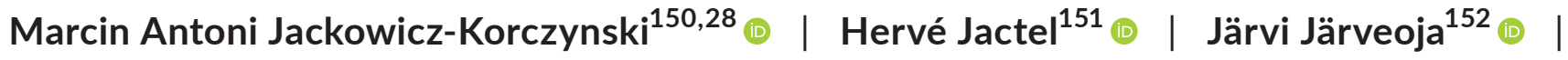

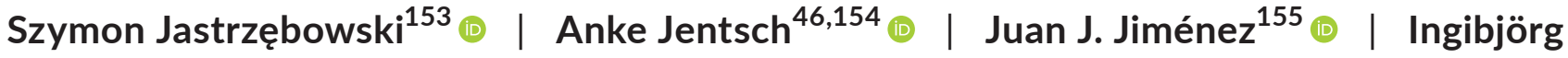

S. Jónsdóttir ${ }^{156}$ @ | Tommaso Jucker ${ }^{157}$ @ | Alistair S. Jump ${ }^{158}$

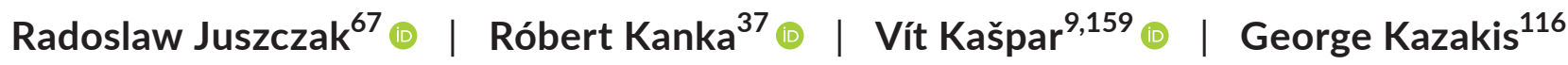

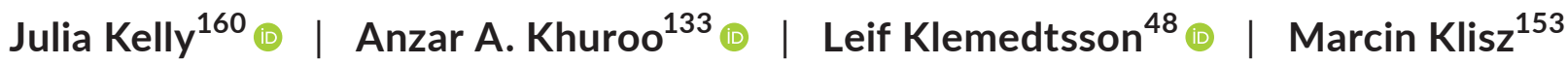

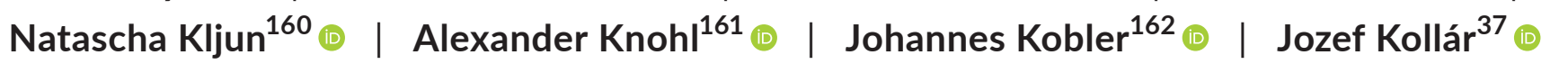

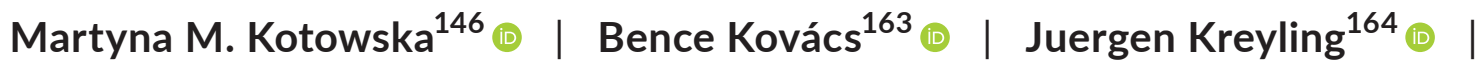

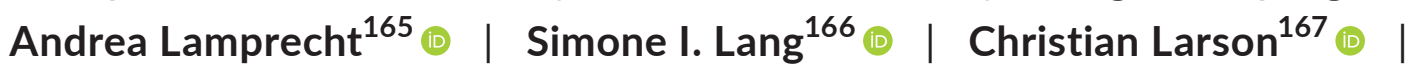

Keith Larson ${ }^{168} \odot$ | Kamil Laska ${ }^{148,169}$ @ | Guerric le Maire ${ }^{127,128}$ ๑

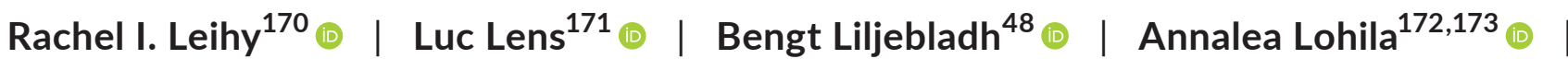

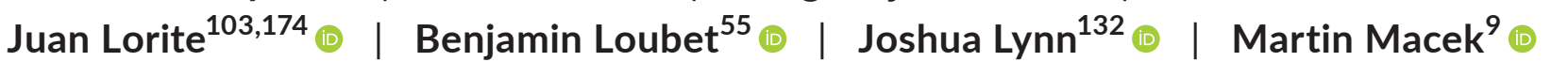

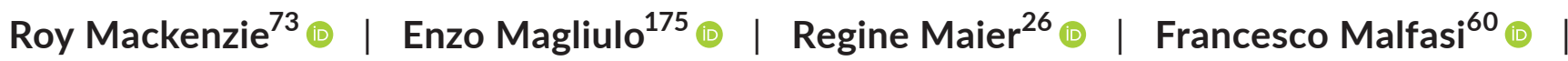

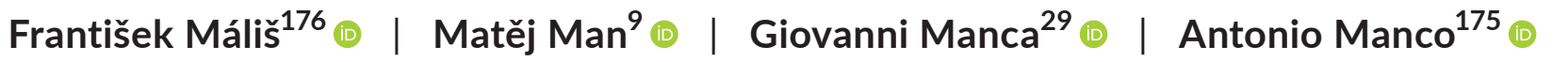

Tanguy Manise $^{137}$ | Paraskevi Manolaki ${ }^{177,178,179}$ @ | Felipe Marciniak ${ }^{54}$

Radim Matula $^{10,180}$ (1) | Ana Clara Mazzolari ${ }^{32}$ | Sergiy Medinets ${ }^{181,182,183}$ (1) |

Volodymyr Medinets $^{181}$ (1) | Camille Meeussen ${ }^{7}$ (i) | Sonia Merinero ${ }^{80}$ ।

Rita de Cássia Guimarães Mesquita ${ }^{184}$ (ㄱ) | Katrin Meusburger ${ }^{185}$ (ㄱ)

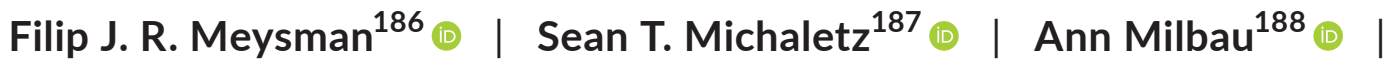

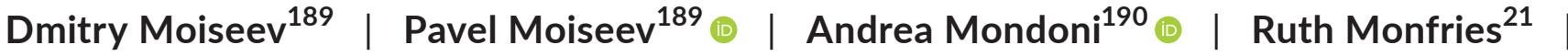


Leonardo Montagnani $^{191}$ (1) | Mikel Moriana-Armendariz ${ }^{76}$

Umberto Morra di Cella ${ }^{192}$ (1) | Martin Mörsdorf ${ }^{193}$ (1) | Jonathan

R. Mosedale ${ }^{194}$ (1) | Lena Muffler ${ }^{146}$ (1) | Miriam Muñoz-Rojas ${ }^{195,196}$

Jonathan A. Myers ${ }^{197}$ (i) ｜ Isla H. Myers-Smith ${ }^{82}$ (1) | Laszlo Nagy ${ }^{198}$

Marianna Nardino ${ }^{199}$ (1) | Ilona Naujokaitis-Lewis ${ }^{200}$ | Emily Newling ${ }^{201}$

Lena Nicklas $^{98}$ (1) | Georg Niedrist ${ }^{202}$ (1) | Armin Niessner ${ }^{203}$ | Mats B. Nilsson ${ }^{152}$ |

Signe Normand ${ }^{34,35}$ (1) | Marcelo D. Nosetto ${ }^{204,205}$ (i) | Yann Nouvellon ${ }^{127,128}$ (1) |

Martin A. Nuñez ${ }^{92,206}$ (D) | Romà Ogaya ${ }^{207,208}$ (i) | Jérôme Ogée ${ }^{101}$ (i) |

Joseph Okello $39,209,210$ (i) | Janusz Olejnik ${ }^{211}$ (i) | Jørgen Eivind Olesen ${ }^{182}$ (i) |

Øystein H. Opedal ${ }^{212}$ (D) | Simone Orsenigo ${ }^{190}$ (i) | Andrej Palaj ${ }^{37}$ (D) |

Timo Pampuch ${ }^{213}$ (i) | Alexey V. Panov ${ }^{214}$ | Meelis Pärtel ${ }^{215}$ (i) | Ada Pastor ${ }^{178}$ (i) |

Aníbal Pauchard ${ }^{111,113}$ (1) | Harald Pauli'i65 | Marian Pavelka ${ }^{95}$ (1) |

William D. Pearse 216,217 (1) | Matthias Peichl $^{152}$ (1) | Loïc Pellissier 218,219

Rachel M. Penczykowski ${ }^{197}$ (D) | Josep Penuelas ${ }^{207,208}$ (i) | Matteo Petit Bon ${ }^{9,76,166}$ (i) |

Alessandro Petraglia61 ${ }^{61}$ | Shyam S. Phartyal ${ }^{220}$ | Gareth K. Phoenix $^{221}$ (i) |

Casimiro Pio ${ }^{222}$ (1) | Andrea Pitacco 223 (1) Camille Pitteloud ${ }^{218,219}$ (i) |

Roman Plichta $^{180}$ (1) | Francesco Porro ${ }^{190}$ (1) | Miguel Portillo-Estrada ${ }^{1}$ (D) |

Jérôme Poulenard ${ }^{224}$ (1) | Rafael Poyatos R3,225 (B) | Anatoly S. Prokushkin $^{30,214}$ (1) |

Radoslaw Puchalka 226,227 (i) | Mihai Pușcaș ${ }^{228,229,230}$ (i) | Dajana Radujković1 (D) |

Krystal Randall ${ }^{5,231}$ (D) | Amanda Ratier Backes ${ }^{65,131}$ (D) | Sabine Remmele ${ }^{203}$

Wolfram Remmers $^{232}$ | David Renault ${ }^{40,233}$ (1) | Anita C. Risch ${ }^{234}$ (1) |

Christian Rixen ${ }^{108,109}$ (i) | Sharon A. Robinson ${ }^{5,231}$ (i) | Bjorn J. M. Robroek ${ }^{235}$ (D) |

Adrian V. Rocha ${ }^{236}$ (1) | Christian Rossi ${ }^{237,238}$ | Graziano Rossi ${ }^{190}$ (1) |

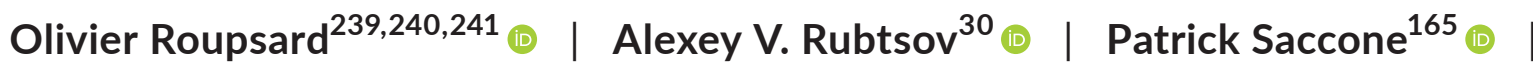

Clotilde Sagot $^{242}$ | Jhonatan Sallo Bravo ${ }^{243,244}$ (i) | Cinthya C. Santos ${ }^{245}$ (1) |

Judith M. Sarneel ${ }^{246}$ (1) | Tobias Scharnweber ${ }^{213}$ (i) | Jonas Schmeddes ${ }^{164}$

Marius Schmidt ${ }^{247}$ (1) | Thomas Scholten ${ }^{248}$ (1) | Max Schuchardt ${ }^{46}$ |

Naomi Schwartz ${ }^{249}$ | Tony Scott ${ }^{121}$ (D) | Julia Seeber ${ }^{134,202}$ (D) |

Ana Cristina Segalin de Andrade ${ }^{245}$ | Tim Seipel $^{167}$ (i) | Philipp Semenchuk ${ }^{250}$ (i) |

Rebecca A. Senior ${ }^{251}$ (i) | Josep M. Serra-Diaz ${ }^{252}$ (i) | Piotr Sewerniak $^{253}$ (I) |

Ankit Shekhar $^{26}$ | Nikita V. Sidenko ${ }^{214}$ | Lukas Siebicke Lib1 $^{16}$

Laura Siegwart Collier ${ }^{142,254}$ (B) | Elizabeth Simpson ${ }^{216}$ (1) | David P. Siqueira ${ }^{255}$ (1) |

Zuzana Sitková $^{256}$ (1) | Johan Six ${ }^{26}$ | Marko Smiljanic ${ }^{213}$ (D) | Stuart W. Smith ${ }^{122,257}$ (D) |

Sarah Smith-Tripp $^{258}$ | Ben Somers ${ }^{259}$ (i) | Mia Vedel Sørensen ${ }^{122}$ |

José João L. L. Souza ${ }^{260}$ (1) | Bartolomeu Israel Souza261 | Arildo Souza Dias ${ }^{245,262}$ (D) |

Marko J. Spasojevic ${ }^{263}$ (i) | James D. M. Speed ${ }^{264}$ (i) | Fabien Spicher ${ }^{265}$

Angela Stanisci $^{266}$ (D) | Klaus Steinbauer ${ }^{165}$ (i) | Rainer Steinbrecher ${ }^{267}$ (i) |

Michael Steinwandter 202 (B) | Michael Stemkovski ${ }^{216}$ (D) | Jörg G. Stephan ${ }^{268}$ (D) 
Christian Stiegler ${ }^{161}$ (1) | Stefan Stoll 232,269 (1) | Martin Svátek ${ }^{180}$

Miroslav Svoboda ${ }^{10}$ (i) | Torbern Tagesson ${ }^{28,270}$ (i) | Andrew J. Tanentzap ${ }^{107}$ (D)

Franziska Tanneberger $^{271}$ (1) ｜ Jean-Paul Theurillat ${ }^{272,273}$ (D) | Haydn J. D. Thomas ${ }^{82}$ (1) |

Andrew D. Thomas ${ }^{274}$ (D) | Katja Tielbörger ${ }^{59}$ | Marcello Tomaselli61

Urs Albert Treier $^{34,35}$ (1) | Mario Trouillier ${ }^{213}$ (i) | Pavel Dan Turtureanu $228,230,275$

Rosamond Tutton $^{276}$ | Vilna A. Tyystjärvi ${ }^{4,277}$ (i) | Masahito Ueyama ${ }^{278}$ (i) |

Karol Ujházy ${ }^{176}$ (1) | Mariana Ujházyová72 (i) | Domas Uogintas ${ }^{279}$

Anastasiya V. Urban ${ }^{180,214}$ | Josef Urban ${ }^{30,180}$ (i) | Marek Urbaniak $^{211}$ (i) |

Tudor-Mihai Ursu ${ }^{280}$ (i) | Francesco Primo Vaccari ${ }^{281}$ (i) | Stijn Van de Vondel V2 $^{282}$ |

Liesbeth van den Brink ${ }^{59}$ (1) | Maarten Van Geel ${ }^{283}$ (i) | Vigdis Vandvik ${ }^{132}$ (1)

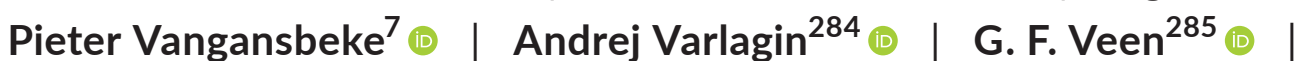

Elmar Veenendaal $^{286}$ (1) | Susanna E. Venn ${ }^{287}$ (1) | Hans Verbeeck ${ }^{288}$

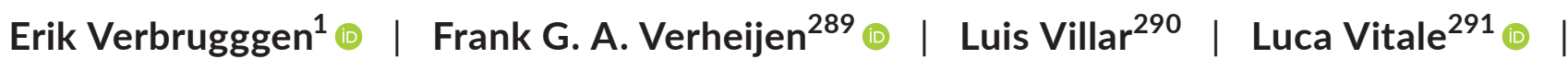

Pascal Vittoz ${ }^{292}$ (1) | Maria Vives-Ingla ${ }^{63}$ (1) Jonathan von Oppen ${ }^{34,35}$ (1) |

Josefine Walz ${ }^{168}$ (1) | Runxi Wang ${ }^{125}$ (i) | Yifeng Wang ${ }^{276}$ (D) Robert G. Way ${ }^{276}$ (1)

Ronja E. M. Wedegärtner ${ }^{122}$ (i) | Robert Weigel ${ }^{146}$ (1) | Jan Wild ${ }^{9,159}$

Matthew Wilkinson ${ }^{42}$ (D) | Martin Wilmking ${ }^{213}$ (D) Lisa Wingate ${ }^{101}$

Manuela Winkler ${ }^{165}$ (i) | Sonja Wipf ${ }^{108,237}$ (i) | Georg Wohlfahrt ${ }^{134}$

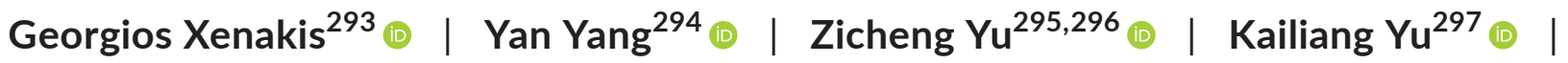

Florian Zellweger ${ }^{110}$ (i) | Jian Zhang ${ }^{298}$ (D) | Zhaochen Zhang ${ }^{298}$ | Peng Zhao ${ }^{152}$ (i) |

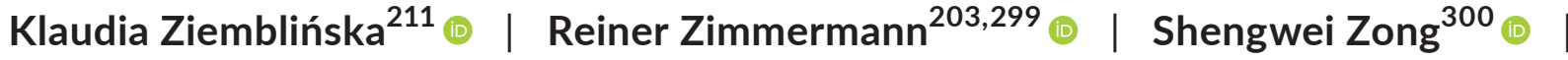

Viacheslav I. Zyryanov ${ }^{214}$ (D) | Ivan Nijs $^{1}$ (D) | Jonathan Lenoir ${ }^{265}$ (D)

${ }^{1}$ Research Group PLECO (Plants and Ecosystems), University of Antwerp, Wilrijk, Belgium

${ }^{2}$ Department of Environmental Systems Science, Institute of Integrative Biology, ETH Zürich, Zürich, Switzerland

${ }^{3}$ Finnish Meteorological Institute, Helsinki, Finland

${ }^{4}$ Department of Geosciences and Geography, University of Helsinki, Finland

${ }^{5}$ Centre for Sustainable Ecosystem Solutions, School of Earth, Atmospheric and Life Sciences, University of Wollongong, Wollongong, New South Wales, Australia

${ }^{6}$ Australian Museum, Sydney, Australia

${ }^{7}$ Forest \& Nature Lab, Department of Environment, Ghent University, Melle-Gontrode, Belgium

${ }^{8}$ Geography Research Unit, University of Oulu, Oulu, Finland

${ }^{9}$ Institute of Botany of the Czech Academy of Sciences, Průhonice, Czech Republic

${ }^{10}$ Faculty of Forestry and Wood Sciences, Czech University of Life Sciences Prague, Prague 6 - Suchdol, Czech Republic

${ }^{11}$ Environment and Sustainability Institute, University of Exeter, Penryn Campus, Penryn, UK

${ }^{12}$ Department of Geography, York St John University, York, UK

${ }^{13}$ Department of Earth and Environmental Sciences, KU Leuven, Leuven, Belgium

${ }^{14}$ School of Natural Resources and Environment, University of Florida, Gainesville, Florida, USA

${ }^{15}$ Smithsonian Environmental Research Center, Edgewater, Maryland, USA

${ }^{16}$ Department of Wildlife Ecology and Conservation, University of Florida, Gainesville, Florida, USA

${ }^{17}$ Department of Natural Sciences and Environmental Health, University of South-Eastern Norway, Bø, Norway

${ }^{18}$ Alpine Ecosystems Research Program, Institute of Ecology, llia State University, Tbilisi, Georgia

${ }^{19}$ Department of Range Management, Faculty of Natural Resources and Marine Sciences, Tarbiat Modares University, Noor, Iran

${ }^{20}$ Department of Ecological Science, Vrije Universiteit Amsterdam, The Netherlands

${ }^{21}$ Royal Botanic Garden Edinburgh, Edinburgh, UK 
${ }^{22}$ Environmental Science Center, Qatar University, Doha, Qatar

${ }^{23}$ Department of Environmental Systems Science, Institute of Integrative Biology, ETH Zurich, Zürich, Switzerland

${ }^{24}$ Research group ECOBE, University of Antwerp, Wilrijk, Belgium

${ }^{25}$ Department of Agroecology and Environment, Agroscope Research Institute, Zürich, Switzerland

${ }^{26}$ Department of Environmental Systems Science, ETH Zurich, Zurich, Switzerland

${ }^{27}$ UK Centre for Ecology and Hydrology, Penicuik, UK

${ }^{28}$ Department of Physical Geography and Ecosystem Science, Lund University, Lund, Sweden

${ }^{29}$ European Commission, Joint Research Centre (JRC), Ispra, Italy

${ }^{30}$ Siberian Federal University, Krasnoyarsk, Russia

${ }^{31}$ Facultad de Ciencias Exactas y Naturales, Universidad Nacional de Cuyo, Mendoza, Argentina

${ }^{32}$ Instituto Argentino de Nivologiá, Glaciologiá y Ciencias Ambientales (IANIGLA), CONICET, CCT-Mendoza, Mendoza, Argentina

${ }^{33}$ Natural History Museum, University of Oslo, Oslo, Norway

${ }^{34}$ Center for Sustainable Landscapes Under Global Change, Department of Biology, Aarhus University, Aarhus C, Denmark

${ }^{35}$ Center for Biodiversity Dynamics in a Changing World, Department of Biology, Aarhus University, Aarhus C, Denmark

${ }^{36}$ Ecological Plant Geography, Faculty of Geography, University of Marburg, Marburg, Germany

${ }^{37}$ Institute of Landscape Ecology Slovak Academy of Sciences, Bratislava, Slovakia

${ }^{38}$ Faculty of Environmental and Forest Sciences, Agricultural University of Iceland, Reykjavík, Iceland

${ }^{39}$ Isotope Bioscience Laboratory - ISOFYS, Ghent University, Gent, Belgium

${ }^{40}$ Université de Rennes, CNRS, EcoBio (Ecosystèmes, biodiversité, évolution) - UMR 6553, Rennes, France

${ }^{41}$ Department of Sustainable Agro-ecosystems and Bioresources, Research and Innovation Centre, Fondazione Edmund Mach, San Michele all'Adige, Italy

${ }^{42}$ Forest Research, Alice Holt Lodge, Wrecclesham, Farnham, UK

${ }^{43}$ Department of Ecology, Pontificia Universidad Javeriana, Bogota, Colombia

${ }^{44}$ Jolube Consultor Botánico. C/Mariano R de Ledesma, Jaca, Huesca, Spain

${ }^{45}$ Institute of Landscape and Plant Ecology, Department of Plant Ecology, University of Hohenheim, Stuttgart, Germany

${ }^{46}$ Disturbance Ecology, BayCEER, University of Bayreuth, Bayreuth, Germany

${ }^{47}$ Norwegian Institute for Nature Research, FRAM - High North Research Centre for Climate and the Environment, Tromsø, Norway

${ }^{48}$ Department of Earth Sciences, University of Gothenburg, Gothenburg, Sweden

${ }^{49}$ Gothenburg Global Biodiversity Centre, Gothenburg, Sweden

${ }^{50}$ Department of Biological and Environmental Sciences, University of Gothenburg, Gothenburg, Sweden

${ }^{51}$ Department of Environmental Science, Policy, and Management, University of California, Berkeley, California, USA

${ }^{52}$ Alfred Wegener Institute Helmholtz Center for Polar and Marine Research, Telegrafenberg A45, Potsdam, Germany

${ }^{53}$ Geography Department, Humboldt-Universität zu Berlin, Germany

${ }^{54}$ Pós-Graduação em Ciências de Florestas Tropicais, Instituto Nacional de Pesquisas da Amazônia, Manaus, Brasil

${ }^{55}$ UMR ECOSYS INRAE, Uinversité Paris Saclay, AgroParisTech, France

${ }^{56}$ Biological Dynamics of Forest Fragments Project, BDFFP, Instituto Nacional de Pesquisas da Amazônia, Manaus, Brazil

${ }^{57}$ Department of Forest Sciences, Federal University of Lavras, Lavras, Brazil

${ }^{58}$ Faculty of Arts and Sciences, Department of Molecular Biology and Genetics, Ordu University, Ordu, Turkey

${ }^{59}$ Plant Ecology Group, Department of Evolution and Ecology, University of Tübingen, Tübingen, Germany

${ }^{60}$ Department of Science and High Technology, Insubria University, Como, Italy

${ }^{61}$ Department of Chemistry, Life Sciences and Environmental Sustainability, University of Parma, Parma, Italy

${ }^{62}$ Department of Evolutionary Biology, Ecology and Environmental Sciences, Biodiversity Research Institute (IRBio), University of Barcelona, Barcelona, Spain

${ }^{63}$ CREAF, E08193 Bellaterra (Cerdanyola del Vallès), Spain

${ }^{64}$ Laboratorio de Ecofisiología Vegetal y Cambio Climático, Laboratorio de Ecofisiología Vegetal y Cambio Climático, Departamento de Ciencias Veterinarias y Salud Pública, Universidad Católica de Temuco, Campus Luis Rivas del Canto and Núcleo de Estudios Ambientales (NEA), Facultad de Recursos Naturales, Universidad Católica de Temuco, Temuco, Chile

${ }^{65}$ German Centre for Integrative Biodiversity Research (iDiv) Halle-Jena-Leipzig, Leipzig, Germany

${ }^{66}$ Institute of Biology, Leipzig University, Leipzig, Germany

${ }^{67}$ Laboratory of Bioclimatology, Department of Ecology and Environmental Protection, Poznan University of Life Sciences, Poznan, Poland

${ }^{68}$ Univ. Grenoble Alpes, Univ. Savoie Mont Blanc, CNRS, LECA, Grenoble, France

${ }^{69}$ Univ. Grenoble Alpes, Univ. Savoie Mont Blanc, CNRS, LTSER Zone Atelier Alpes, Grenoble, France

${ }^{70}$ Securing Antarctica's Environmental Future, School of Biological Sciences, Monash University, Melbourne, Victoria, Australia

${ }^{71}$ Forest Ecology and Conservation Group, Department of Plant Sciences, University of Cambridge, Cambridge, UK

${ }^{72}$ Faculty of Ecology and Environmental Sciences, Technical University in Zvolen, Zvolen, Slovakia

${ }^{73}$ Millennium Institute Biodiversity of Antarctic and Subantarctic Ecosystems (BASE), University Austral of Chile, Valdivia, Chile 
${ }^{74}$ Cape Horn International Center (CHIC), Puerto Williams, Chile

${ }^{75}$ British Antarctic Survey, NERC, High Cross, Cambridge, UK

${ }^{76}$ Department of Arctic and Marine Biology, Faculty of Biosciences Fisheries and Economics, UiT-The Arctic University of Norway, Troms $\varnothing$, Norway

${ }^{77}$ Climate Change Unit, Environmental Protection Agency of Aosta Valley, Italy

${ }^{78}$ Department of Biological Sciences, University of Notre Dame, Notre Dame, Indiana, USA

${ }^{79}$ Department of Science, University of Roma Tre, Rome, Italy

${ }^{80}$ Department of Ecology, Environment and Plant Sciences and Bolin Centre for Climate Research, Stockholm University, Stockholm, Sweden

${ }^{81}$ The County Administrative Board of Västra Götaland, Gothenburg, Sweden

${ }^{82}$ School of GeoSciences, University of Edinburgh, Edinburgh, UK

${ }^{83}$ Department of Geology, Geography and Environment, University of Alcalá, Madrid, Spain

${ }^{84}$ Chair of Geoinformatics, Technische Universität Dresden, Dresden, Germany

${ }^{85}$ Vegetation Ecology, Institute of Natural Resource Sciences (IUNR), ZHAW Zurich University of Applied Sciences, Wädenswil, Switzerland

${ }^{86}$ Plant Ecology, Bayreuth Center of Ecology and Environmental Research (BayCEER), University of Bayreuth, Bayreuth, Germany

${ }^{87}$ VITO-TAP, Mol, Belgium

${ }^{88}$ Swiss Federal Research Institute WSL, Birmensdorf, Switzerland

${ }^{89}$ Majella Seed Bank, Majella National Park, Colle Madonna, Lama dei Peligni, Italy

${ }^{90}$ Department of Life, Health and Environmental Sciences, University of L'Aquila, L'Aquila, Italy

${ }^{91}$ Grupo de Ecología de Poblaciones de Insectos, IFAB (INTA - CONICET), Bariloche, Argentina

${ }^{92}$ Department of Biology and Biochemistry, University of Houston, Houston, Texas, USA

${ }^{93}$ Faculty of Science, Department of Botany, University of South Bohemia, České Budějovice, Czech Republic

${ }^{94}$ Climate Impacts Research Centre, Department of Ecology and Environmental Science, Umeå University, Abisko, Sweden

${ }^{95}$ Global Change Research Institute, Academy of Sciences of the Czech Republic, Czech Republic

${ }^{96}$ School of Biological Sciences, The University of Western Australia, Crawley, Western Australia, Australia

${ }^{97}$ Kings Park Science, Department of Biodiversity, Conservation and Attractions, Kings Park, Australia

${ }^{98}$ Department of Botany, Faculty of Biology, University of Innsbruck, Innsbruck, Austria

${ }^{99}$ Imperial College London, Ascot, UK

${ }^{100}$ Operation Wallacea, Lincolnshire, UK

${ }^{101}$ INRAE, Bordeaux Sciences Agro, UMR 1391 ISPA, Villenave d'Ornon, France

${ }^{102}$ Department of Life and Environmental Sciences, University of Cagliari, Cagliari, Italy

${ }^{103}$ Department of Botany, University of Granada, Granada, Spain

${ }^{104}$ IMIB - Biodiversity Research Institute, University of Oviedo, Mieres, Spain

${ }^{105}$ Institute for Plant Science and Microbiology, University of Hamburg, Hamburg, Germany

${ }^{106}$ Dartmouth College, Hanover, New Hampshire, USA

${ }^{107}$ Ecosystems and Global Change Group, Department of Plant Sciences, University of Cambridge, Cambridge, UK

${ }^{108}$ WSL Institute for Snow and Avalanche Research SLF, Davos Dorf, Switzerland

${ }^{109}$ Climate Change, Extremes and Natural Hazards in Alpine Regions Research Center CERC, Davos Dorf, Switzerland

${ }^{110}$ Swiss Federal Institute for Forest, Snow and Landscape Research WSL, Birmensdorf, Switzerland

${ }^{111}$ Laboratorio de Invasiones Biológicas (LIB), Facultad de Ciencias Forestales, Universidad de Concepción, Concepción, Chile

${ }^{112}$ School of Education and Social Sciences, Adventist University of Chile, Chile

${ }^{113}$ Instituto de Ecología y Biodiversidad (IEB), Santiago, Chile

${ }^{114}$ Pyrenean Institute of Ecology (CSIC), Zaragoza, Spain

${ }^{115}$ Biodiversity and Landscape, TERRA Research Centre, Gembloux Agro-Bio Tech, University of Liège, Gembloux, Belgium

${ }^{116}$ Department of Geo-information in Environmental Management, Mediterranean Agronomic Institute of Chania, Chania, Greece

${ }^{117}$ Department of Environmental Management and Policy, Georgian Institute of Public Affairs, Tbilisi, Georgia

${ }^{118}$ Flemish Institute for Technological Research, Mol, Belgium

${ }^{119}$ Department of Earth and Environmental Science, Faculty of BioScience Engineering, KULeuven, Belgium

${ }^{120}$ Department of Biogeochemical Signals, Max Planck Institute for Biogeochemistry, Jena, Germany

${ }^{121}$ Sustainable Agricultural Sciences Department, Rothamsted Research, Harpenden, UK

${ }^{122}$ Department of Biology, Norwegian University of Science and Technology, Trondheim, Norway

${ }^{123}$ Biodiversity, Wildlife and Ecosystem Health, Biomedical Sciences, University of Edinburgh, Edinburgh, UK

${ }^{124}$ Department of Ecology, Swedish University of Agricultural Sciences, Uppsala, Sweden

${ }^{125}$ School of Biological Sciences, The University of Hong Kong, Hong Kong SAR, China

${ }^{126}$ Department of Theoretical and Applied Sciences, Insubria University, Varese, Italy 
${ }^{127}$ CIRAD, UMR Eco\&Sols, Montpellier, France

${ }^{128}$ Eco\&Sols, Univ Montpellier, CIRAD, INRAE, IRD, Montpellier SupAgro, Montpellier, France

${ }^{129}$ Senckenberg Research Institute and Natural History Museum Frankfurt, Gelnhausen, Germany

${ }^{130}$ Faculty of Biology, University of Duisburg-Essen, Essen, Germany

${ }^{131}$ Institute of Biology / Geobotany and Botanical Garden, Martin Luther University Halle-Wittenberg, Halle (Saale), Germany

${ }^{132}$ Department of Biological Sciences and Bjerknes Centre for Climate Research, University of Bergen, Bergen, Norway

${ }^{133}$ Centre for Biodiversity and Taxonomy, Department of Botany, University of Kashmir, Srinagar, India

${ }^{134}$ Department of Ecology, University of Innsbruck, Innsbruck, Austria

${ }^{135}$ INRAE, Univ. Bordeaux, BIOGECO, Cestas, France

${ }^{136}$ The Heathland Centre, Alver, Norway

${ }^{137}$ TERRA Teaching and Research Center, Faculty of Gembloux Agro-Bio Tech, University of Liege, Gembloux, Belgium

${ }^{138}$ UK Centre for Ecology and Hydrology, Penicuik, UK

${ }^{139}$ Vegetation Ecology, Institute of Natural Resource Sciences, ZHAW Zurich University of Applied Sciences, Grüental, Switzerland

${ }^{140}$ Institute for Botany, University of Natural Resources and Life Sciences Vienna (BOKU), Vienna, Austria

${ }^{141}$ Centre for Agrometeorological Research (ZAMF), German Meteorological Service (DWD), Braunschweig, Germany

${ }^{142}$ Dept of Biology, Memorial University, St. John's, Newfoundland, Canada

${ }^{143}$ Department of Biological Sciences, Simon Fraser University, Burnaby, British Columbia, Canada

${ }^{144}$ Department of Geography, University of Zaragoza, Zaragoza, Spain

${ }^{145}$ Faculty of Resource Management, HAWK University of Applied Sciences and Arts, Göttingen, Germany

${ }^{146}$ Plant Ecology, Albrecht-von-Haller-Institute for Plant Sciences, Georg-August University of Göttingen, Göttingen, Germany

${ }^{147}$ Department of Ecoscience and Arctic Research Centre, Aarhus University, Rønde, Denmark

${ }^{148}$ Department of Geography, Faculty of Science, Masaryk University, Brno, Czech Republic

${ }^{149}$ Department of Environmental Science, Shinshu University, Matsumoto, Japan

${ }^{150}$ Department of Ecoscience and Arctic Research Centre, Aarhus University, Roskilde, Denmark

${ }^{151}$ INRAE, University of Bordeaux, BIOGECO, Cestas, France

${ }^{152}$ Department of Forest Ecology and Management, Swedish University of Agricultural Sciences, Umeå, Sweden

${ }^{153}$ Department of Silviculture and Forest Tree Genetics, Forest Research Institute, Raszyn, Poland

${ }^{154}$ Bayreuth Center of Ecology and Environmental Research, Bayreuth, Germany

${ }^{155}$ ARAID/IPE-CSIC, Pyrenean Institute of Ecology, Avda. Llano de la Victoria, Spain

${ }^{156}$ Life and Environmental Sciences, University of Iceland, Reykjavík, Iceland

${ }^{157}$ School of Biological Sciences, University of Bristol, Bristol, UK

${ }^{158}$ Biological and Environmental Sciences, Faculty of Natural Sciences, University of Stirling, Scotland

${ }^{159}$ Faculty of Environmental Sciences, Czech University of Life Sciences Prague, Prague 6 - Suchdol, Czech Republic

${ }^{160}$ Centre for Environmental and Climate Science, Lund University, Lund, Sweden

${ }^{161}$ Bioclimatology, University of Göttingen, Göttingen, Germany

${ }^{162}$ Environment Agency Austria, Vienna, Austria

${ }^{163}$ Centre for Ecological Research, Institute of Ecology and Botany, Vácrátót, Hungary

${ }^{164}$ Experimental Plant Ecology, Institute of Botany and Landscape Ecology, University of Greifswald, Greifswald, Germany

${ }^{165}$ GLORIA Coordination, Institute for Interdisciplinary Mountain Research, Austrian Academy of Sciences (ÖAW) \& Department of Integrative Biology and Biodiversity Research, University of Natural Resources and Life Sciences, Vienna, Austria

${ }^{166}$ Department of Arctic Biology, The University Centre in Svalbard (UNIS), Longyearbyen, Svalbard, Norway

${ }^{167}$ Department of Land Resources and Environmental Sciences, Montana State University, Bozeman, Montana, USA

${ }^{168}$ Climate Impacts Research Centre, Department of Ecology and Environmental Sciences, Umeå University, Abisko, Sweden

${ }^{169}$ Centre for Polar Ecology, Faculty of Science, University of South Bohemia, České Budějovice, Czech Republic

${ }^{170}$ School of Biological Sciences, Monash University, Melbourne, Victoria, Australia

${ }^{171}$ Terrestrial Ecology Unit, Department of Biology, Ghent University, Gent, Belgium

${ }^{172}$ Finnish Meteorological Institute, Climate System Research, Helsinki, Finland

${ }^{173}$ INAR Institute for Atmospheric and Earth System Research/Physics, Faculty of Science, University of Helsinki, Finland

${ }^{174}$ Interuniversity Institute for Earth System Research, University of Granada, Granada, Spain

${ }^{175}$ CNR Institute for Agricultural and Forestry Systems in the Mediterranean, Portici (Napoli), Italy

${ }^{176}$ Faculty of Forestry, Technical University in Zvolen, Zvolen, Slovakia

${ }^{177}$ School of Pure \& Applied Sciences, Environmental Conservation and Management Programme, Open University of Cyprus, Latsia, Cyprus

${ }^{178}$ Department of Biology, Aarhus University, Aarhus C, Denmark 
${ }^{179}$ Aarhus Institute of Advanced Studies, AIAS Høegh-Guldbergs Gade 6B, Aarhus, Denmark

${ }^{180}$ Department of Forest Botany, Dendrology and Geobiocoenology, Faculty of Forestry and Wood Technology, Mendel University in Brno, Brno, Czech Republic

${ }^{181}$ Regional Centre for Integrated Environmental Monitoring, Odesa National I.I. Mechnikov University, Odesa, Ukraine

${ }^{182}$ Department of Agroecology, Aarhus University, Tjele, Denmark

${ }^{183}$ NGO New Energy, Kharkiv, Ukraine

${ }^{184}$ Biological Dynamics of Forest Fragments Project, Coordenação de Dinâmica Ambiental, Instituto Nacional de Pesquisas da Amazônia, Manaus, Brazil

${ }^{185}$ Swiss Federal Institute for Forest, Snow and Landscape Research (WSL), Birmensdorf, Switzerland

${ }^{186}$ Department of Biology, University of Antwerp, Wilrijk, Belgium

${ }^{187}$ Department of Botany and Biodiversity Research Centre, University of British Columbia, Vancouver, British Columbia, Canada

${ }^{188}$ Department of Environment, Province of Antwerp, Antwerpen, Belgium

${ }^{189}$ Institute of Plant and Animal Ecology of Ural Division of Russian Academy of Science, Ekaterinburg, Russia

${ }^{190}$ Department of Earth and Environmental Sciences, University of Pavia, Pavia, Italy

${ }^{191}$ Faculty of Science and Technology, Free University of Bolzano, Bolzano, Italy

${ }^{192}$ Climate Change Unit, Environmental Protection Agency of Aosta Valley, Saint-Christophe, Italy

${ }^{193}$ Chair of Geobotany, University of Freiburg, Freiburg, Germany

${ }^{194}$ Environment and Sustainability Institute, University of Exeter, Penryn Campus, Cornwall, UK

${ }^{195}$ Centre for Ecosystem Science, School of Biological, Earth and Environmental Sciences, UNSW Sydney, Sydney, New South Wales, Australia

${ }^{196}$ Department of Plant Biology and Ecology, University of Seville, Seville, Spain

${ }^{197}$ Department of Biology, Washington University in St. Louis, St. Louis, Missouri, USA

${ }^{198}$ Department of Animal Biology, Institute of Biology, University of Campinas, Campinas, Brazil

${ }^{199}$ CNR Institute of BioEconomy, Bologna, Italy

${ }^{200}$ National Wildlife Research Centre, Environment and Climate Change Canada, Carleton University, Ottawa, Ontario, Canada

${ }^{201}$ School of Life and Environmental Sciences, Deakin University, Burwood, Victoria, Australia

${ }^{202}$ Institute for Alpine Environment, Eurac Research, Bozen/Bolzano, Italy

${ }^{203}$ Institute of Biology, Department of Molecular Botany, University of Hohenheim, Stuttgart, Germany

${ }^{204}$ Instituto de Matemática Aplicada San Luis, IMASL, CONICET and Universidad Nacional de San Luis, San Luis, Argentina

${ }^{205}$ Cátedra de Climatología Agrícola (FCA-UNER), Entre Ríos, Argentina

${ }^{206}$ Grupo de Ecología de Invasiones, INIBIOMA, CONICET/ Universidad Nacional del Comahue, Bariloche, Argentina

${ }^{207}$ CSIC, Global Ecology Unit CREAF- CSIC-UAB, Bellaterra, Spain

${ }^{208}$ CREAF, Spain

${ }^{209}$ Mountains of the Moon University, Fort Portal, Uganda

${ }^{210}$ National Agricultural Research Organisation, Mbarara Zonal Agricultural Research and Development Institute, Mbarara, Uganda

${ }^{211}$ Laboratory of Meteorology, Department of Construction and Geoengineering, Faculty of Environmental Engineering and Mechanical Engineering, Poznan University of Life Sciences, Poznan, Poland

${ }^{212}$ Department of Biology, Lund University, Lund, Sweden

${ }^{213}$ Institute of Botany and Landscape Ecology, University Greifswald, Greifswald, Germany

${ }^{214}$ V.N. Sukachev Institute of Forest SB RAS, Krasnoyarsk, Russia

${ }^{215}$ Institute of Ecology and Earth Sciences, University of Tartu, Tartu, Estonia

${ }^{216}$ Department of Biology and Ecology Center, Utah State University, Logan, Utah, USA

${ }^{217}$ Department of Life Sciences, Imperial College, Ascot, Berkshire, UK

${ }^{218}$ Landscape Ecology, Institute of Terrestrial Ecosystems, Department of Environmental Systems Science, ETH Zürich, Zürich, Switzerland

${ }^{219}$ Unit of Land Change Science, Swiss Federal Research Institute WSL, Birmensdorf, Switzerland

${ }^{220}$ School of Ecology and Environment Studies, Nalanda University, Rajgir, India

${ }^{221}$ School of Biosciences, University of Sheffield, Sheffield, UK

${ }^{222}$ CESAM \& Department of Environment, University of Aveiro, Aveiro, Portugal

${ }^{223}$ Department of Agronomy, Food, Natural resources, Animals and Environment - University of Padua, Legnaro, Italy

${ }^{224}$ Univ. Savoie Mont Blanc, CNRS, Univ. Grenoble Alpes, EDYTEM, Chambéry, France

${ }^{225}$ Universitat Autònoma de Barcelona, Spain

${ }^{226}$ Department of Ecology and Biogeography, Faculty of Biological and Veterinary Sciences, Nicolaus Copernicus University, Toruń, Poland

${ }^{227}$ Centre for Climate Change Research, Nicolaus Copernicus University, Toruń, Poland

${ }^{228}$ A. Borza Botanic Garden, Babeș-Bolyai University, Cluj-Napoca, Romania

${ }^{229}$ Faculty of Biology and Geology, Department of Taxonomy and Ecology, Babeș-Bolyai University, Cluj-Napoca, Romania

${ }^{230}$ E. G. Racoviță Institute, Babeș-Bolyai University, Cluj-Napoca, Romania 
${ }^{231}$ Securing Antarctica's Environmental Future, School of Earth, Atmospheric and Life Sciences, University of Wollongong, Wollongong, New South Wales, Australia

${ }^{232}$ University of Applied Sciences Trier, Environmental Campus Birkenfeld, Birkenfeld, Germany

${ }^{233}$ Institut Universitaire de France, Paris, France

${ }^{234}$ Swiss Federal Institute for Forest, Snow and Landscape Research WSL, Birmensdorf, Switzerland

${ }^{235}$ Aquatic Ecology and Environmental Biology, Radboud Institute for Environmental and Biological Sciences, Radboud University Nijmegen, Nijmegen, The Netherlands

${ }^{236}$ Department of Biological Sciences and the Environmental Change Initiative, University of Notre Dame, Notre Dame, Indiana, USA

${ }^{237}$ Swiss National Park, Chastè Planta-Wildenberg, Zernez, Switzerland

${ }^{238}$ Remote Sensing Laboratories, Department of Geography, University of Zurich, Zurich, Switzerland

${ }^{239}$ CIRAD, UMR Eco\&Sols, Dakar, Senegal

${ }^{240}$ Eco\&Sols, Univ Montpellier, CIRAD, INRAE, IRD, Institut Agro, Montpellier, France

${ }^{241}$ LMI IESOL, Centre IRD-ISRA de Bel Air, Dakar, Senegal

${ }^{242}$ Parc national des Ecrins - Domaine de Charance, France

${ }^{243}$ Universidad Nacional de San Antonio Abad del Cusco, Cusco, Perú

${ }^{244}$ Centro de Investigación de la Biodiversidad Wilhelm L. Johannsen, Cusco, Perú

${ }^{245}$ Biological Dynamics of Forest Fragments Project, PDBFF, Instituto Nacional de Pesquisas da Amazônia, Manaus, Brazil

${ }^{246}$ Department of Ecology and Environmental Science, Umeå University, Umeå, Sweden

${ }^{247}$ Institute of Bio- and Geosciences (IBG-3): Agrosphere, Forschungszentrum Jülich GmbH, Jülich, Germany

${ }^{248}$ Chair of Soil Science and Geomorphology, Department of Geosciences, University of Tuebingen, Tuebingen, Germany

${ }^{249}$ Department of Geography, The University of British Columbia, Vancouver, British Columbia, Canada

${ }^{250}$ Department of Botany and Biodiversity Research, Vienna, Austria

${ }^{251}$ Princeton School of Public and International Affairs, Princeton University, Princeton, New Jersey, USA

${ }^{252}$ Université de Lorraine, AgroParisTech, INRAE, Nancy, France

${ }^{253}$ Department of Soil Science and Landscape Management, Faculty of Earth Sciences and Spatial Management, Nicolaus Copernicus University, Toruń, Poland

${ }^{254}$ Terra Nova National Park, Parks Canada Agency, Glovertown, Newfoundland, Canada

${ }^{255}$ Universidade Estadual do Norte Fluminense Darcy Ribeiro, Rio de Janeiro, Brazil

${ }^{256}$ National Forest Centre, Forest Research Institute Zvolen, Zvolen, Slovakia

${ }^{257}$ Department of Physical Geography, Stockholm University, Stockholm, Sweden

${ }^{258}$ Department of Geography, University of British Columbia, Vancouver, British Columbia, Canada

${ }^{259}$ Department of Earth and Environmental Sciences, Leuven, Belgium

${ }^{260}$ Soil Science Department, Federal University of Viçosa, Viçosa-MG, Brazil

${ }^{261}$ Departamento de Geociências. Cidade Universitária, Universidade Federal da Paraíba, João Pessoa - PB, Brasil

${ }^{262}$ Department of Physical Geography, Goethe-Universität Frankfurt, Frankfurt am Main, Germany

${ }^{263}$ Department of Evolution, Ecology, and Organismal Biology, University of California Riverside, Riverside, California, USA

${ }^{264}$ Department of Natural History, NTNU University Museum, Norwegian University of Science and Technology, Trondheim, Norway

${ }^{265}$ UMR 7058 CNRS 'Ecologie et Dynamique des Systèmes Anthropisés' (EDYSAN), Univ. de Picardie Jules Verne, Amiens, France

${ }^{266}$ EnvixLab, Dipartimento di Bioscienze e Territorio, Università degli Studi del Molise, Termoli, Italy

${ }^{267}$ Institute of Meteorology and Climate Research (IMK), Department of Atmospheric Environmental Research (IFU), Karlsruhe Institute of Technology (KIT), Garmisch-Partenkirchen, Germany

${ }^{268}$ Swedish University of Agricultural Sciences, SLU Swedish Species Information Centre, Uppsala, Sweden

${ }^{269}$ Faculty for Biology, University Duisburg-Essen, Essen, Germany

${ }^{270}$ Department of Geosciences and Natural Resource Management, University of Copenhagen, Copenhagen, Denmark

${ }^{271}$ Experimental Plant Ecology, Institute of Botany and Landscape Ecology, University of Greifswald, partner in the Greifswald Mire Centre, Greifswald, Germany

${ }^{272}$ Foundation J.-M. Aubert, Champex-Lac, Switzerland

${ }^{273}$ Département de Botanique et Biologie végétale, Université de Genève, Chambésy, Switzerland

${ }^{274}$ Department of Geography and Earth Sciences, Aberystwyth University, Wales, UK

${ }^{275}$ Center for Systematic Biology, Biodiversity and Bioresources - 3B, Babeș-Bolyai University, Cluj-Napoca, Romania

${ }^{276}$ Northern Environmental Geoscience Laboratory, Department of Geography and Planning, Queen's University, Kingston, Ontario, Canada

${ }^{277}$ Finnish Meteorological Inst, Helsinki, Finland

${ }^{278}$ Graduate School of Life and Environmental Sciences, Osaka Prefecture University, Japan

${ }^{279}$ Nature Research Centre, Vilnius, Lithuania

${ }^{280}$ Institute of Biological Research Cluj-Napoca, National Institute of Research and Development for Biological Sciences, Bucharest, Romania 


\footnotetext{
${ }^{281} \mathrm{CNR}$ Institute for BioEconomy, Firenze, Italy
}

${ }^{282}$ The Ecosystem Management Research Group (ECOBE), University of Antwerp, Wilrijk (Antwerpen), Belgium

${ }^{283}$ Plant Conservation and Population Biology, Department of Biology, KU Leuven, Heverlee, Belgium

${ }^{284}$ A.N. Severtsov Institute of Ecology and Evolution, Russian Academy of Sciences, Moscow, Russia

${ }^{285}$ Netherlands Institute of Ecology, Wageningen, the Netherlands

${ }^{286}$ Plant Ecology and Nature Conservation Group, Wageningen University, Wageningen, the Netherlands

${ }^{287}$ Centre for Integrative Ecology, School of Life and Environmental Sciences, Deakin University, Burwood, Victoria, Australia

${ }^{288}$ CAVElab - Computational and Applied Vegetation Ecology, Department of Environment, Ghent University, Gent, Belgium

${ }^{289}$ Earth Surface Processes Team, Centre for Environmental and Marine Studies (CESAM), Department of Environment and Planning, University of Aveiro, Aveiro, Portugal

${ }^{290}$ Instituto Pirenaico de Ecología, IPE-CSIC. Av. Llano de la Victoria, Jaca (Huesca), Spain

${ }^{291}$ CNR - Institute for Agricultural and Forestry Systems in the Mediterranean, Portici, Italy

${ }^{292}$ Institute of Earth Surface Dynamics, Faculty of Geosciences and Environment, University of Lausanne, Géopolis, Switzerland

${ }^{293}$ Forest Research, Northern Research Station, Roslin, UK

${ }^{294}$ Institute of Mountain Hazards and Environment, Chinese Academy of Sciences, Chengdu, P.R. China

${ }^{295}$ MOE Key Laboratory of Geographical Processes and Ecological Security in Changbai Mountains, School of Geographical Sciences, Northeast Normal University, Changchun, China

${ }^{296}$ Department of Earth and Environmental Sciences, Lehigh University, Bethlehem, Pennsylvania, USA

${ }^{297}$ High Meadows Environmental Institute, Princeton University, New Jersey, USA

${ }^{298}$ Zhejiang Tiantong Forest Ecosystem National Observation and Research Station, School of Ecological and Environmental Sciences, East China Normal University, Shanghai, China

${ }^{299}$ Ecological-Botanical Gardens, University of Bayreuth, Bayreuth, Germany

${ }^{300}$ Key Laboratory of Geographical Processes and Ecological Security in Changbai Mountains, Ministry of Education, School of Geographical Sciences, Northeast Normal University, Changchun, China

\section{Correspondence}

Jonas J. Lembrechts, Research Group PLECO (Plants and Ecosystems), University of Antwerp, 2610 Wilrijk, Belgium.

Email: jonas.lembrechts@uantwerpen.be

Jonathan Lenoir, UMR 7058 CNRS

'Ecologie et Dynamique des Systèmes

Anthropisés' (EDYSAN), Univ. de Picardie Jules Verne, Amiens, France.

Email: jonathan.lenoir@u-picardie.fr

Funding information

Fonds Wetenschappelijk Onderzoek, Grant/Award Number: 12P1819N, and G018919N, W001919N; for full list of funders see acknowledgements

\section{Abstract}

Research in global change ecology relies heavily on global climatic grids derived from estimates of air temperature in open areas at around $2 \mathrm{~m}$ above the ground. These climatic grids do not reflect conditions below vegetation canopies and near the ground surface, where critical ecosystem functions occur and most terrestrial species reside. Here, we provide global maps of soil temperature and bioclimatic variables at a $1-\mathrm{km}^{2}$ resolution for $0-5$ and $5-15 \mathrm{~cm}$ soil depth. These maps were created by calculating the difference (i.e. offset) between in situ soil temperature measurements, based on time series from over $12001-\mathrm{km}^{2}$ pixels (summarized from 8519 unique temperature sensors) across all the world's major terrestrial biomes, and coarse-grained air temperature estimates from ERA5-Land (an atmospheric reanalysis by the European Centre for Medium-Range Weather Forecasts). We show that mean annual soil temperature differs markedly from the corresponding gridded air temperature, by up to $10^{\circ} \mathrm{C}$ (mean $=3.0 \pm 2.1^{\circ} \mathrm{C}$ ), with substantial variation across biomes and seasons. Over the year, soils in cold and/or dry biomes are substantially warmer $\left(+3.6 \pm 2.3^{\circ} \mathrm{C}\right)$ than gridded air temperature, whereas soils in warm and humid environments are on average slightly cooler $\left(-0.7 \pm 2.3^{\circ} \mathrm{C}\right)$. The observed substantial and biome-specific offsets emphasize that the projected impacts of climate and climate change on near-surface biodiversity and ecosystem functioning are inaccurately assessed when air rather than soil temperature is used, especially in cold environments. The global soil-related 
bioclimatic variables provided here are an important step forward for any application in ecology and related disciplines. Nevertheless, we highlight the need to fill remaining geographic gaps by collecting more in situ measurements of microclimate conditions to further enhance the spatiotemporal resolution of global soil temperature products for ecological applications.

\section{KEYWORDS}

bioclimatic variables, global maps, microclimate, near-surface temperatures, soil-dwelling organisms, soil temperature, temperature offset, weather stations

\section{1 | INTRODUCTION}

With the rapidly increasing availability of big data on species distributions, functional traits and ecosystem functioning (BondLamberty \& Thomson, 2018; Bruelheide et al., 2018; Kattge et al., 2019; Kissling et al., 2018; Lenoir et al., 2020), we can now study biodiversity and ecosystem responses to global changes in unprecedented detail (Antão et al., 2020; van den Hoogen et al., 2019; Senior et al., 2019; Steidinger et al., 2019). However, despite this increasing availability of ecological data, most spatially explicit studies of ecological, biophysical and biogeochemical processes still have to rely on the same global gridded temperature data (Du et al., 2020; van den Hoogen et al., 2019; Soudzilovskaia et al., 2015). Thus far, these global gridded products are based on measurements from standard meteorological stations that record freeair temperature inside well-ventilated protective shields placed up to $2 \mathrm{~m}$ above-ground in open, shade-free habitats, where abiotic conditions may differ substantially from those actually experienced by most organisms (Lembrechts et al., 2020; World Meteorological Organization, 2008).

Ecological patterns and processes often relate more directly to below-canopy soil temperature rather than to well-ventilated air temperature inside a weather station. Near-surface, rather than air, temperature better predicts ecosystem functions like biogeochemical cycling (e.g. organic matter decomposition, soil respiration and other aspects of the global carbon balance) (Davis et al., 2020; Gottschall et al., 2019; Hursh et al., 2017; Jian et al., 2021; Perera-Castro et al., 2020; Pleim \& Gilliam, 2009; PortilloEstrada et al., 2016; Schimel et al., 2004). Similarly, the use of soil temperature in correlative analyses or predictive models may improve predictions of climate impacts on organismal physiology and behaviour, as well as on population and community dynamics and species distributions (Ashcroft et al., 2008; Berner et al., 2020; Kearney et al., 2009; Körner \& Paulsen, 2004; Opedal et al., 2015; Scherrer et al., 2011; Schimel et al., 2004; Zellweger et al., 2020). Given the key role of soil-related processes for both aboveground and belowground parts of the ecosystem and their feedbacks to the atmosphere (Crowther et al., 2016), adequate soil temperature data are critical for a broad range of fields of study, such as ecology, biogeography, biogeochemistry, agronomy, soil science and climate system dynamics. Nevertheless, existing global soil temperature products such as those from ERA5-Land (Copernicus Climate Change Service (C3S), 2019), with a resolution of $0.08 \times 0.08$ degrees $(\approx 9 \times 9 \mathrm{~km}$ at the equator) remain too coarse for most ecological applications.

The direction and magnitude of the difference or offset between in situ soil temperature and coarse-gridded air temperature products result from a combination of two factors: (i) the (vertical) microclimatic difference between air and soil temperature and (ii) the (horizontal) mesoclimatic difference between air temperature in flat, cleared areas (i.e. where meteorological stations are located) and air temperature within different vegetation types (e.g. below a dense canopy of trees) or topographies (e.g. within a ravine or on a ridge) (De Frenne et al., 2021; Lembrechts et al., 2020). In essence, the offset is thus the combination of both the vertical and horizontal differences that result from factors affecting the energy budget at the Earth's surface, principally radiative energy: the ground absorbs radiative energy, which is transferred to the air by convective heat exchange, evaporation and spatial variation in net radiation, and lower convective conductance near the Earth's surface results in horizontal and vertical variation in temperature (Geiger, 1950; Richardson, 1922). Both these vertical and horizontal differences in temperature vary significantly across the globe and in time as a result of environmental conditions affecting the radiation budget (e.g. as a result of topographic orientation, canopy cover or surface albedo), convective heat exchange and evaporation (e.g. foliage density, variation in the degree of wind shear caused by surface friction) and the capacity for the soil to store and conduct heat (e.g. water content and soil structure and texture) (De Frenne et al., 2019; Geiger, 1950; Way \& Lewkowicz, 2018; Zhang et al., 2008).

Although the physics of soil temperatures have long been well understood (Geiger, 1950; Richardson, 1922), the creation of highresolution global gridded soil temperature products has not been feasible before, partially due to the absence of detailed global in situ soil temperature measurements (Lembrechts et al., 2020; Lembrechts \& Lenoir, 2019). Recently, however, the call for microclimate temperature data representative of in situ conditions (i.e. microhabitat) as experienced by organisms living close to the ground surface or in the soil has become more urgent (Bramer et al., 2018). In this paper, we address this issue by generating 
global gridded maps of below-canopy and near-surface soil temperature at $1-\mathrm{km}^{2}$ resolution (in line with most existing global air temperature products). These maps are more representative of the habitat conditions as experienced by organisms living under vegetation canopies, in the topsoil or near the soil surface. They were created using the abovementioned offset between gridded air temperature data and in situ soil temperature measurements. We expect these soil temperature maps to be substantially more representative of actual microclimatic conditions than existing products as they capture relevant near-surface and belowground abiotic conditions where ecosystem functions and processes operate (Bramer et al., 2018; Daly, 2006; Körner \& Hiltbrunner, 2018). Indeed, the offset between free-air (macroclimate) and soil (microclimate) temperature, and between cleared areas and other habitats, can easily reach up to $\pm 10^{\circ} \mathrm{C}$ annually, even at the $1-\mathrm{km}^{2}$ spatial resolution used here (Lembrechts et al., 2019; Wild et al., 2019; Zhang et al., 2018).

To create the global gridded soil temperature maps introduced above, we used over 8500 time series of soil temperature measured in situ across the world's major terrestrial biomes, which are compiled and stored in the SoilTemp database (Lembrechts et al., 2020) (Figure 1a, Figure S1) and averaged into 1200 (or 1000 for the second soil layer) unique $1-\mathrm{km}^{2}$ pixels. First, to illustrate the magnitude of the studied effect, we visualized the global and biome-specific patterns in the mean annual offset between in situ soil temperature $(0-5 \mathrm{~cm}$ and $5-15 \mathrm{~cm}$ depth) and coarse-scale interpolated air temperature from ERA5-Land using the average within $1 \times 1 \mathrm{~km}$ grid cells. Hereafter, we refer to this difference between soil temperature and air temperature as the temperature offset (or offset), sensu (De Frenne et al., 2021); elsewhere called the surface offset (Smith \& Riseborough, 1996, 2002). Secondly, we used a machine learning approach with 31 environmental predictor variables (including macroclimate, soil, topography, reflectance, vegetation and anthropogenic variables) to model the spatial variation in monthly temperature offsets at a $1 \times 1 \mathrm{~km}$ resolution for all continents except Antarctica (as not covered by many of the used predictor variable layers). Using these offsets, we then calculated relevant soil-related bioclimatic variables (SBIO), mirroring the existing global bioclimatic variables for air temperature. Finally, we compared the modelled mean annual temperature (SBIO1, topsoil layer) with a similar product based on monthly ERA5L topsoil $(0-7 \mathrm{~cm})$ temperature with a spatial resolution of $0.08 \times 0.08 \mathrm{de}-$ grees ( $\approx 9 \times 9 \mathrm{~km}$ at the equator).

\section{2 | METHODS}

\section{1 | Data acquisition}

Analyses are based on SoilTemp, a global database of microclimate time series (Lembrechts et al., 2020). We compiled soil temperature measurements from 9362 unique sensors (mean duration 2.9 years, median duration 1.0 year, ranging from 1 month to 41 years) from 60 countries, using both published and unpublished data sources (Figure 1, Figure S1). Each sensor corresponds to one independent time series.

We used time series spanning a minimum of 1 month, with a temporal resolution of $4 \mathrm{~h}$ or less. Sensors of any type were included (Table S1), as long as they measured in situ. Sensors in experimentally manipulated plots, that is, plots in which microclimate has been manipulated, such as in open top chambers, were excluded. Most data (>90\%) came from low-cost rugged microclimate loggers such as iButtons (Maxim Integrated, USA) or TMS4-sensors (Wild et al., 2019), with measurement errors of around $0.5-1^{\circ} \mathrm{C}$ (note that we are using degree Celsius over Kelvin throughout, for ease of understanding), while in a minority of cases sensors with higher meteorological specifications such as industrial or scientific-grade thermocouples and thermistors (measurement errors of less than $0.5^{\circ} \mathrm{C}$ ) were used. Contributing data sets mostly consisted of short-term regional networks of microclimate measurements, yet also included a set $(<5 \%)$ of soil temperature sensors from long-term research networks equipped with weather stations (e.g. Pastorello et al., 2017). By combining these two types of data, a much higher spatial density of sensors and broader distribution of microhabitats could be obtained than by using weather station data only.

About $68 \%$ of sensors were deployed between 2010 and 2020 and 93\% between 2000 and 2020; we, thus, focus on the latter period in our analyses. Additionally, given the relatively short time frame covered by most individual sensors and thus the lack of spatially unbiased long-term time series, we were not able to test for systematic differences in the temperature offset between old and recent data sets, and thus we did not correct for this in our models. We strongly urge future studies to assess such temporal dynamics in the offset once long-term microclimate data have become sufficient and more available.

For each of the individual 9362 time series, we calculated monthly mean, minimum (5\% percentile of all monthly values) and maximum (95\% percentile) temperature, after checking all time series

FIGURE 1 Temperature offsets between soil and air temperature differed significantly among biomes. (a) Distribution of in situ measurement locations across the globe, coloured by the mean annual temperature offset (in ${ }^{\circ} \mathrm{C}$ ) between in situ measured soil temperature (topsoil, 0-5 cm depth) and gridded air temperature (ERA5-Land). Offsets were averaged per hexagon, each with a size of approximately $70,000 \mathrm{~km}^{2}$. Mollweide projection. (b) Mean annual temperature offsets per Whittaker biome (adapted from Whittaker 1970, based on geographic location of sensors averaged at $1 \mathrm{~km}^{2} ; 0-5 \mathrm{~cm}$ depth), ordered by mean temperature offset and coloured by mean annual precipitation. (c-d) Distribution of sensors in 2D climate space for the topsoil (c, $0-5 \mathrm{~cm}$ depth, $N=4530$ ) and the second layer (d, $5-15 \mathrm{~cm}$ depth, $N=3989)$. Colours of hexagons indicate the number of sensors at each climatic location, with a resolution of $1.2^{\circ} \mathrm{C}(x$-axis) and 100 $\mathrm{mm}$ ( $y$-axis). Grey dots in the background represent the global variation in climatic space (obtained by sampling 1,000,000 random locations from the CHELSA world maps). Overlay with grey lines depicts a delineation of Whittaker biomes 
for plausibility and erroneous data. These monthly values, while perhaps not fully intercomparable between the Northern and Southern Hemisphere, are those that have traditionally been used to calculate bioclimatic variables (Fick \& Hijmans, 2017). Months with more than
1 day of missing data, either at the beginning or end of the measurement period, or due to logger malfunctioning during measurement, were excluded, resulting in a final subset of 380,676 months of soil temperature time series that were used for further analyses. For

(a)

Mean annual temperature offset $\left({ }^{\circ} \mathrm{C}\right)$

(b)

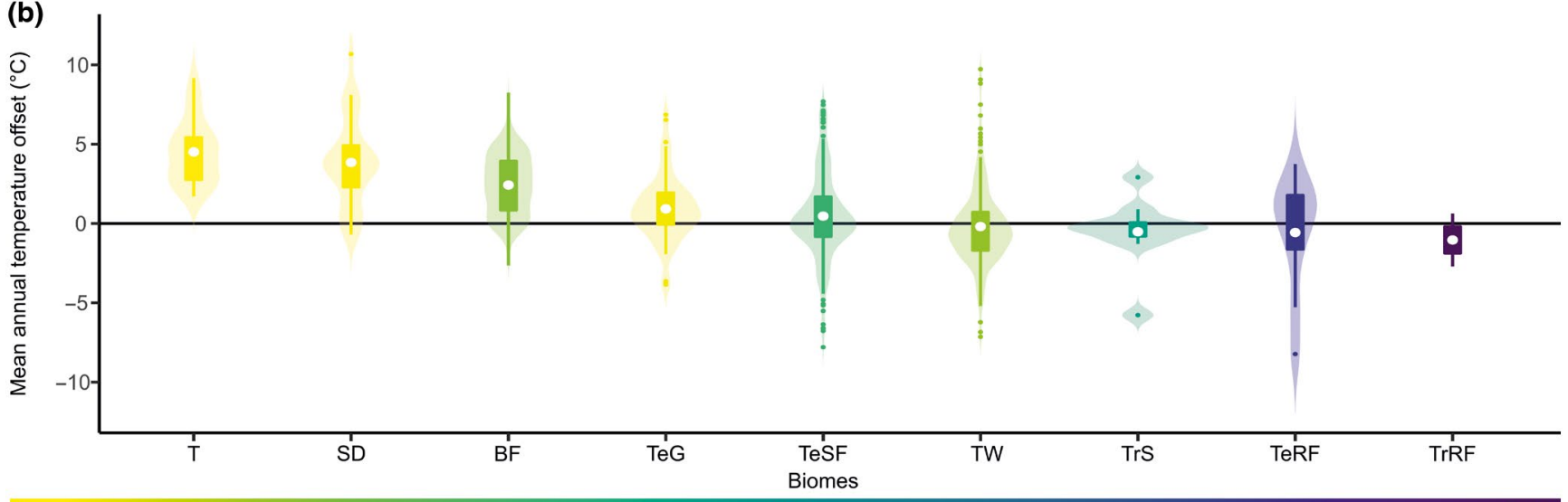

0

(c)

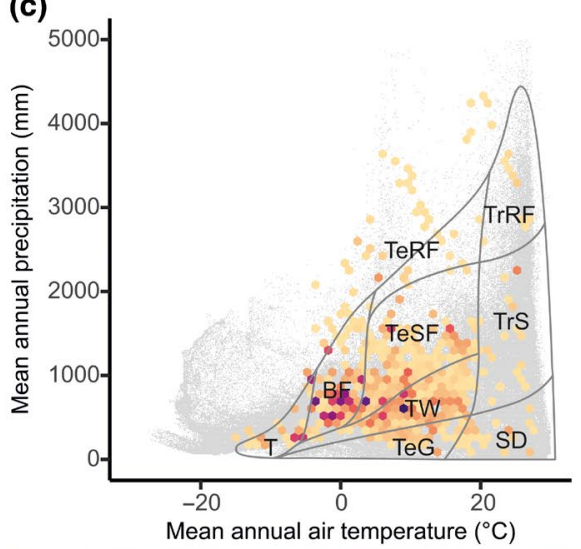

(d)

Mean annual precipitation (mm)

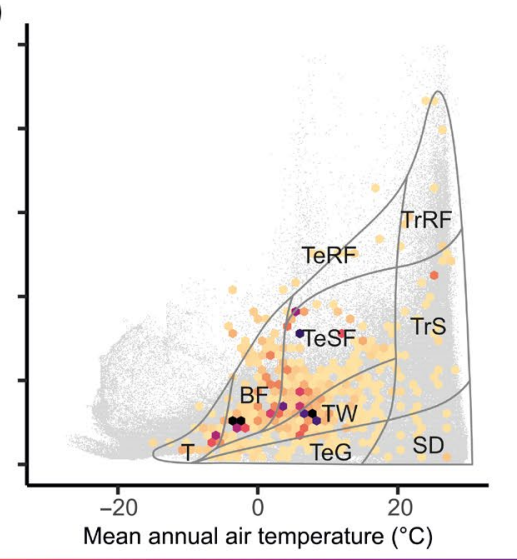

T Tundra

SD

Subtropical Desert

BF Boreal Forest

TeG Temperate Grassland

TeSF Temperate Seasonal Forest

TW Temperate Woodland

TrS Tropical Savanna

TeRF Temperate Rainforest

TrRF Tropical Rainforest

0 
each sensor with more than 12 months of data, we calculated moving averages of annual mean temperature, using each consecutive month as a starting month and calculating the mean temperature including the next 11 months. We used these moving averages to make maximal use of the full temporal extent covered by each sensor because each time series spanned a different time period, often including parts of calendar years only.

The selected data set contained sensors installed strictly belowground, measuring temperature at depths between 0 and $200 \mathrm{~cm}$ below the ground surface. Sensors recording several measurements at the same site but located at different (vertical) depths were included separately (the 9362 unique sensors thus came from 7251 unique loggers).

Sensors were grouped in different soil depth categories $(0-5,5-$ $15,15-30,30-60,60-100,100-200 \mathrm{~cm}$, Table S2) to incorporate the effects of soil temperature dampening associated with vertical stratification. We limited our analyses to the topsoil $(0-5 \mathrm{~cm})$ and the second soil layer $(5-15 \mathrm{~cm})$, as we currently lack sufficient global coverage to make accurate models at deeper soil depths (8519 time series, about $91 \%$, came from the two upper depth layers). Due to uncertainty in the identification of these soil depths between studies (e.g. due to litter layers), no finer categorization is used.

We tested for potential bias in temporal resolution (i.e. measurement interval) by calculating mean, minimum and maximum temperature for a selection of 2000 months for data measured every $15 \mathrm{~min}$, and the same data aggregated to 30, 60, 90, 120 and 240 min. Monthly mean, minimum and maximum temperature calculated with any of the aggregated data sets differed on average less than $0.2^{\circ} \mathrm{C}$ from the ones with the highest temporal resolution. We were, thus, confident that pooling data with different temporal resolutions of $4 \mathrm{~h}$ or finer would not significantly affect our results.

\section{2 | Temperature offset calculation}

For each monthly value at each sensor location (see Table S3 for number of data points per month), we extracted the corresponding monthly means of the $2 \mathrm{~m}$ air temperature from the European Centre for Medium-Range Weather (ECMWF) Forecast's 5th reanalysis (ERA5) (from 1979 to 1981) and ERA5-Land from 1981 to 2020 (Copernicus Climate Change Service (C3S), 2019), hereafter called ERA5L. The latter data set models the global climate with a spatial resolution of $0.08 \times 0.08$ degrees $(\approx 9 \times 9 \mathrm{~km}$ at the equator) with an hourly resolution, converted into monthly means using daily means for the whole month. Similarly, monthly minima and maxima were obtained from TerraClimate (Abatzoglou et al., 2018) for the period 2000 to 2020 at a $0.04 \times 0.04$ degrees $(\approx 4 \times 4 \mathrm{~km}$ at the equator) resolution. Monthly means for TerraClimate were not available, and we therefore estimated them by averaging the monthly minima and maxima. Finally, we also obtained monthly mean temperatures from CHELSA (Karger et al., 2017a, 2017b) for the period 2000 to 2013 at a $30 \times 30$ arc second $(\approx 1 \times 1 \mathrm{~km}$ at the equator) resolution. In our modelling exercises (see section 2.5 Modelling below), we opted to use the mean temperature offsets as calculated based on ERA5L rather than on CHELSA. While CHELSA's higher spatial resolution is definitely an advantage, its time period (stopping in 2013) insufficiently overlapped with the time period covered by our in situ measurements (2000-2020), soil temperature offsets based on the CHELSA data set were only used for comparative purposes. We used TerraClimate to model offsets in monthly minimum and maximum temperature.

We calculated moving annual averages of the gridded air temperature data in the same way as for soil temperature. These were used to create annual temperature offset values following the same approach as above.

The offset between the in situ measured soil temperature in the SoilTemp database and the $2 \mathrm{~m}$ free-air temperature obtained from the air-temperature grids (ERA5L, TerraClimate and CHELSA, hereafter called 'gridded air temperature') was calculated by subtracting the monthly or annual mean air temperature from the monthly or annual mean soil temperature. Positive offset values indicate a measured soil temperature higher than gridded air temperature, whereas negative offset values represent cooler soils. Similarly, monthly minimum and maximum air temperature were subtracted from minimum and maximum soil temperature, respectively. Monthly minima and maxima of the soil temperature were calculated as, respectively, the $5 \%$ lowest and highest instantaneous measurement in that month, to correct for outliers, which can be especially pronounced at the soil surface (Speak et al., 2020). As a result, patterns in minima and maxima are more conservative estimates than if we had used the absolute lowest and highest values.

Importantly, the temperature offset calculated here is a result of three key groups of drivers: (1) height effects $(2 \mathrm{~m}$ versus $0-15 \mathrm{~cm}$ below the soil surface); (2) environmental or habitat effects (e.g. spatial variability in vegetation, snow or topography); and (3) spatial scale effects (resolution of gridded air temperature) (Lembrechts et al., 2020). We investigated the potential role of scale effects by comparing gridded air temperature data sources with different resolutions (ERA5L, TerraClimate and CHELSA, see below; Figures S2-S3). Height effects and environmental effects are, however, not disentangled here, as the offset we propose incorporates both the difference between air and soil temperature (vertically), as well as the difference between free-air macroclimate and in situ microclimate (horizontally) in one measure (Lembrechts et al., 2020). While it can be argued that it would be better to treat both vertical and horizontal effects separately, this would require a similar database of coupled in situ air and soil temperature measurements, which is not yet available. Using in situ measured air temperature could also solve spatial mismatches (i.e. spatially averaged air temperature represents the whole 1 to $81 \mathrm{~km}^{2}$ pixel, depending on pixel size, not only the exact location of the sensor). However, coupled air and soil temperature measurements are not only rare, but the air temperature measurements also have large measurement errors, especially in open habitats (Maclean et al., 2021). These errors can be up to several degrees in open habitats when using non-standardized sensors, loggers and shielding (Holden et al., 2013; Maclean et al., 2021; Terando et al., 2017). Hence, using in situ measured air temperature without correcting for these measurement errors would be misleading. 


\section{3 | Global and biome-level analyses}

For the purpose of visualization, annual offsets were first averaged in hexagons with a resolution of approximately $70,000 \mathrm{~km}^{2}$, using the dggridR-package (version 2.0.4) in R (Barnes et al., 2017) (Figure 1). Next, we plotted mean, minimum and maximum annual soil temperature as a function of corresponding gridded air temperature from ERA5L, TerraClimate and CHELSA and used generalized additive models (GAMs, package mgcv 1.8-31; Wood, 2012) to visualize deviations from the 1:1-line (i.e. temperature offsets deviating from zero, Figures S4-S5).

All annual and monthly values within each soil depth category and falling within the same $1-\mathrm{km}^{2}$ pixel were aggregated as a mean, resulting in a total of c. 1200 unique pixels at $0-5 \mathrm{~cm}$, and c. 1000 unique pixels at 5-15 cm each month, across the globe (Tables S3$\mathrm{S} 5)$. This averaging includes summarizing the data over space, that is, multiple sensors within the same $1-\mathrm{km}^{2}$ pixel, and time, that is, data from multi-year time series from a certain sensor, to reduce spatial and temporal autocorrelation and sampling bias. We assigned these $1-\mathrm{km}^{2}$ averages to the corresponding Whittaker biome of their georeferenced location, using the package plotbiomes (version 0.0.0.9901) in R (Figure 1c,d, Tables S4-S5 (Stefan \& Levin, 2018)). We ranked biomes based on their offset and compared this with the mean annual precipitation in each biome (Figure 1b). This was done separately for each air temperature data source (ERA5L, TerraClimate and CHELSA), soi depth $(0-5 \mathrm{~cm}, 5-15 \mathrm{~cm}$ ) and time frame (ERA5L 1979-2020, 20002020), as well as for the offset between monthly minimum and maximum soil temperature and the minimum and maximum gridded air temperature from TerraClimate. Our analyses showed that patterns were robust to variation in spatial resolution, sensor depth, climate interpolation method and temporal scale (Figures S2-S5).

\section{\begin{tabular}{l|l}
2.4 & Acquisition of global predictor variables
\end{tabular}}

To create spatial predictive models of the offset between in situ soil temperature and gridded air temperature, we first sampled a stack of global map layers at each of the logger locations within the data set. These layers included long-term macroclimatic conditions, soil texture and physiochemical information, vegetation, radiation and topographic indices as well as anthropogenic variables. Details of all layers, including descriptions, units and source information, are described in Supplementary Data S1. In short, information about soil texture, structure and physiochemical properties was obtained from SoilGrids (version 1 [Hengl et al., 2017]), limited to the upper soil layer (top $5 \mathrm{~cm}$ ). Long-term averages of macroclimatic conditions (i.e. monthly mean, maximum and minimum temperature, monthly precipitation) was obtained from CHELSA (version 2017 [Karger et al., 2017a]), which includes climate data averaged across 1979-2013, and from WorldClim (version 2 [Fick \& Hijmans, 2017]). Monthly snow probability is based on a pixel-wise frequency of snow occurrence (snow cover $>10 \%$ ) in MODIS daily snow cover products (MOD10A1 \& MYD10A1 [Hall et al., 2002]) in 2001-2019. Spectral vegetation indices (i.e. averaged MODIS NDVI product MYD13Q1) and surface reflectance data (i.e.
MODIS MCD43A4) were obtained from the Google Earth Engine Data Catalog (developers.google.com/earth-engine/datasets) and averaged from 2015 to 2019. Landcover and topographic information were obtained from EarthEnv (Amatulli et al., 2018). Aridity index (AI) and potential evapotranspiration layers were obtained from CGIAR (Zomer et al., 2008). Anthropogenic information (population density) was obtained from the EU JRC (ghsl.jrc.ec.europa.eu/ghs_pop2019. php). Aboveground biomass data were obtained from GlobBiomass (Santoro, 2018). RESOLVE ecoregion classifications were used to categorize sampling locations into biomes (Dinerstein et al., 2017). With this set of predictor variables, we included information on all different categories of drivers of soil temperature. An important variable that had to be excluded was snow depth, due to the lack of a relevant $1-\mathrm{km}^{2}$ resolution global product. The final set of predictor variables included 24 'static' variables and eight monthly layers (i.e. maximum, mean, and minimum temperature, precipitation, cloud cover, solar radiation, water vapour pressure and snow cover). As cloud cover estimates were not available for high-latitude regions in the Northern Hemisphere in January and December due to a lack of daylight, we excluded cloud cover as an explanatory variable for these months (i.e. 'EarthEnvCloudCover_MODCF_monthlymean_XX', with XX representing the months in two-digit form Supplementary Data S1).

All variable map layers were reprojected and resampled to a unified pixel grid in EPSG:4326 (WGS84) at 30 arc-sec resolution $(\approx 1 \times 1 \mathrm{~km}$ at the equator). Areas covered by permanent snow or ice (e.g. the Greenland ice cap or glaciated mountain ranges, identified using SoilGrids) were excluded from the analyses. Antarctic sampling points were excluded from the modelling data set owing to the limited coverage of several covariate layers in the region.

\section{5 | Modelling}

To generate global maps of monthly temperature offsets (Figure 2), we trained Random Forest (RF) models for each month, using the temperature offsets as the response variables and the global variable layers as predictors (Breiman, 2001; Hengl et al., 2018). We used a geospatial RF modelling pipeline as developed by van den Hoogen et al. (2021). RF models are machine learning models that combine many classification trees using randomized subsets of the data, with each tree iteratively dividing data into groups of most closely related data points (Hengl et al., 2018). They are particularly valuable here due to their capacity to uncover nonlinear relationships (e.g. due to increased decoupling of soil from air temperature in colder and thus snow-covered areas) and their ability to capture complex interactions among covariates (e.g. between snow and vegetation cover) (Olden et al., 2008). Furthermore, they may currently have advantages over mechanistic microclimate models for global modelling (Maclean \& Klinges, 2021), as the latter require highly detailed physical input parameters for calibration, and current computational barriers preclude global assessments at a $1 \mathrm{~km}^{2}$ resolution and over multiple decades. Nevertheless, we urge future endeavours to compare and potentially improve our results with estimates based on such mechanistic models. 
(a)

Annual
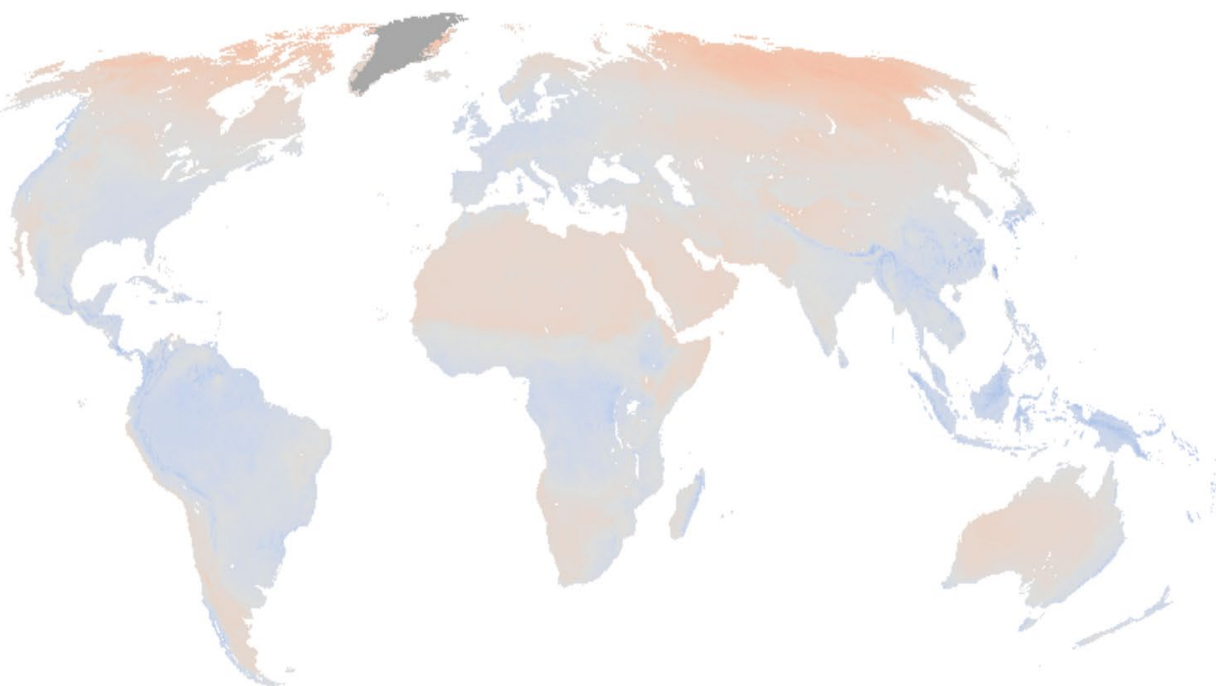

(b)

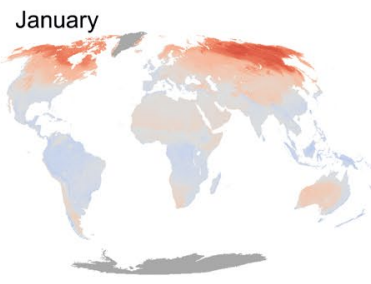

(e)

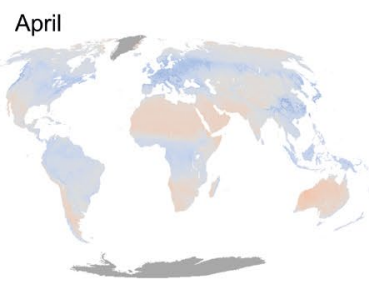

(h)

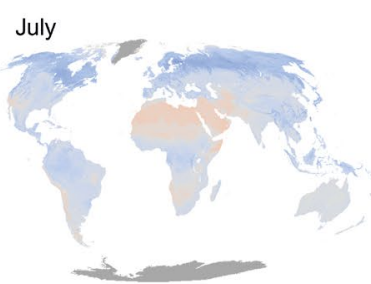

(k)

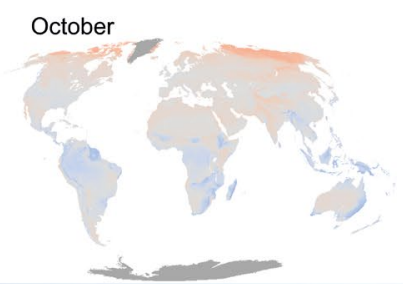

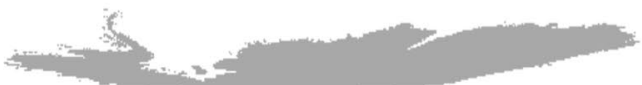

(c)

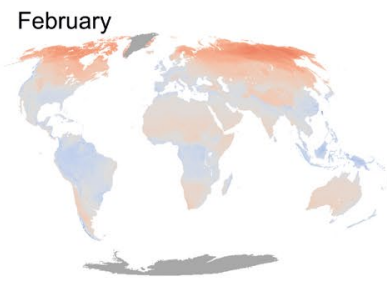

(f)

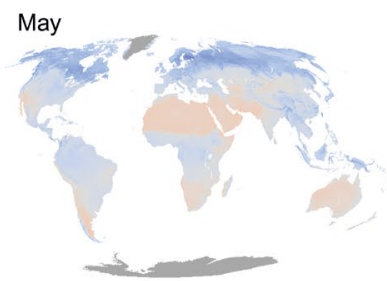

(i)

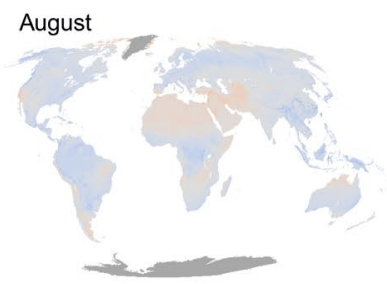

(I)

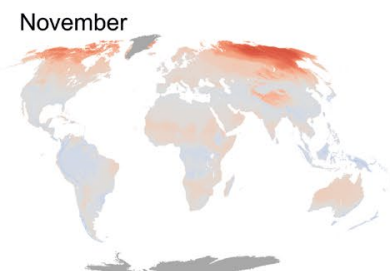

(d)

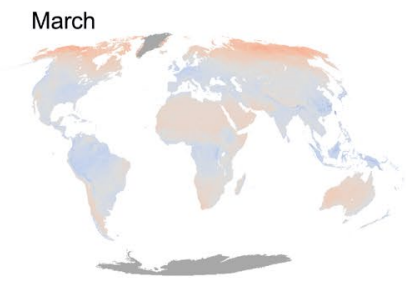

(g)

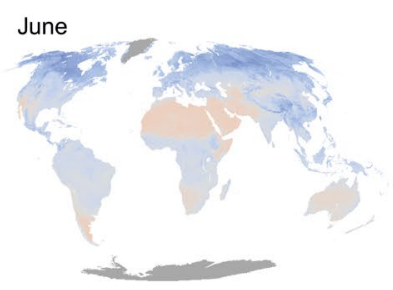

(j)

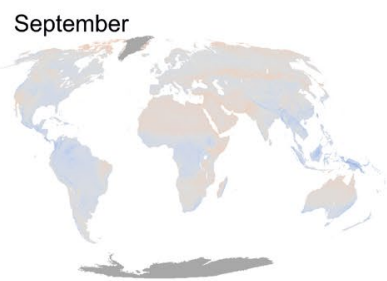

(m)

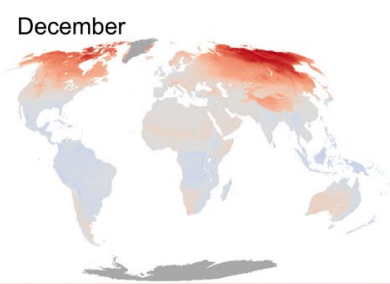

0

Mean temperature offset $\left({ }^{\circ} \mathrm{C}\right)$

FIGURE 2 Global modelled temperature offsets between soil and air temperature show strong spatiotemporal variation across months. Modelled annual (a) and monthly $(b-m)$ temperature offset (in ${ }^{\circ} \mathrm{C}$ ) between in situ measured soil temperature (topsoil, $0-5 \mathrm{~cm}$ ) and gridded air temperature. Positive (red) values indicate soils that are warmer than the air. Dark grey represents regions outside the modelling area

We performed a grid search procedure to tune the RF models across a range of 52 hyperparameter settings (variables per split: $2-14$, minimum leaf population: $2-5$, in all combinations adding up to 52 models, each time with 250 trees). During this procedure, we assessed each of the 52 model's performance using $k$-fold cross-validation ( $k=10$; folds assigned randomly, stratified per biome). The models' mean and standard 
deviation values were the basis for choosing the best of all evaluated models. This procedure was repeated for each month separately for the two soil depth layers $(0-5 \mathrm{~cm}, 5-15 \mathrm{~cm})$, for offsets in mean, minimum and maximum temperature. The importance of predictor variables was assessed using the variable importance and ordered by mean variable importance across all models. This variable importance adds up the decreases in the impurity criterion (i.e. the measure on which the local optimal condition is chosen) at each split of a node for each individual variable over all trees in the forest (van den Hoogen et al., 2021).

\subsection{Soil bioclimatic variables}

The resulting global maps of the annual and monthly offsets between mean, minimum and maximum soil and air temperature were used to calculate relevant bioclimatic variables following the definition used in CHELSA, BIOCLIM, ANUCLIM and WorldClim (Booth et al., 2014; Fick \& Hijmans, 2017; Karger et al., 2017a; Xu $\&$ Hutchinson, 2011) (Table 1, Figures 3-4). First, we calculated monthly soil mean, maximum and minimum temperature by adding monthly temperature offsets to the respective CHELSA monthly mean, maximum and minimum temperature (Karger et al., 2017a). Next, we used these soil temperature layers to compute 11 soil bioclimatic layers (SBIO, Table 1) (O'Donnell \& Ignizio, 2012). Wettest and driest quarters were identified for each pixel based on CHELSA's monthly values.

\section{7 | Model uncertainty}

To assess the uncertainty in the monthly models, we performed a stratified bootstrapping procedure, with total size of the bootstrap samples equal to the original training data (van den Hoogen et al., 2021). Using biomes as a stratification category, we ensured the samples included in each of the bootstrap training collections were proportionally representative of each biome's total area. Next, we trained RF models (with the same hyperparameters as selected during the grid-search procedure) using each of 100 bootstrap iterations. Each of these trained RF models was then used to classify the predictor layer stack, to generate per-pixel 95\% confidence intervals and standard deviation for the modelled monthly offsets (Figure $5 \mathrm{a}$, Figure S6a). The mean $\mathrm{R}^{2}$ value of the RF models for the monthly mean temperature offset was 0.70 (from 0.64 to 0.78 ) at $0-5 \mathrm{~cm}$ and $0.76(0.63-0.85)$ at 5 to $15 \mathrm{~cm}$ across all 12 monthly models. Mean RMSE of the models was $2.20^{\circ} \mathrm{C}\left(1.94-2.51^{\circ} \mathrm{C}\right)$ at $0-5 \mathrm{~cm}$, and $2.06^{\circ} \mathrm{C}\left(1.67-2.35^{\circ} \mathrm{C}\right)$ at $5-15 \mathrm{~cm}$.

Importantly, model uncertainty as reported in Figure $5 \mathrm{a}$ and Figure S6a comes on top of existing uncertainties in (1) in situ soil temperature measurements and (2) the ERA5L macroclimate models as used in our models. However, both of those are usually under $1^{\circ} \mathrm{C}$ (Copernicus Climate Change Service (C3S), 2019; Wild et al., 2019).

To assess the spatial extent of extrapolation, which is necessary due to the incomplete global coverage of the training data, we first performed a principal component analysis (PCA) on the full environmental space covered by the monthly training data, including all explanatory variables as used in the models, and then transformed the composite image into the same principal comonents' (PC) spaces as of the sampled data (van den Hoogen et al., 2019). Next, we created convex hulls for each of the bivariate combinations from the first 10 to 12 PCs, covering at least $90 \%$ of the sample space variation, with the number of PCs depending on the month. Using the coordinates of these convex hulls, we assessed whether each pixel fell within or outside each of these convex hulls and calculated the percentage of bivariate combinations for which this was the case (Figure 5b, Figure S6b). This process was repeated for each month and for each of the two soil depths separately.

These uncertainty maps are important because one should be careful with extrapolation beyond the range of conditions covered by the environmental variables included in the original calibration data set, especially in the case of non-linear patterns such as modelled here. The maps are provided as spatial masks to remove or reduce the weighting of the pixels for which predictions are beyond the range of values covered by the models during calibration. To assess this further, we used a spatial leave-one-out cross-validation analysis to test for spatial autocorrelation in the data set (Figure S7) (van den Hoogen et al., 2021). This approach trains a model for each sample in the data set on all remaining
TABLE 1 Overview of soil bioclimatic variables as calculated in this study

\begin{tabular}{|ll}
\hline Bioclimatic variable & Meaning \\
\hline SBIO1 & annual mean temperature \\
\hline SBIO2 & mean diurnal range $($ mean of monthly $(\mathrm{max}$ temp - min temp)) \\
\hline $\mathrm{SBIO} 3$ & isothermality $(\mathrm{SBIO} / \mathrm{SBIO})(\times 100)$ \\
\hline $\mathrm{SBIO} 4$ & temperature seasonality $($ standard deviation $\times 100)$ \\
\hline $\mathrm{SBIO} 5$ & max temperature of warmest month \\
\hline $\mathrm{SBIO} 6$ & min temperature of coldest month \\
\hline $\mathrm{SBIO} 7$ & temperature annual range $(\mathrm{SBIO}-\mathrm{SBIO})$ \\
\hline $\mathrm{SBIO} 8$ & mean temperature of wettest quarter \\
\hline $\mathrm{SBIO} 9$ & mean temperature of driest quarter \\
\hline $\mathrm{SBIO} 10$ & mean temperature of warmest quarter \\
\hline $\mathrm{SBIO} 11$ & mean temperature of coldest quarter \\
\hline
\end{tabular}


(a) Annual mean temperature, SBIO1
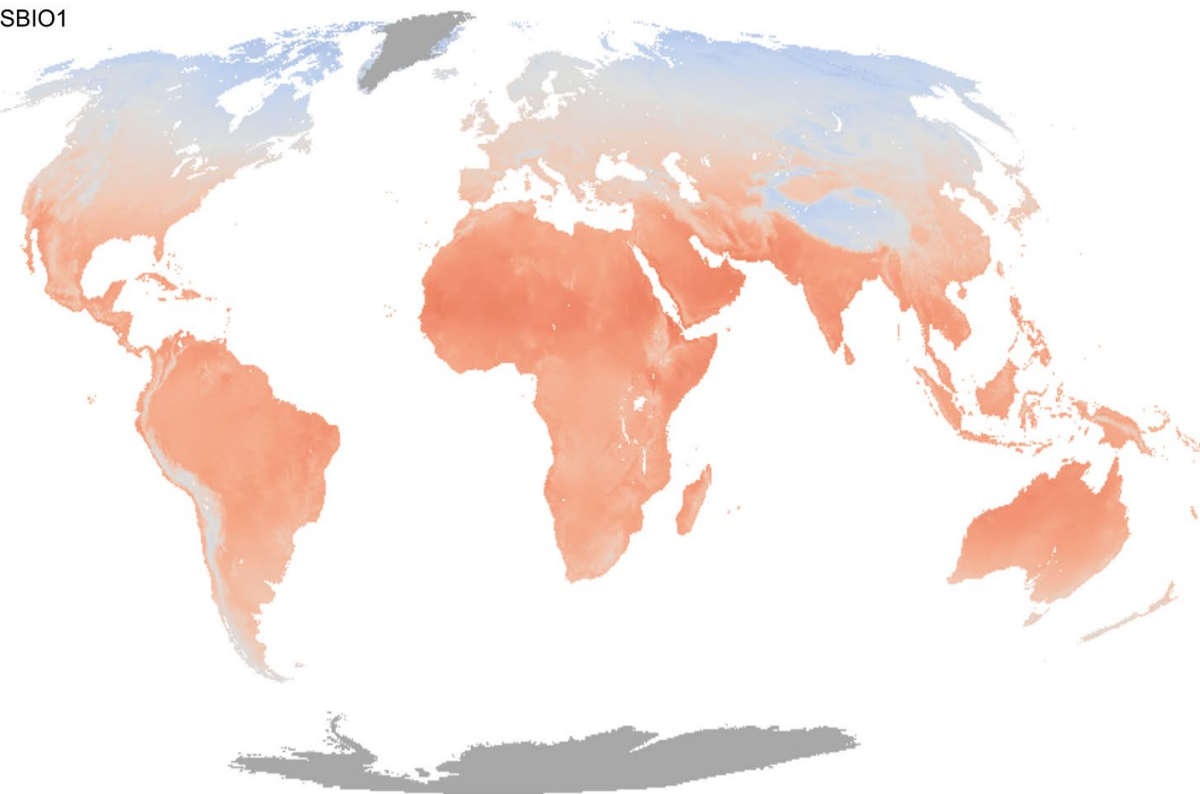

(b) Mean Diurnal Range

Mean of monthly (max $-\min ), \mathrm{SBIO} 2$

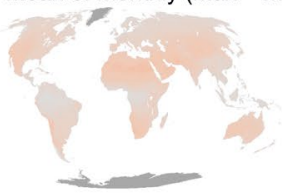

(f) Mean Temperature of Wettest Quarter, SBIO8

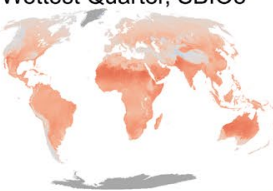

$-38$

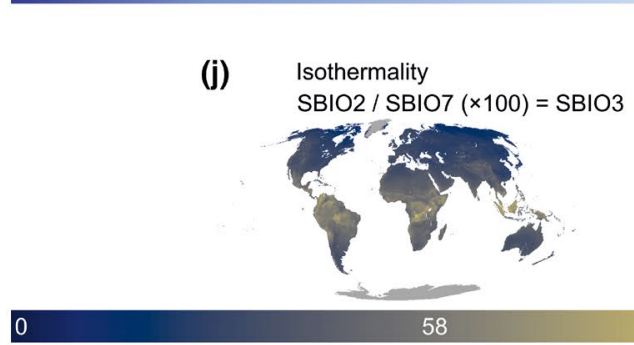

Temperature $\left({ }^{\circ} \mathrm{C} \times 100\right)$ (c) Max Temperature of

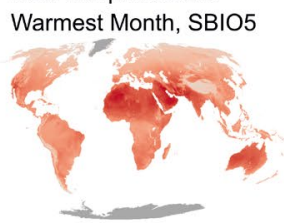

(g) Mean Temperature of

Driest Quarter, SBIO9

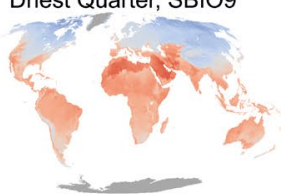

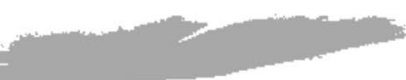

(d)

Min Temperature of

Coldest Month, SBIO6

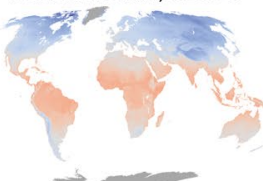

(h) Mean Temperature of

Warmest Quarter, SBIO10

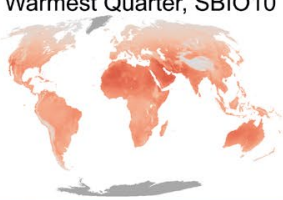

(e) Temperature Annual Range $\mathrm{SBIO} 5-\mathrm{SBIO} 6=\mathrm{SBIO} 7$

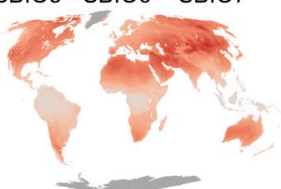

(i) Mean Temperature of Coldest Quarter, SBIO11

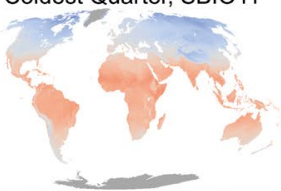

0 Temperature $\left({ }^{\circ} \mathrm{C}\right)$

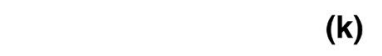

(k) Temperature Seasonality Standard deviation $(\times 100)$, SBIO4

0

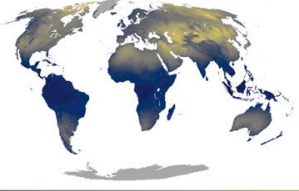

580

Temperature $\left({ }^{\circ} \mathrm{C} \times 100\right)$

FIGURE 3 Soil bioclimatic variables. Global maps of bioclimatic variables for topsoil $(0-5 \mathrm{~cm}$ depth) climate, calculated using the maps of the monthly offsets between soil and air temperature (see Figure 2), and the bioclimatic variables for air temperature from CHELSA

samples, excluding data points that fall within an increasingly large buffer around that focal sample. Results show lowest confidence for May to September at $5-15 \mathrm{~cm}$, likely driven by uneven global coverage of data points.

Finally, we compared the modelled mean annual temperature (SBIO1, topsoil layer) with a similar product based on monthly ERA5L topsoil $(0-7 \mathrm{~cm})$ temperature with a spatial resolution of $0.08 \times 0.08 \mathrm{de}$ grees ( $\approx 9 \times 9 \mathrm{~km}$ at the equator, Copernicus Climate Change Service (C3S), 2019). The corresponding SBIO1 based on ERA5L was calculated using the means of the monthly averages for each month over the period 1981 to 2016, and averaging these 12 monthly values into one annual product. We then visualized spatial differences between SBIO1 and ERA5, as well as differences across the macroclimatic gradient, to identify mismatches between both data sets.

All geospatial modelling was performed using the Python API in Google Earth Engine (Gorelick et al., 2017). The R statistical software, version 4.0.2 (R Core Team, 2020), was used for data visualizations. All maps were plotted using the Mollweide projection, 
(a)

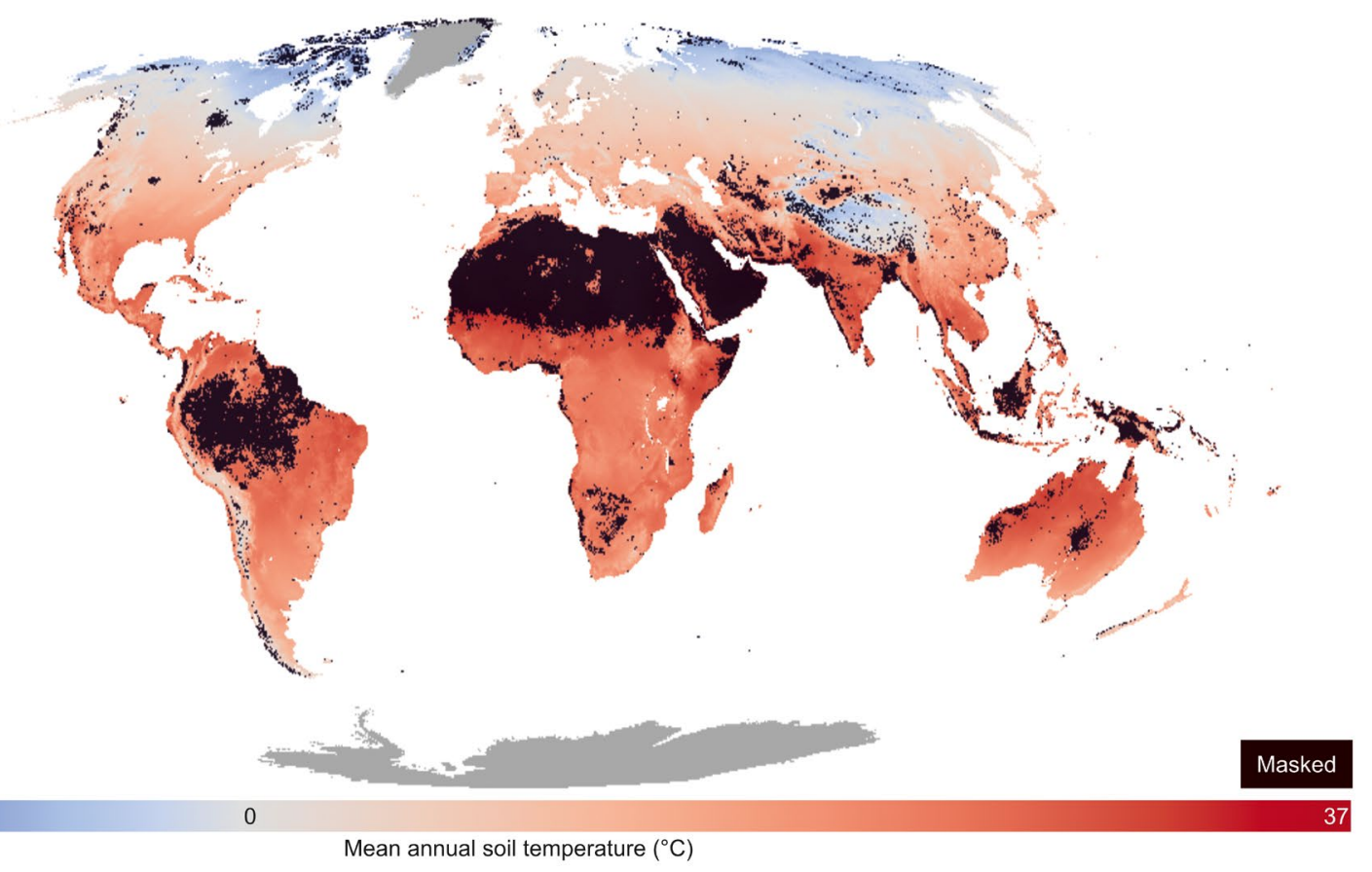

(b)

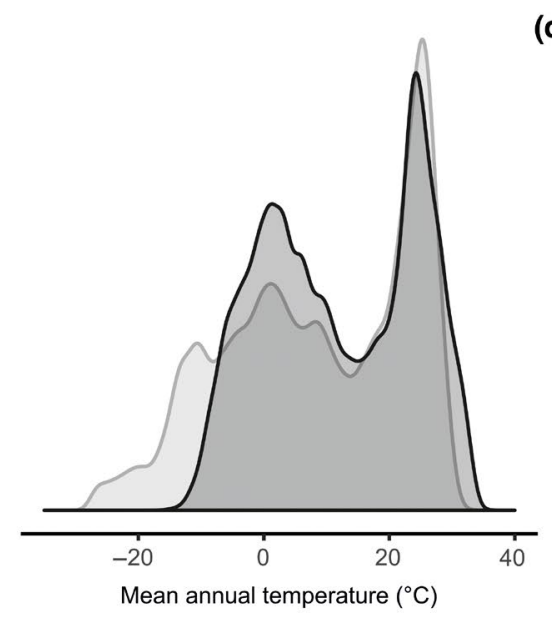

(c)

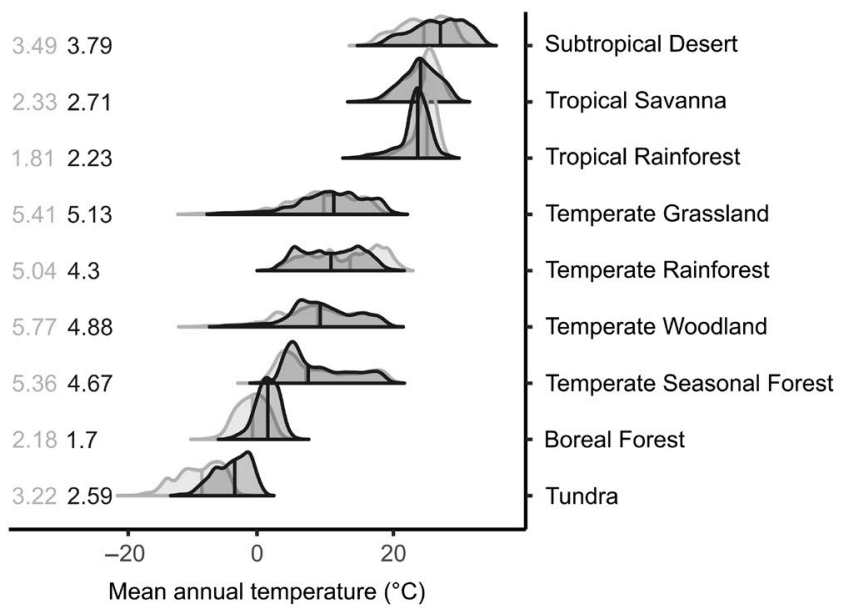

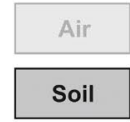

Soil

FIGURE 4 Mean annual soil temperature shows significantly lower spatial variability than air temperature. (a) Global map of mean annual topsoil temperature (SBIO1, $0-5 \mathrm{~cm}$ depth, in ${ }^{\circ} \mathrm{C}$ ), created by adding the monthly offset between soil and air temperature for the period 2000-2020 (Figure 2) to the monthly air temperature from CHELSA. A black mask is used to exclude regions where our models are extrapolating (i.e. interpolation values in Figure 5 are $<0.9,18 \%$ of pixels). Dark grey represents regions outside the modelling area. (b-c) Density plots of mean annual soil temperature across the globe (b) and for each Whittaker biome separately (c) for SBIO1 (dark grey, soil temperature), compared with BIO1 from CHELSA (light grey, air temperature), created by extracting 1,000,000 random points from the $1-\mathrm{km}^{2}$ gridded bioclimatic products. The numbers in (c) represent the standard deviations of air temperature (light grey) and soil temperature (dark grey). Biomes are ordered according to the median annual soil temperature values (vertical black line) from the highest temperature (subtropical desert) to the lowest (tundra)

which preserves relative areas, to avoid large distortions at high latitudes.

\section{8 | Sources of uncertainty}

The temporal mismatch between the period covered by CHELSA (19792013) and our in situ measurements (2000-2020) prevented us from directly using CHELSA climate to calculate the temperature offsets used in our models. This temporal mismatch might affect the offsets calculated here because the relationship between temperature offset and macroclimate will change through time as the climate warms. Similarly, inter-annual differences in offsets due to specific weather conditions cannot be implemented in the used approach. However, we are confident that, at the relatively coarse spatial $\left(1 \mathrm{~km}^{2}\right)$ and temporal (monthly averages) resolution we are working at, our results are sufficiently robust to withstand these 
(a) January

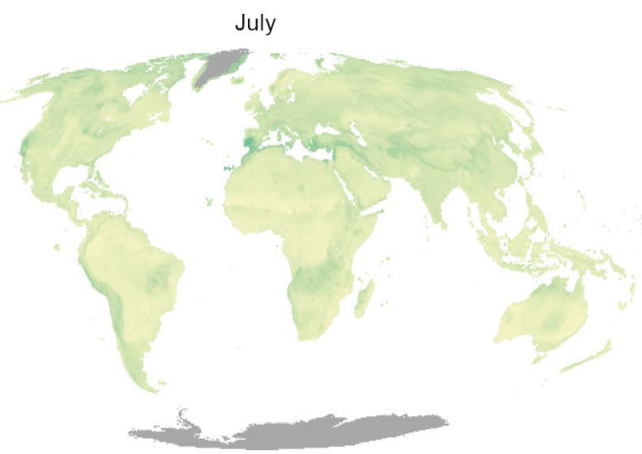

0.14

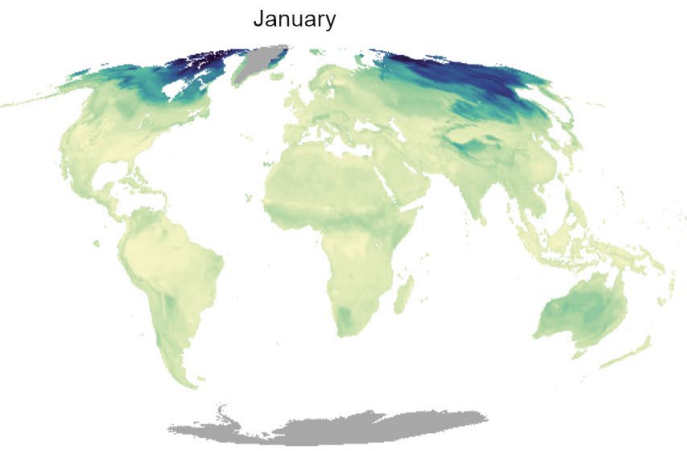

ard deviation

(b)
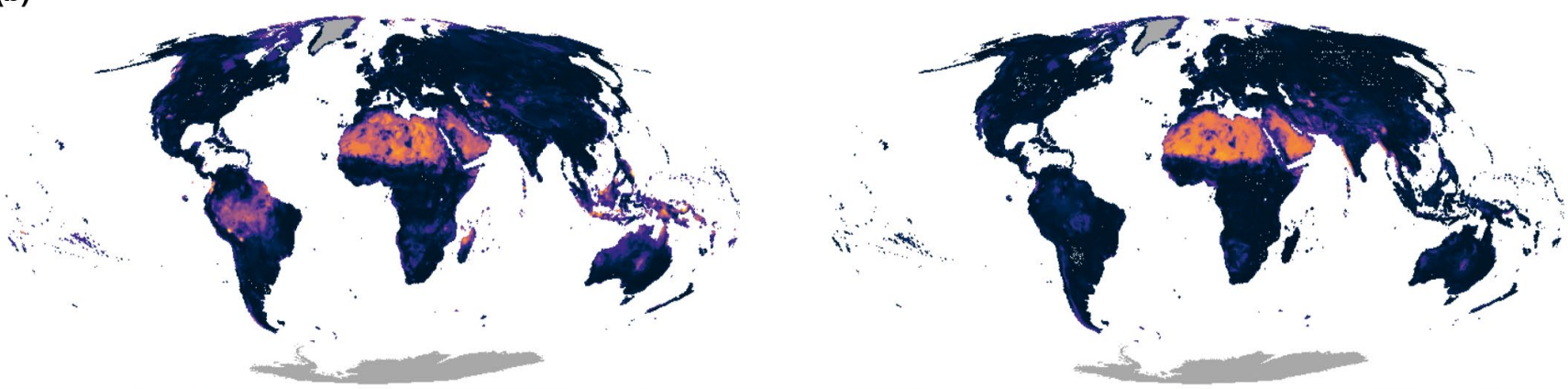

0.00

FIGURE 5 Models of the temperature offset between soil and air temperature have low standard deviations and good global coverage. Analyses for the temperature offset between in situ measured topsoil (0-5 cm depth) temperature and gridded air temperature. (a) Standard deviation (in ${ }^{\circ} \mathrm{C}$ ) over the predictions from a cross-validation analysis that iteratively varied the set of covariates (explanatory data layers) and model hyperparameters across 100 models and evaluated model strength using 10 -fold cross-validation, for January (left) and July (right), as examples of the two most contrasting months. (b) The fraction of axes in the multidimensional environmental space for which the pixel lies inside the range of data covered by the sensors in the database. Low values indicate increased extrapolation

temporal issues, given that we found high consistency in offset patterns between the different time frames and air temperature data sets examined (Figures S2-S5). Nevertheless, we strongly urge future research to disentangle these potential temporal dynamics, especially given the increasing rate at which the climate is warming (GISTEMPTeam, 2021; Xu et al., 2018).

Similarly, a potential bias could result from the mismatch in method and resolution between ERA5L-used to calculate the temperature offsets-and CHELSA, which was used to create the bioclimatic variables. However, even though temperature offsets have slightly larger variation when based on the coarser-grained ERA5L-data than on the finer-grained CHELSA-data, Figures S2-S5 show that relationships between soil and air temperature are largely consistent in all biomes and across the whole global temperature gradient. Therefore, the larger offsets created additional random scatter, yet no consistent bias.

Finally, we acknowledge that the $1-\mathrm{km}^{2}$ resolution gridded products might not be representative of conditions at the in situ measurement locations within each pixel. This issue could be particularly significant for different vegetation types (here proxied at the pixel level using total aboveground biomass (unit: tons/ha i.e., $\mathrm{Mg} / \mathrm{ha}$, for the year 2010; Santoro, 2018) and NDVI (MODIS NDVI product MYD13Q1, averaged over 2015-2019). To verify this, we compared a pixel's estimated aboveground biomass with the dominant in situ habitat (forest versus open) surrounding the sensors in that pixel
(Table S6). Importantly, all sensors installed in forests fell indeed in pixels with more than 1 ton/ha aboveground biomass. Similarly, 75\% or more of sensors in open terrain fell in pixels with biomass estimates of less than 1 ton/ha. Only in the temperate woodland biome was the match between in situ habitat estimates and pixel-level aboveground biomass lower, with less than $95 \%$ of sensors in forested locations correctly placed in pixels with more than 1 ton/ha biomass, and less than $50 \%$ of open terrain sensors in pixels with less than 1 ton/ha biomass. While our predictions will thus not be accurate for locations within a pixel that largely deviate from average conditions (e.g. open terrain in pixels identified as largely forested, or vice versa), they should be largely representative for those pixel-level averages.

\section{3 | RESULTS}

\subsection{Biome-wide patterns in the temperature offset}

We found positive and negative temperature offsets of up to $10^{\circ} \mathrm{C}$ between in situ measured mean annual topsoil temperature and gridded air temperature (mean $=3.0 \pm 2.1^{\circ} \mathrm{C}$ standard deviation, Figure 1, $0-5 \mathrm{~cm}$, depth; $5-15 \mathrm{~cm}$ is available in Figures $\mathrm{S} 2, \mathrm{~S} 5)$. The magnitude 
and direction of these temperature offsets varied considerably within and across biomes. Mean annual topsoil temperature was on average $3.6 \pm 2.3^{\circ} \mathrm{C}$ higher than gridded air temperature in cold and/or dry biomes, namely tundra, boreal forests, temperate grasslands and subtropical deserts. In contrast, offsets were slightly negative in warm and wet biomes (tropical savannas, temperate forests and tropical rainforests) where soils were, on average, $0.7 \pm 2.7^{\circ} \mathrm{C}$ cooler than gridded air temperature (Figure 1b, Figures S2 and S5; note, however the lower spatial coverage in these biomes in Figure 1a,c,d, Table S4). Temperature offsets in annual minimum and maximum temperature amounted to $\mathrm{C} .10^{\circ} \mathrm{C}$ maximum. While annual soil temperature minima were on average higher than corresponding gridded air temperature minima in all biomes, temperature offsets of annual maxima followed largely the same biome-related trends as seen for the annual means, albeit with the higher variability expected for temperature extremes (Figures S2g, S2h, S4g, S4h). Using different air temperature data sources did not alter the annual temperature offset and biome-related patterns (see Methods and Figures S2-S5).

Soils in the temperate seasonal forest biome were on average $0.8^{\circ} \mathrm{C}\left( \pm 2.2^{\circ} \mathrm{C}\right)$ cooler than air temperature within $1-\mathrm{km}^{2}$ grid cells of forested habitats, and $1.0^{\circ} \mathrm{C}\left( \pm 4.0^{\circ} \mathrm{C}\right)$ warmer than the air within $1-\mathrm{km}^{2}$ grid cells of non-forested habitats, resulting in a biome-wide average of $0.5^{\circ} \mathrm{C}$ (Table S7). Similar patterns were observed in other biomes.

\subsection{Temporal and spatial variation in temperature offsets}

Our RF outputs highlighted a strong seasonality in monthly temperature offsets, especially towards higher latitudes (Figure 2). Highlatitude soils were found to be several degrees warmer than the air (monthly offsets of up to $25^{\circ} \mathrm{C}$ ) during their respective winter months, and cooler (up to $10^{\circ} \mathrm{C}$ ) in summer months, both at $0-5 \mathrm{~cm}$ (Figure 2) and 5-15 cm (Figure S8) soil depths. In the tropics and subtropics, soils in dry biomes (e.g. in the Sahara Desert or southern Africa) were predicted to be warmer than air throughout most of the year, while soils in mesic biomes (e.g. tropical biomes in South America, central Africa and Southeast Asia) were modelled to be consistently cooler, at both soil depths. These global gridded products were then used to create temperature-based global bioclimatic variables for soils (SBIO, Figure 3, Figure S9).

\section{3 | Global variation in soil temperature}

We observed $17 \%$ less spatial variation in mean annual soil temperature globally (expressed by the standard deviation) than in air temperature, largely driven by the positive offset between soil and air temperature in cold environments (Figure 4). Importantly, our machine learning models slightly (up to $1^{\circ} \mathrm{C}$, or around $10 \%$ of variation) underestimated temperature offsets at both extremes of the temperature gradient at the $1-\mathrm{km}^{2}$ resolution (Figure S10) and likely even more in comparison with finer-resolution products. Estimates of the reduction in variation across space are thus conservative, especially in the coldest biomes. The reduction in spatial temperature variation was observed in all cold and cool biomes, with tundra and boreal forests having both a significant positive mean temperature offset and a reduction of $20 \%$ and $22 \%$ in variation, respectively (Figure 4c). In the warmest biomes (e.g. tropical savanna and subtropical desert), however, we found an increase in variation of, on average, $10 \%$.

Our bootstrap approach to validate modelled monthly offsets indicated high consistency among the outcomes of 100 bootstrapped models (Figure 5, Figure S6a), with standard deviations in most months and across most parts of the globe around or below $\pm 1^{\circ} \mathrm{C}$. One exception to this was the temperature offset at high latitudes of the Northern Hemisphere during winter months (standard deviation up to $\pm 5^{\circ} \mathrm{C}$ in the 0-5 cm layer). Predictive performance was comparable across biomes, although with large variation in data availability (Figure S11).

The importance of predictor variables in the RF models was largely consistent across months. Macroclimatic variables such as incoming solar radiation as well as long-term averages in air temperature and precipitation were by far the most influential explanatory variables in the spatial models of the monthly temperature offset (Figures S12 and S13).

We highlight that the current availability of in situ soil temperature measurements is significantly lower in the tropics (Table S5), where our model had to extrapolate temperatures beyond the range used to calibrate the model (Figure 5b, Figure S6b).

Finally, our comparison with a mean annual soil temperature product derived from the coarse-resolution ERA5L topsoil temperature showed that spatial variability, for example, driven by topographic heterogeneity, is much better captured here than in the coarser resolution of the ERA5Lbased product (Figure 6c-e). Nevertheless, our predictions at the coarse scale showed to be condensed within a $5^{\circ} \mathrm{C}$ range of values from the ERA5L-predictions, for more than $95 \%$ of pixels globally. Noteworthy, our predictions resulted in consistently cooler soil temperature predictions than topsoil conditions provided by ERA5L across large areas, such as the boreal and tropical forest biomes (Figure 6a,b). Additionally, our models predicted lower values for SBIO1 than ERA5L in all regions with mean annual soil temperature below $0^{\circ} \mathrm{C}$, except for a few locations around Greenland and Svalbard (Figure 6a,b).

\section{4 | DISCUSSION}

\subsection{Global patterns in soil temperature}

We observed large spatiotemporal heterogeneity in the global offset between soil and air temperature, often in the order of several degrees annually and up to more than $20^{\circ} \mathrm{C}$ during winter months at high latitudes. These values are in line with empirical data from regional studies (Lembrechts et al., 2019; Obu et al., 2019; Zhang et al., 2018). Both annual and monthly offsets showed clear discrepancies between cold and dry versus warm and wet biomes. The modelled monthly offsets 
(a) Difference between $\mathrm{SBIO} 1$ and ERA5 soil temperature $\left({ }^{\circ} \mathrm{C}\right)$

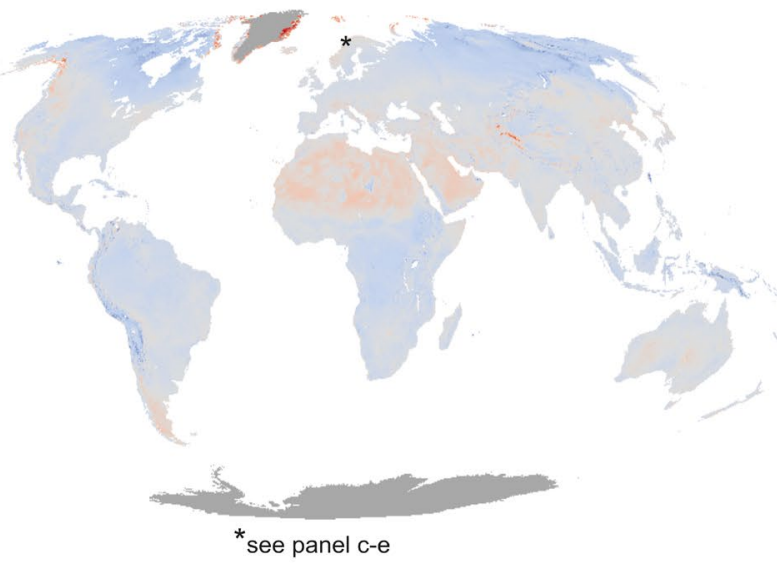

(b)

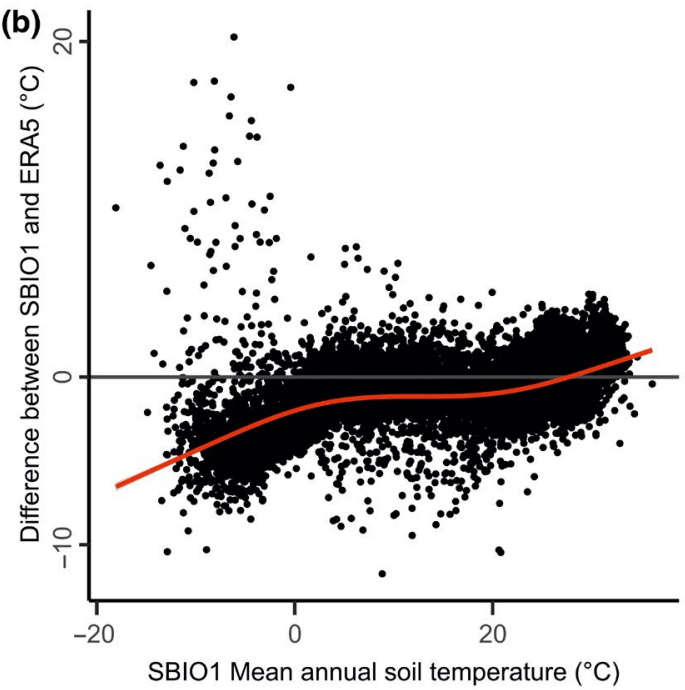

(c)

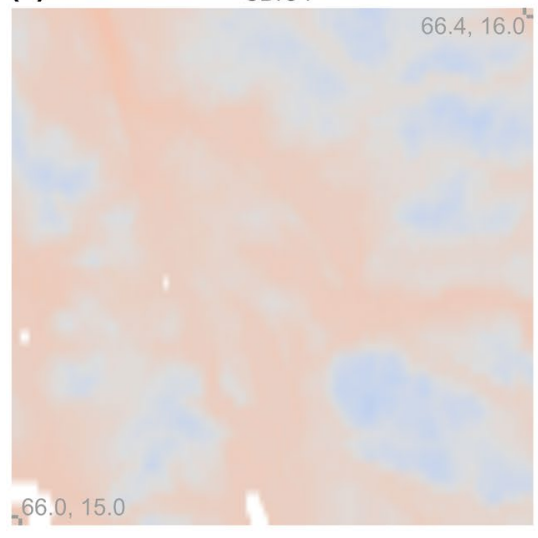

(d)

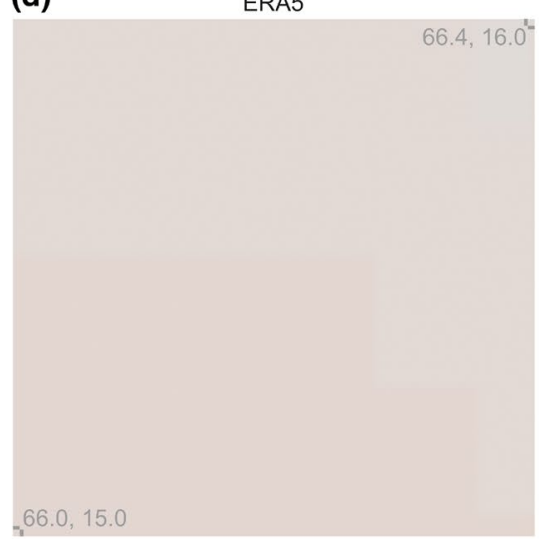

(e) Difference between SBIO1 and ERA5

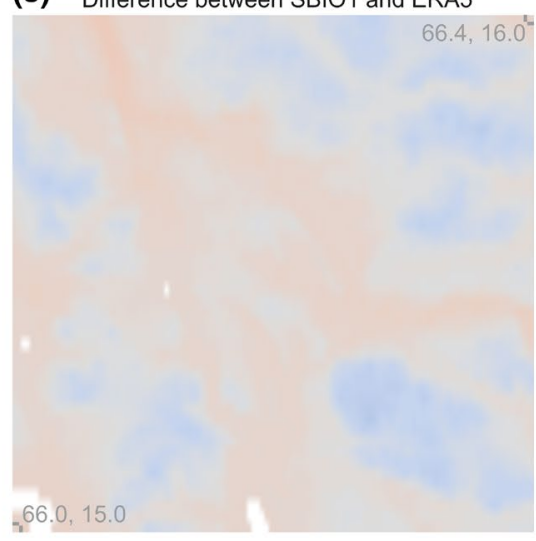

Temperature $\left({ }^{\circ} \mathrm{C}\right)$

FIGURE 6 The mean annual soil temperature (SBIO1, $1 \times 1 \mathrm{~km}$ resolution) modelled here is consistently cooler than ERA5L (9 $9 \mathrm{~km})$ soil temperature in forested areas. (a) Spatial representation of the difference between SBIO1 based on our model and based on ERA5L soil temperature data. Negative values (blue colours) indicate areas where our model predicts cooler soil temperature. Dark grey areas (Greenland and Antarctica) are excluded from our models. Asterisk in Scandinavia indicates the highlighted area in panels $d$ to $f(s e e$ below). (b) Distribution of the difference between SBIO1 and ERA5L along the macroclimatic gradient (represented by SBIO1 itself) based on a random subsample of 50,000 points from the map in a). Red line from a Generalized Additive Model (GAM) with k = 4. (c-e) High-resolution zoomed panels of an area of high elevational contrast in Norway (from 66.0-66.4 ${ }^{\circ} \mathrm{N}, 15.0-16.0^{\circ} \mathrm{E}$ ) visualizing SBIO1 (c), ERA5L (d) and their difference (e), to highlight the higher spatial resolution as obtained with SBIO1

covaried strongly negatively with both long-term averages in free-air temperature and solar radiation, linking to the well-known decoupling of soil from air temperature due to snow (for cold extremes in cold and cool biomes) (Grundstein et al., 2005). However, the secondary importance of variables related to precipitation and soil structure hints to the additional distinction between wet and dry biomes at the warm end of the temperature gradient. There, buffering due to shading, evapotranspiration and the specific heat of water (mostly against warm extremes in warm and wet biomes) results in cooler soil temperature (De Frenne et al., 2013; Geiger, 1950; Grünberg et al., 2020; Grundstein et al., 2005; Hennon et al., 2010; Wang \& Dickinson, 2012), while such buffering is not as strong in warm and dry biomes due to the lower water availability (Greiser et al., 2018; Wang \& Dickinson, 2012; Zhou et al., 2021). As such, these results highlight strong macroclimatic impacts on the soil microclimate across the globe (see also De Frenne et al., 2019), yet with soil temperature importantly non-linearly related to air temperature at the global scale. This confirms that the latter is not sufficient as a proxy for temperature conditions near or in the soil. With our soil-specific global bioclimatic products, we have provided the means to correct for these important region-specific, non-linear differences between soil and air temperature at an unprecedented spatial resolution.

\subsection{Drivers of the temperature offset}

Our empirical modelling approach enabled us to accurately map global patterns in soil temperature. In doing so we did not aim to 
disentangle the mechanisms governing the temperature offset: such an endeavour would require modelling the biophysics of energy exchange at the soil surface across biomes (Kearney et al., 2019; Maclean \& Klinges, 2021; Maclean et al., 2019). Importantly, many of the predictor variables used in our study (e.g. long-term averages in macroclimatic conditions or solar radiation) are unlikely to represent direct causal relationships underlying the temperature offset, but may rather indirectly relate to many ensuing factors that affect the functioning of ecosystems at fine spatial scales which, in turn, feedback on local temperature offsets, such as energy and water balances, snow cover, wind intensity and vegetation cover (De Frenne et al., 2021). For example, while increased solar radiation itself would theoretically result in soils warming more than the air, high solar radiation at the global scale often coincides with high vegetation cover blocking radiation input to the soil, thus correlating with relatively cooler soils (De Frenne et al., 2021). Our results highlight, however, that the complex relationship between microclimatic soil temperature and macroclimatic air temperature is predictable across large spatial extents thanks to broad scale patterns, even if this is governed by a multitude of local-scale factors involving fine spatiotemporal resolutions. Nevertheless, the predictive quality of our models was lower in high latitude regions, where high variation in the in situ measured offsets-likely driven by the interactions between snow, local topography and vegetation-reduced predictive power of the models at the 1-km² resolution (Greiser et al., 2018; Grünberg et al., 2020; Myers-Smith et al., 2020; Niittynen et al., 2020; Way \& Lewkowicz, 2018).

\section{3 | Implications for microclimate warming}

Our results highlight clear biome-specific differences in mean annual temperature between air and soil temperatures, as well as a significant reduction in the spatial variation in temperature in the soil or near the soil surface, especially in cold and cool biomes (Figure 4). These patterns remain even despite the presence of often strongly opposing monthly offset trends (Figure 2). The observed correlation between long-term averages in macroclimatic conditions and the annual temperature offset illustrates that soil temperature is unlikely to warm at the same rate as air temperature when macroclimate warms. Indeed, one degree of air temperature warming could result in either a bigger or smaller soil temperature change, depending on where along the macroclimatic gradient this is happening. These effects might be seen in cold biome soils most strongly, as they not only experience the largest (positive) temperature offsets and reductions in climate range compared to air temperature (Figure $4 b, c$ ), but they are also expected to experience the strongest magnitude of macroclimate warming (Chen et al., 2021; Cooper, 2014; GISTEMP Team, 2021; Overland et al., 2014). As a result, mean annual temperatures in cold climate soils can be expected to warm slower than the corresponding macroclimate as offsets shrink with increasing macroclimate warming.
Contrastingly, predicted climate warming in hot and dry biomes could be amplified in the topsoil, where we show soils to become increasingly warmer than the air at higher temperatures. Similarly, changes in precipitation regimes-and thus soil moisture-can significantly alter the relationship between air and soil temperature, with critical implications for soil moistureatmosphere feedbacks, especially in hot biomes (Zhou et al., 2021). Indeed, as precipitation decreases, offsets could turn more positive and soil temperatures might warm even faster than the observed macroclimate warming. Therefore, future research should not only use soil temperature data as provided here to study belowground ecological processes (De Frenne et al., 2013; Lembrechts et al., 2020), it should also urgently investigate future scenarios of soil climate warming in light of changing air temperature and precipitation, at ecologically relevant spatial and temporal resolutions to incorporate the non-linear relationships exposed so far (Lembrechts \& Nijs, 2020).

\section{4 | Within-pixel heterogeneity}

We chose to use a $1-\mathrm{km}^{2}$ resolution spatial grid to model mismatches between soil and air temperature, aggregating all values from different microhabitats within the same $1-\mathrm{km}^{2}$ grid cell (e.g. sensors in forested versus open patches) as well as all daily and diurnal variation within a month. Additionally, we used coarse-grained free-air temperature rather than in situ measured air temperatures. We are aware that higher spatiotemporal resolutions would likely reveal the importance of locally heterogeneous variables. Finer-scale factors that affect the local radiation balance and wind (e.g. topography, snow and vegetation cover, urbanization) at the landscape to local scales and those that directly affect neighbouring locations (e.g. topographic shading and cold-air drainage, Ashcroft \& Gollan, 2012; Lembrechts et al., 2020; Whiteman, 1982) would probably have emerged as more important drivers at regional scales and with higher spatiotemporal resolutions than those used here (Figure S12). The latter is illustrated by the multi-degree Celsius difference in mean annual temperature between forested and non-forested locations within the same biome (Table S7), as well as the lower accuracy obtained during winter months at high latitudes, where and when fine-scale spatial heterogeneity in snow cover and depth probably lowers models' predictability at the $1-\mathrm{km}^{2}$ resolution. In situ measurements were largely from areas with a representative vegetation type, supporting the reliability of our predictions for the dominant habitat type within a pixel. However, improved accuracy at high latitudes will depend on the future development of high-resolution snow depth and/or snow water equivalent estimates (Luojus et al., 2010).

The SoilTemp database (Lembrechts et al., 2020) will facilitate the necessary steps towards mapping soil temperature at higher spatiotemporal resolutions in the future, with its georeferenced time series of in situ measured soil and near-surface temperature and associated metadata. Nevertheless, compared 
with existing soil temperature products such as those from ERA5L (Copernicus Climate Change Service (C3S), 2019), we emphasize that the increased resolution of our data products already provides a major technical advance, even though substantial finer within-pixel variation is still lost through spatiotemporal aggregation.

\section{5 | CONCLUSIONS}

The spatial (biome-specific) and temporal (seasonally variable) offsets between air and soil temperature quantified here likely bias predictions of current and future climate impacts on species and ecosystems (Bergstrom et al., 2021; Cooper, 2014; Graae et al., 2018; Kearney et al., 2009; Körner \& Paulsen, 2004; Opedal et al., 2015; Zellweger et al., 2020). Temperature in the topsoil rather than in the air ultimately defines the distribution and performance of most terrestrial species, as well as many ecosystem functions at or below the soil surface (Gottschall et al., 2019; Hursh et al., 2017; Pleim \& Gilliam, 2009; Portillo-Estrada et al., 2016). As many ecosystem functions are highly correlated with temperature (yet often non-lineary, Johnston et al., 2021), soil temperature rather than air temperature should in those instances be the preferred predictor for estimating their rates and temperature thresholds (Coûteaux et al., 1995; Rosenberg et al., 1990; Schimel et al., 1996). Correcting for the non-linear relationship between air and soil temperature identified here is, thus, vital for all fields investigating abiotic and biotic processes relating to terrestrial environments (White et al., 2020). Indeed, soil temperature, macroclimate and land-use change will interact to define the future climate as experienced by organisms, and high-resolution soil temperature data are needed to tackle current and future challenges.

By making our global soil temperature maps and the underlying monthly offset data openly available, we offer gridded soil temperature data for climate research, ecology, agronomy and other life and environmental sciences. Future research has the important task of further improving the spatial and temporal resolution of global microclimate products as microclimate operates at much higher temporal resolutions, with temporal variation over hours, days, seasons and years (Bütikofer et al., 2020; Potter et al., 2013), as well as to confirm accuracy of predictions in undersampled regions in the underlying maps (Lembrechts et al., 2021). However, we are convinced that the maps presented here bring us one step closer to having accessible climate data exactly where it matters most for many terrestrial organisms (Ashcroft et al., 2014; Kearney \& Porter, 2009; Lembrechts \& Lenoir, 2019; Niittynen \& Luoto, 2018; Pincebourde et al., 2016). We, nevertheless, highlight that there is still a long way to go towards global soil microclimate data with an optimal spatiotemporal resolution. We, therefore, urge all scientists to submit their microclimate time series to the SoilTemp database to fill data gaps and help to increase the spatial resolution until it matches with the scale at which ecological processes take place (Bütikofer et al., 2020; Lembrechts et al., 2020).

\section{ACKNOWLEDGEMENTS}

$J \mathrm{JL}$ received funding from the Research Foundation Flanders (grant nr. 12P1819N). The project received funding from the Research Foundation Flanders (grants nrs, G018919N, W001919N). JVDH and TWC received funding from DOB Ecology. JA received funding from the University of Helsinki, Faculty of Science (MICROCLIM, grant nr. 7510145) and Academy of Finland Flagship (grant no. 337552). PDF, CM and PV received funding from the European Research Council (ERC) under the European Union's Horizon 2020 research and innovation programme (ERC Starting Grant FORMICA 757833). JK received funding from the Arctic Interactions at the University of Oulu and Academy of Finland (318930, Profi 4), Maaja vesitekniikan tuki ry., Tiina and Antti Herlin Foundation, Nordenskiöld Samfundet and Societas pro Fauna et Flora Fennica. MK received funding from the Czech Science Foundation (grant nr. 20-28119S) and the Czech Academy of Sciences (grant nr. RVO 67985939). TWC received funding from National Geographic Society grant no. 9480-14 and WW-240R-17. MA received funding from CISSC (program ICRP (grant nr:2397) and INSF (grant nr: 96005914). The Royal Botanic Garden Edinburgh is supported by the Scottish Government's Rural and Environment Science and Analytical Services Division. JMA received funding from the Funding Org. Qatar Petroleum (grant nr. QUEX-CAS-QP-RD-18/19). JMA received funding from the European Union's Horizon 2020 research and innovation program (grant no. 678841) and from the Swiss National Science Foundation (grant no. 31003A_176044). JA was supported by research grants LTAUSA19137 (program INTER-EXCELLENCE, subprogram INTER-ACTION) provided by Czech Ministry of Education, Youth and Sports and 20-05840Y of the Czech Science Foundation. AA was supported by the Ministry of Science and Higher Education of the Russian Federation (grant FSRZ-2020-0014). SN, UAT, JJA, and $\mathrm{JVO}$ received funding from the Independent Research Fund Denmark (7027-00133B). LvdB, KT, MYB and RC acknowledge funding from the German Research Foundation within the Priority Program SPP-1803 'EarthShape: Earth Surface Shaping by Biota' (grant TI 338/14-1\&2 and BA 3843/6-1). PB was supported by grant project VEGA of the Ministry of Education of the Slovak Republic and the Slovak Academy of Sciences No. 2/0132/18. Forest Research received funding from the Forestry Commission (climate change research programme). JCB acknowledges the support of Universidad Javeriana. JLBA received funding from the Dirección General de Cambio Climático del Gobierno de Aragón; JLBA acknowledges fieldwork assistance by Ana Acín, the Ordesa y Monte Perdido National Park, and the Servicio de Medio Ambiente de Soria de la Junta de Castilla y León. RGB and MPB received funding from BECC - Biodiversity and Ecosystem services in a Changing Climate. MPB received funding from The European Union's Horizon 2020 research and innovation program under the Marie Skłodowska-Curie Grant Agreement No. 657627 and The Swedish Research Council FORMAS - future research leaders No. 2016-01187. JB received funding from the Czech Academy of Sciences (grant nr. RVO 67985939). NB received 
funding from the SNF (grant numbers 40FA40_154245, 20FI21_148992, 20FI20_173691, 407340_172433) and from the EU (contract no. 774124). ICOS EU research infrastructure. EU FP7 NitroEurope. EU FP7 ECLAIRE. The authors from Biological Dynamics of Forest Fragments Project, PDBFF, Instituto Nacional de Pesquisas da Amazônia, Brazil were supported by the MCTI/ CNPq/FNDCT - Ação Transversal n68/2013 - Programa de Grande Escala da Biosfera-Atmosfera na Amazônia - LBA; Project 'Como as florestas da Amazônia Central respondem às variações climáticas? Efeitos sobre dinâmica florestal e sinergia com a fragmentação florestal'. This is the study 829 of the BDFFP Technical Series. to The EUCFLUX Cooperative Research Program and Forest Science and Research Institute-IPEF. NC acknowledges funding by Stelvio National Park. JC was funded by the Spanish government grant CGL2016-78093-R. ANID-FONDECYT 1181745 AND INSTITUTO ANTARTICO CHILENO (INACH FR0418). SC received funding from the German Research Foundation (grant no. DFG- FZT 118, 202548816). The National Science Foundation, Poland (grant no. UMO-2017/27/B/ST10/02228), within the framework of the 'Carbon dioxide uptake potential of sphagnum peatlands in the context of atmospheric optical parameters and climate changes' (KUSCO2) project. SLC received funding from the South African National Research Foundation and the Australian Research Council. FM, MČ, KU and MU received funding from Slovak Research and Development Agency (no. APVV19-0319). Instituto Antartico Chileno (INACH_RT-48_16), Iniciativa Científica Milenio Núcleo Milenio de Salmónidos Invasores INVASAL, Institute of Ecology and Biodiversity (IEB), CONICYT PIA APOYO CCTE AFB170008. PC is supported by NERC core funding to the BAS 'Biodiversity, Evolution and Adaptation Team. EJC received funding from the Norwegian Research Council (grant number 230970). GND was supported by NERC E3 doctoral training partnership grant (NE/L002558/1) at the University of Edinburgh and the Carnegie Trust for the Universities of Scotland. Monitoring stations on Livingston Island, Antarctica, were funded by different research projects of the Gobern of Spain (PERMAPLANET CTM2009-10165-E; ANTARPERMA CTM2011-15565-E; PERMASNOW CTM201452021-R), and the PERMATHERMAL arrangement between the University of Alcalá and the Spanish Polar Committee. GN received funding from the Autonomous Province of Bolzano (ITA). The infrastructure, part of the UK Environmental Change Network, was funded historically in part by ScotNature and NERC National Capability LTS-S: UK-SCAPE; NE/R016429/1). JD was supported by the Czech Science Foundation (GA17-19376S) and MSMT (LTAUSA18007). ED received funding from the Kempe Foundation (JCK-1112 and JCK-1822). The infrastructure was supported by the Ministry of Education, Youth and Sports of the Czech Republic within the National Sustainability Programme I (NPU I), grant number LO1415 and by the project for national infrastructure support CzeCOS/ICOS Reg. No. LM2015061. NE received funding from the German Research Foundation (DFG- FZT 118, 202548816). $B E$ received funding from the GLORIA-EU project no
EVK2-CT2000-00056, the Autonomous Province of Bolzano (ITA), from the Tiroler Wissenschaftsfonds and from the University of Innsbruck. RME was supported by funding to the SAFE Project from the Sime Darby Foundation. OF received funding from the German Research Foundation (DFG- FZT 118, 202548816). EFP was supported by the Jardín Botánico Atlántico (SV-20-GIJONJBA). MF was funded by the German Federal Ministry of Education and Research (BMBF) in the context of The Future Okavango (Grant No. 01LL0912) and SASSCAL (01LG1201M; 01LG1201N) projects. EFL received funding from ANID PIA / BASAL FB210006. RAG received funding from Fondecyt 11170516, CONICYT PIA AFB170008 and ANID PIA / BASAL FB210006. MBG received funding from National Parks (DYNBIO, \#1656/2015) and The Spanish Research Agency (VULBIMON, \#CGL2017-90040-R). MG received funding from the Swiss National Science Foundation (ICOS-CH Phase 2 20FI20_173691). FG received funding from the German Research Foundation (DFG- FZT 118, 202548816). KG and TS received funding from the UK Biotechnology and Biological Research Council (grant $=206 /$ D16053). SG was supported by the Research Foundation Flanders (FWO) (project GOH1517N). KJ and $\mathrm{PH}$ received funding from the EU Horizon2020 INFRAIA project eLTER-PLUS (871128), the project LTER-CWN (FFG, F\&E Infrastrukturförderung, project number 858024) and the Austrian Climate Research Program (ACRP7 - CentForCSink KR14AC7K11960). SH and ARB received funding through iDiv funded by the German Research Foundation (DFG- FZT 118, 202548816). LH received funding from the Czech Science Foundation (grant nr. 20-28119S) and the Czech Academy of Sciences (grant nr. RVO 67985939). MH received funding from the Baden-Württemberg Ministry of Science, Research and Arts via the project DRleR (Drought impacts, processes and resilience: making the in-visible visible). LH received funding from International Polar Year, Weston Foundation, and ArcticNet. DH received funding from Natural Sciences and Engineering Council (Canada) (RGPIN-06691). TTH received funding from Independent Research Fund Denmark (grant no. 8021-00423B) and Villum Foundation (grant no. 17523). Ministry of Education, Youth and Sports of the Czech Republic (projects LM2015078, VAN2020/01 and CZ.02.1.01/0.0/0.0/16_013/0001708). KH, CG and CJD received funding from Bolin Centre for Climate Research, Stockholm University and from the Swedish research council Formas [grant n:o 2014-00530 to $\mathrm{KH}$ ]. JJ received funding from the Funding Org. Swedish Forest Society Foundation (grant nr. 2018-485-Steg 2 2017) and Swedish Research Council FORMAS (grant nr. 201800792). AJ received funding from the German Federal Ministry of Education and Research BMBF (Grant Nr. FKZ 031B0516C SUSALPS) and the Oberfrankenstiftung (Grant Nr. OFS FP00237). ISJ received funding from the Energy Research Fund (NÝR-11 2019, NÝR-18 - 2020). TJ was supported by a UK NERC Independent Research Fellowship (grant number: NE/S01537X/1). RJ received funding from National Science Centre of Poland (grant number: 2016/21/B/ST10/02271) and Polish National Centre for Research and Development (grant number: Pol-Nor/203258/31/2013). VK 
received funding from the Czech Academy of Sciences (grant nr. RVO 67985939). AAK received funding from MoEFCC, Govt of India (AICOPTAX project F. No. 22018/12/2015/RE/Tax). NK received funding from FORMAS (grants nr. 2018-01781, 2018 02700, 2019-00836), VR, support from the research infrastructure ICOS-SE. BK received funding from the National Research, Development and Innovation Fund of Hungary (grant nr. K128441). Ministry of Education, Youth and Sports of the Czech Republic (projects LM2015078 and CZ.02.1.01/0.0/0.0/16_013/0001708). Project B1-RNM-163-UGR-18-Programa Operativo FEDER 2018, partially funded data collection. Norwegian Research Council (NORKLIMA grants \#184912 and \#244525) awarded to Vigdis Vandvik. MM received funding from the Czech Science Foundation (grant nr. 20-28119S) and the Czech Academy of Sciences (grant nr. RVO 67985939). Project CONICYT-PAI 79170119 and ANIDMPG 190029 awarded to Roy Mackenzie. This work was partly funded by project MIUR PON Cluster OT4CLIMA. RM received funding from the SNF project number 407340_172433. FM received funding from the Stelvio National Park. PM received funding from AIAS-COFUND fellowship programme supported by the Marie Skłodowska- Curie actions under the European Union's Seventh Framework Pro-gramme for Research, Technological development and Demonstration (grant agreement no 609033) and the Aarhus University Research Foundation, Denmark. RM received funding from the Ministry of Education, Youth and Sports of the Czech Republic (project LTT17033). SM and VM received funding from EU FP6 NitroEurope (grant nr. 17841), EU FP7 ÉCLAIRE (grant nr. 282910), the Ministry of Education and Science of Ukraine (projects nr. 505, 550, 574, 602), GEF-UNEP funded "Toward INMS" project (grant nr. NEC05348) and ENI CBC BSB PONTOS (grant nr. BSB 889). The authors from Biological Dynamics of Forest Fragments Project, PDBFF, Instituto Nacional de Pesquisas da Amazônia, Brazil were supported by the MCTI/ CNPq/FNDCT - Ação Transversal n68/2013 - Programa de Grande Escala da Biosfera-Atmosfera na Amazônia - LBA; Project 'Como as florestas da Amazônia Central respondem às variações climáticas? Efeitos sobre dinâmica florestal e sinergia com a fragmentação florestal'. FJRM was financially supported by the Netherlands Organization for Scientific Research (VICI grant 016. $\mathrm{VICl}$.170.072) and Research Foundation Flanders (FWO-SBO grant S000619N). STM received funding from New Frontiers in Research Fund-Exploration (grant nr. NFRF-2018-02043) and NSERC Discovery. MMR received funding from the Australian Research Council Discovery Early Career Research Award (grant nr. DE180100570). JAM received funding from the National Science Foundation (DEB 1557094), International Center for Advanced Renewable Energy and Sustainability (I-CARES) at Washington University in St. Louis, ForestGEO, and Tyson Research Center. IM-S was funded by the UK Natural Environment Research Council through the ShrubTundra Project (NE) M016323/1). MBN received funding from FORMAS, VR, Kempe Foundations support from the research infrastructures ICOS and SITES. MDN received funding from CONICET (grant nr. PIP
112-201501-00609). Spanish Ministry of Science grant PID2019110521GB-100 and Catalan government grant 2017-1005. French National Research Agency (ANR) in the frame of the Cluster of Excellence COTE (project HydroBeech, ANR-10-LABX-45). VLIROUS, under the Institutional University Coorperation programme (IUC) with Mountains of the Moon University. Project LAS III 77/2017/B entitled: \"Estimation of net carbon dioxide fluxes exchanged between the forest ecosystem on post-agricultural land and between the tornado-damaged forest area and the atmosphere using spectroscopic and numerical methods \", source of funding: General Directorate of State Forests, Warsaw, Poland. Max Planck Society (Germany), RFBR, Krasnoyarsk Territory and Krasnoyarsk Regional Fund of Science, project number 20-45242908. Estonian Research Council (PRG609), and the European Regional Development Fund (Centre of Excellence EcolChange). Canada-Denmark Arctic Research Station Early Career Scientist Exchange Program, from Polar knowledge Canada (POLAR) and the Danish Agency for Science and Higher Education. AP received funding from Fondecyt 1180205, CONICYT PIA AFB170008 and ANID PIA / BASAL FB210006. MP received funding from the Funding Org. Knut and Alice Wallenberg Foundation (grant nr. 2015.0047), and acknowledges funding from the Swedish Research Council (VR) with contributing research institutes to both the SITES and ICOS Sweden infrastructures. JP and RO were funded by the Spanish Ministry of Science grant PID2019110521GB-100, the fundación Ramón Areces grant ELEMENTALCLIMATE, and the Catalan government grant 2017-1005. MPB received funding from the Svalbard Environmental Protection Fund (grant project number 15/128) and the Research Council of Norway (Arctic Field Grant, project number 269957). RP received funding from the Ministry of Education, Youth and Sports of the Czech Republic (grant INTER-TRANSFER nr. LTT20017). LTSER Zone Atelier Alpes; Fédération FREE-Alpes. RP received funding from a Humboldt Fellowship for Experienced Researchers. Prokushkin AS and Zyryanov VI contribution has been supported by the RFBR grant \#18-05-60203-Arktika. RPu received founding from the Polish National Science Centre (grant project number 2017/27/B/NZ8/00316). ODYSSEE project (ANR-13-ISV7-0004, PN-II-ID-JRP-RO-FR-2012). KR was supported through an Australian Government Research Training Program Scholarship. Fieldwork was supported by the Global Challenges program at the University of Wollongong, the ARC the Australian Antarctic Division and INACH. DR was funded by the project SUBANTECO IPEV 136 (French Polar Institute Paul-Emile Victor), Zone Atelier CNRS Antarctique et Terres Australes, SAD Région Bretagne (Project INFLICT), BiodivERsa 2019-2020 BioDivClim call 'ASICS' (ANR-20-EBI5-0004). SAR received funding from the Australian Research Council. NSF grant \#1556772 to the University of Notre Dame. Pavia University (Italy). OR received funding from EULEAP-Agri (RAMSES II), EU-DESIRA (CASSECS), EU-H2020 (SustainSahel), AGROPOLIS and TOTAL Foundations (DSCATT), CGIAR (GLDC). AR was supported by the Russian Science Foundation (Grant 18-74-10048). Parc national des Ecrins. JS 
received funding from Vetenskapsrådet grant nr (No: 201404270), ALTER-net multi-site grant, River LIFE project (LIFE08 NAT/S/000266), Flexpeil. Helmholtz Association long-term research program TERENO (Terrestrial Environmental Observatories). PS received funding from the Polish Ministry of Science and Higher Education (grant nr. N N305 304840). AS acknowledges funding by ETH Zürich project FEVER ETH-27 19-1. LSC received funding from NSERC Canada Graduate Scholarship (Doctoral) Program; LSC was also supported by ArcticNet-NCE (insert grant \#). Conselho Nacional de Desenvolvimento Científico e Tecnológico (141513/2017-9); Fundação Carlos Chagas Filho de Amparo à Pesquisa do Estado do Rio de Janeiro (E26/200.84/2019). ZS received funding from the SRDA (grants nos. APVV-16-0325 and APVV-20-0365) and from the ERDF (grant no. ITMS 313011S735, CE LignoSilva). JS, MB and CA received funding from core budget of ETH Zurich. State excellence Program $M-V$ $\backslash$ "WETSCAPES \". AfricanBioServices project funded by the EU Horizon 2020 grant number 641918. The authors from KIT/IMKIFU acknowledge the funding received within the German Terrestrial Environmental Observatories (TERENO) research program of the Helmholtz Association and from the Bavarian Ministry of the Environment and Public Health (UGV06080204000). Deutsche Forschungsgemeinschaft (DFG, German Research Foundation), project number 192626868, in the framework of the collaborative German-Indonesian research project CRC 990 (SFB): 'EFForTS, Ecological and Socioeconomic Functions of Tropical Lowland Rainforest Transformation Systems (Sumatra, Indonesia)'. MS received funding from the Ministry of Education, Youth and Sports of the Czech Republic (grant nr. INTER-TRANSFER LTT19018). TT received funding from the Swedish National Space Board (SNSB Dnr 95/16) and the CASSECS project supported by the European Union. HJDT received funding from the UK Natural Environment Research Council (NERC doctoral training partnership grant NE/L002558/1). German Science Foundation (DFG) GraKo $2010 \backslash$ \Responsel". PDT received funding from the MEMOIRE project (PN-III-P1-1.1-PD2016-0925). Arctic Challenge for Sustainability II (ArCS II; JPMXD1420318865). JU received funding from Czech Science Foundation (grant nr. 21-11487S). TU received funding from the Romanian Ministry of Education and Research (CCCDI - UEFISCDI -project PN-III-P2-2.1-PED2019-4924 and PN2019-2022/19270201-Ctr. 25N BIODIVERS 3-BIOSERV). AV acknowledge funding from RSF, project 21-1400209. GFV received funding from the Dutch Research Council NWO (Veni grant, no. 863.14.013). Australian Research Council Discovery Early Career Research Award DE140101611. FGAV received funding from the Portuguese Science Foundation (FCT) under CEECIND/02509/2018, CESAM (UIDP/50017/2020+U IDB/50017/2020), FCT/MCTES through national funds, and the co-funding by the FEDER, within the PT2020 Partnership Agreement and Compete 2020. Ordesa y Monte Perdido National Park. MVI received funding from the Spanish Ministry of Science and Innovation through a doctoral grant (FPU17/05869). JW received funding from the Czech Science Foundation (grant nr.
20-28119S) and the Czech Academy of Sciences (grant nr. RVO 67985939). CR and SW received funding from the Swiss Federal Office for the Environment (FOEN) and the de Giacomi foundation. $Y Y$ received funding from the National Natural Science Foundation of China (Grant no. 41861134039 and 41941015). ZY received funding from the National Natural Science Foundation of China (grant nr. 41877458). FZ received funding from the Swiss National Science Foundation (grant nr. 172198 and 193645). PZ received funding from the Funding Org. Knut and Alice Wallenberg Foundation (grant no. 2015.0047). JL received funding from (i) the Agence Nationale de la Recherche (ANR), under the framework of the young investigators (JCJC) funding instrument (ANR JCJC Grant project NANR-19-CE32-0005-01: IMPRINT) (ii) the Centre National de la Recherche Scientifique (CNRS) (Défi INFINITI 2018: MORFO); and the Structure Fédérative de Recherche (SFR) Condorcet (FR CNRS 3417: CREUSE).

Fieldwork in the Arctic got facilitated by funding from the EU INTERACT program. SN, UAT, JJA and JVO would like to thank the field team of the Vegetation Dynamics group for their efforts and hard work. We acknowledge Dominique Tristan for letting access to the field. For the logistic support the crew of INACH and Gabriel de Castilla Station team on Deception Island. We thank the Inuvialuit and Kluane First Nations for the opportunity to work on their land. MAdP acknowledges fieldwork assistance and logistics support to Unidad de Tecnología Marina CSIC, and the crew of Juan Carlos I and Gabriel de Castilla Spanish Antarctic Stations, as well as to the different colleagues from UAH that helped on the instrument maintenance. ERF acknowledges fieldwork assistance by Martin Heggli. MBG acknowledges fieldwork and technical assistance by P Abadía, C Benedé, P Bravo, J Gómez, M Grasa, R Jimenez, H Miranda, B Ponz, J Revilla and P Tejero and the Ordesa and Monte Perdido National Park staff. LH acknowledges field assistance by John Jacobs, Andrew Trant, Robert Way, Darroch Whitaker; we acknowledge the Inuit of Nunatsiavut, and the Co-management Board of Torngat Mountains National Park for their support of this project and acknowledge that the field research was conducted on their traditional lands. We thank our many bear guides, especially Boonie, Eli, Herman, John and Maria Merkuratsuk. AAK acknowledges field support of Akhtar Malik, Rameez Ahmad. Part of microclimatic records from Saxony was funded by the Saxon Switzerland National Park Administration. Tyson Research Center. JP acknowledges field support of Emmanuel Malet (Edytem) and Rangers of Reserves Naturelles de Haute-Savoie (ASTERS). Practical help: Roel H. Janssen, N. Huig, E. Bakker, Schools in the tepåseförsöket, Forskar fredag, Erik Herberg. The support by the Bavarian Forest National Park administration is highly appreciated. LvdB acknowledges CONAF and onsite support from the park rangers from PN Pan de Azucar, PN La Campana, PN Nahuelbuta and from communidad agricola Quebrada de Talca. JL and FS acknowledge Manuel Nicolas and all forest officers from the Office National des Forêts (ONF) who are in charge of the RENECOFOR network and who provided help and local support for the installation and maintenance of temperature loggers in the field. 


\section{CONFLICT OF INTEREST}

The authors declare no conflict of interest.

\section{AUTHOR CONTRIBUTIONS}

Jonas J. Lembrechts, Johan van den Hoogen and Jonathan Lenoir conceptualized the project; Jonas J. Lembrechts, Johan van den Hoogen, Juha Aalto, Michael B. Ashcroft, Pieter De Frenne, Martin Kopecký, Miska Luoto, Ilya M. D. Maclean, Tom W. Crowther, Ivan Nijs and Jonathan Lenoir designed the paper; the SoilTemp consortium acquired the data; Jonas J. Lembrechts, Johan van den Hoogen, Julia Kemppinen, Pekka Niittynen and Jonathan Lenoir analyzed the data; Jonas J. Lembrechts, Johan van den Hoogen, Juha Aalto, Michael B. Ashcroft, Pieter De Frenne, Julia Kemppinen, Martin Kopecký, Miska Luoto, Ilya M. D. Maclean, Tom W. Crowther, Joseph J. Bailey, Stef Haesen, David H. Klinges, Pekka Niittynen, Brett R. Scheffers, Koenraad Van Meerbeek, Ivan Nijs and Jonathan Lenoir interpreted the analyses. All authors significantly revised the manuscript and approved it for submission.

\section{CODE AVAILABILITY}

All source codes are available at https://doi.org/10.5281/zenodo. 4558663.

\section{DATA AVAILABILITY STATEMENT}

All gridded maps are available at https://zenodo.org/record/ 4558732\#.Ydv0Hf7MJPY. Soil bioclimatic layers SBIO1-11 are also available on Google Earth Engine under projects/crowtherlab/soil_ bioclim/SBIO_v1_0_5cm and projects/crowtherlab/soil_bioclim/ SBIO_v1_5_15cm. Monthly soil temperature maps are available under projects/crowtherlab/soil_bioclim/soil_temp_monthly_0_5_cm and projects/crowtherlab/soil_bioclim/soil_temp_monthly_5_15_cm. All monthly data to train the models and reproduce the figures, sampled covariate data and models are available at https://doi.org/10.5281/ zenodo.4558663.

\section{ORCID}

Jonas J. Lembrechts (ID https://orcid.org/0000-0002-1933-0750 Johan van den Hoogen (D) https://orcid.org/0000-0001-6624-8461 Juha Aalto (D) https://orcid.org/0000-0001-6819-4911 Pieter De Frenne (D) https://orcid.org/0000-0002-8613-0943 Julia Kemppinen (D) https://orcid.org/0000-0001-7521-7229 Martin Kopecký (D) https://orcid.org/0000-0002-1018-9316 Miska Luoto (D) https://orcid.org/0000-0001-6203-5143 Ilya M. D. Maclean (D) https://orcid.org/0000-0001-8030-9136 Thomas W. Crowther (D) https://orcid.org/0000-0001-5674-8913 Joseph J. Bailey (D) https://orcid.org/0000-0002-9526-7095 Stef Haesen (D) https://orcid.org/0000-0002-4491-4213 David H. Klinges (D) https://orcid.org/0000-0002-7900-9379 Pekka Niittynen (D) https://orcid.org/0000-0002-7290-029X Brett R. Scheffers (D) https://orcid.org/0000-0003-2423-3821 Koenraad Van Meerbeek (D) https://orcid.org/0000-0002-9260-3815 Peter Aartsma (D) https://orcid.org/0000-0001-5086-856X Otar Abdalaze (D) https://orcid.org/0000-0001-8140-0900
Mehdi Abedi (D) https://orcid.org/0000-0002-1499-0119 Rien Aerts (D) https://orcid.org/0000-0001-6694-0669 Negar Ahmadian (D) https://orcid.org/0000-0002-7427-7198 Antje Ahrends (D) https://orcid.org/0000-0002-5083-7760 Juha M. Alatalo (D) https://orcid.org/0000-0001-5084-850X Jake M. Alexander (D) https://orcid.org/0000-0003-2226-7913 Camille Nina Allonsius (D) https://orcid.org/0000-0003-2599-9941 Jan Altman (D) https://orcid.org/0000-0003-4879-5773 Christof Ammann (D) https://orcid.org/0000-0002-0783-5444 Christian Andres (D) https://orcid.org/0000-0003-0576-6446 Christopher Andrews (D) https://orcid.org/0000-0003-2428-272X Jonas Ardö (D) https://orcid.org/0000-0002-9318-0973 Nicola Arriga (D) https://orcid.org/0000-0001-5321-3497 Alberto Arzac (D) https://orcid.org/0000-0002-3361-5349 Valeria Aschero (D) https://orcid.org/0000-0003-3865-4133 Rafael L. Assis (D) https://orcid.org/0000-0001-8468-6414 Jakob Johann Assmann (D) https://orcid.org/0000-0002-3492-8419 Maaike Y. Bader (D) https://orcid.org/0000-0003-4300-7598 Khadijeh Bahalkeh (D) https://orcid.org/0000-0003-1485-0316 Peter Barančok (D) https://orcid.org/0000-0003-1171-2524 Isabel C. Barrio (D) https://orcid.org/0000-0002-8120-5248 Agustina Barros (D) https://orcid.org/0000-0002-6810-2391 Edmund W. Basham (D) https://orcid.org/0000-0002-0167-7908 Marijn Bauters (D) https://orcid.org/0000-0003-0978-6639 Manuele Bazzichetto (D) https://orcid.org/0000-0002-9874-5064 Luca Belelli Marchesini (D) https://orcid.org/0000-0001-8408-4675 Michael C. Bell (D) https://orcid.org/0000-0002-3401-7746 Juan C. Benavides (D) https://orcid.org/0000-0002-9694-2195 José Luis Benito Alonso (D) https://orcid.org/0000-0003-1086-8834 Bernd J. Berauer (D) https://orcid.org/0000-0002-9472-1532 Jarle W. Bjerke (D) https://orcid.org/0000-0003-2721-1492 Robert G. Björk (D) https://orcid.org/0000-0001-7346-666X Mats P. Björkman (D) https://orcid.org/0000-0001-5768-1976 Katrin Björnsdóttir (D) https://orcid.org/0000-0001-7421-9441 Benjamin Blonder (D) https://orcid.org/0000-0002-5061-2385 Pascal Boeckx (D) https://orcid.org/0000-0003-3998-0010 Julia Boike (1D) https://orcid.org/0000-0002-5875-2112 Stef Bokhorst (D) https://orcid.org/0000-0003-0184-1162 Bárbara N. S. Brum (D) https://orcid.org/0000-0002-8421-3200 Josef Brůna (D) https://orcid.org/0000-0002-4839-4593 Nina Buchmann (D) https://orcid.org/0000-0003-0826-2980 José Luís Camargo (D) https://orcid.org/0000-0003-0370-9878 Otávio C. Campoe (D) https://orcid.org/0000-0001-9810-8834 Onur Candan (D) https://orcid.org/0000-0002-9254-4122 Rafaella Canessa (D) https://orcid.org/0000-0002-6979-9880 Nicoletta Cannone (D) https://orcid.org/0000-0002-3390-3965 Michele Carbognani D https://orcid.org/0000-0001-7701-9859 Jofre Carnicer (D) https://orcid.org/0000-0001-7454-8296 Angélica Casanova-Katny (D) https://orcid.org/0000-0003-3860-1445 Simone Cesarz (D) https://orcid.org/0000-0003-2334-5119 Bogdan Chojnicki (D) https://orcid.org/0000-0002-9012-4060 Philippe Choler (D) https://orcid.org/0000-0002-9062-2721 Steven L. Chown (D) https://orcid.org/0000-0001-6069-5105 
Edgar F. Cifuentes (D) https://orcid.org/0000-0001-5918-5861 Marek Čiliak (D) https://orcid.org/0000-0002-6720-9365 Tamara Contador (D) https://orcid.org/0000-0002-0250-9877 Peter Convey (D) https://orcid.org/0000-0001-8497-9903 Elisabeth J. Cooper (D) https://orcid.org/0000-0002-0634-1282 Edoardo Cremonese (D) https://orcid.org/0000-0002-6708-8532 Salvatore R. Curasi (D) https://orcid.org/0000-0002-4534-3344 Maurizio Cutini (D) https://orcid.org/0000-0002-8597-8221 C. Johan Dahlberg (D) https://orcid.org/0000-0003-0271-3306 Gergana N. Daskalova (D) https://orcid.org/0000-0002-5674-5322 Miguel Angel de Pablo (D) https://orcid.org/0000-0002-4496-2741 Stefano Della Chiesa (D) https://orcid.org/0000-0002-6693-2199 Jürgen Dengler (DD https://orcid.org/0000-0003-3221-660X Patrice Descombes (D) https://orcid.org/0000-0002-3760-9907 Valter Di Cecco (D) https://orcid.org/0000-0001-9862-1267 Michele Di Musciano (D) https://orcid.org/0000-0002-3130-7270 Jan Dick (D) https://orcid.org/0000-0002-4180-9338 Jiri Dolezal (D) https://orcid.org/0000-0002-5829-4051 Ellen Dorrepaal (D) https://orcid.org/0000-0002-0523-2471 Jiří Dušek (D) https://orcid.org/0000-0001-6119-0838 Nico Eisenhauer (D) https://orcid.org/0000-0002-0371-6720 Lars Eklundh (D) https://orcid.org/0000-0001-7644-6517 Todd E. Erickson (D) https://orcid.org/0000-0003-4537-0251 Brigitta Erschbamer (D) https://orcid.org/0000-0002-6792-1395 Werner Eugster (D) https://orcid.org/0000-0001-6067-0741 Dan A. Exton (D) https://orcid.org/0000-0001-8885-5828 Nicolas Fanin (D) https://orcid.org/0000-0003-4195-855X Fatih Fazlioglu (D) https://orcid.org/0000-0002-4723-3640 Iris Feigenwinter (D) https://orcid.org/0000-0001-7493-6790 Giuseppe Fenu (D) https://orcid.org/0000-0003-4762-5043 Olga Ferlian (D) https://orcid.org/0000-0002-2536-7592 Eduardo Fernández-Pascual (D) https://orcid.org/0000-0002-4743-9577 Manfred Finckh (D) https://orcid.org/0000-0003-2186-0854 Rebecca Finger Higgens (D) https://orcid.org/0000-0002-7645-504X T'ai G. W. Forte (D) https://orcid.org/0000-0002-8685-5872 Erika C. Freeman (D) https://orcid.org/0000-0001-7161-6038 Esther R. Frei (D) https://orcid.org/0000-0003-1910-7900 Eduardo Fuentes-Lillo (D) https://orcid.org/0000-0001-5657-954X Rafael A. García (D) https://orcid.org/0000-0002-0591-0391 María B. García (D) https://orcid.org/0000-0003-4231-6006 Charly Géron (D) https://orcid.org/0000-0001-7912-4708 Mana Gharun (D) https://orcid.org/0000-0003-0337-7367 Dany Ghosn (D) https://orcid.org/0000-0003-1898-9681 Khatuna Gigauri (D) https://orcid.org/0000-0002-6707-0818 Anne Gobin (1) https://orcid.org/0000-0002-3742-7062 Ignacio Goded (D) https://orcid.org/0000-0002-1912-325X Mathias Goeckede (D) https://orcid.org/0000-0003-2833-8401 Felix Gottschall (D) https://orcid.org/0000-0002-1247-8728 Keith Goulding (D) https://orcid.org/0000-0002-6465-1465 Sanne Govaert (D) https://orcid.org/0000-0002-8939-1305 Bente Jessen Graae (D) https://orcid.org/0000-0002-5568-4759 Sarah Greenwood (iD https://orcid.org/0000-0001-9104-7936 Caroline Greiser (D) https://orcid.org/0000-0003-4023-4402
Achim Grelle (D) https://orcid.org/0000-0003-3468-9419 Benoit Guénard (D) https://orcid.org/0000-0002-7144-1175 Joannès Guillemot (iD) https://orcid.org/0000-0003-4385-7656 Peter Haase (D) https://orcid.org/0000-0002-9340-0438 Sylvia Haider (D) https://orcid.org/0000-0002-2966-0534 Aud H. Halbritter (D) https://orcid.org/0000-0003-2597-6328 Maroof Hamid (D) https://orcid.org/0000-0003-3406-5008 Albin Hammerle (D) https://orcid.org/0000-0003-1963-5906 Arndt Hampe (D) https://orcid.org/0000-0003-2551-9784 Siri V. Haugum (D) https://orcid.org/0000-0003-4958-7132 Lucia Hederová (DD) https://orcid.org/0000-0003-1283-0952 Bernard Heinesch (D) https://orcid.org/0000-0001-7594-6341 Carole Helfter (D) https://orcid.org/0000-0001-5773-4652 Daniel Hepenstrick (D) https://orcid.org/0000-0003-1090-6888 Maximiliane Herberich (D) https://orcid.org/0000-0003-0716-1520 Luise Hermanutz (D) https://orcid.org/0000-0003-0706-7067 David S. Hik (D) https://orcid.org/0000-0002-8994-9305 Raúl Hoffrén (D) https://orcid.org/0000-0002-9123-304X Jürgen Homeier (D) https://orcid.org/0000-0001-5676-3267 Lukas Hörtnagl (D) https://orcid.org/0000-0002-5569-0761 Toke T. Høye (D) https://orcid.org/0000-0001-5387-3284 Filip Hrbacek (D) https://orcid.org/0000-0001-5032-9216 Kristoffer Hylander (D) https://orcid.org/0000-0002-1215-2648 Hiroki Iwata (D) https://orcid.org/0000-0002-8962-8982 Marcin Antoni Jackowicz-Korczynski (D) https://orcid. org/0000-0002-6574-5703

Hervé Jactel (D) https://orcid.org/0000-0002-8106-5310 Järvi Järveoja (D) https://orcid.org/0000-0001-6317-660X Szymon Jastrzębowski (iD https://orcid.org/0000-0003-1239-4847 Anke Jentsch (D) https://orcid.org/0000-0002-2345-8300 Juan J. Jiménez (D) https://orcid.org/0000-0003-2398-0796 Ingibjörg S. Jónsdóttir (D) https://orcid.org/0000-0003-3804-7077 Tommaso Jucker (D) https://orcid.org/0000-0002-0751-6312 Alistair S. Jump (D) https://orcid.org/0000-0002-2167-6451 Radoslaw Juszczak (D) https://orcid.org/0000-0002-5212-7383 Róbert Kanka (D) https://orcid.org/0000-0002-7071-7280 Vit Kašpar (D) https://orcid.org/0000-0002-0879-0137 Julia Kelly (D) https://orcid.org/0000-0002-7370-1401 Anzar A. Khuroo (D) https://orcid.org/0000-0002-0251-2793 Leif Klemedtsson (D) https://orcid.org/0000-0002-1122-0717 Marcin Klisz (D) https://orcid.org/0000-0001-9486-6988 Natascha Kljun (D) https://orcid.org/0000-0001-9650-2184 Alexander Knohl (D) https://orcid.org/0000-0002-7615-8870 Johannes Kobler (D) https://orcid.org/0000-0003-0052-4245 Jozef Kollár (D) https://orcid.org/0000-0002-0069-4220 Martyna M. Kotowska (D) https://orcid.org/0000-0002-2283-5979 Bence Kovács (D) https://orcid.org/0000-0002-8045-8489 Juergen Kreyling (D) https://orcid.org/0000-0001-8489-7289 Andrea Lamprecht (D) https://orcid.org/0000-0002-8719-026X Simone I. Lang (D) https://orcid.org/0000-0002-6812-2528 Christian Larson (D) https://orcid.org/0000-0002-7567-4953 Keith Larson (D) https://orcid.org/0000-0001-7089-524X Kamil Laska (D) https://orcid.org/0000-0002-5199-9737 
Guerric le Maire (D) https://orcid.org/0000-0002-5227-958X Rachel I. Leihy (D) https://orcid.org/0000-0001-9672-625X Luc Lens (D) https://orcid.org/0000-0002-0241-2215 Bengt Liljebladh (D) https://orcid.org/0000-0002-2998-5865 Annalea Lohila (D) https://orcid.org/0000-0003-3541-672X Juan Lorite (D) https://orcid.org/0000-0003-4617-8069 Benjamin Loubet (D) https://orcid.org/0000-0001-8825-8775 Joshua Lynn (D) https://orcid.org/0000-0002-7190-7991 Martin Macek (D) https://orcid.org/0000-0002-5609-5921 Roy Mackenzie (D) https://orcid.org/0000-0001-6620-1532 Enzo Magliulo (D) https://orcid.org/0000-0001-5505-6552 Regine Maier (D) https://orcid.org/0000-0003-3158-4136 Francesco Malfasi (D) https://orcid.org/0000-0002-2660-8327 František Máliš (D) https://orcid.org/0000-0003-2760-6988 Matěj Man (1D) https://orcid.org/0000-0002-4557-8768 Giovanni Manca (D) https://orcid.org/0000-0002-9376-0310 Antonio Manco (D) https://orcid.org/0000-0002-3677-4134 Paraskevi Manolaki (D) https://orcid.org/0000-0003-3958-0199 Radim Matula (D) https://orcid.org/0000-0002-7460-0100 Sergiy Medinets (D) https://orcid.org/0000-0001-5980-1054 Volodymyr Medinets (D) https://orcid.org/0000-0001-7543-7504 Camille Meeussen (iD https://orcid.org/0000-0002-5869-4936 Sonia Merinero (D) https://orcid.org/0000-0002-1405-6254 Rita de Cássia Guimarães Mesquita (D) https://orcid. org/0000-0003-1746-3215

Katrin Meusburger (D) https://orcid.org/0000-0003-4623-6249 Filip J. R. Meysman (D) https://orcid.org/0000-0001-5334-7655 Sean T. Michaletz (D) https://orcid.org/0000-0003-2158-6525 Ann Milbau (D) https://orcid.org/0000-0003-3555-8883 Pavel Moiseev (D) https://orcid.org/0000-0003-4808-295X Andrea Mondoni (D) https://orcid.org/0000-0002-4605-6304 Leonardo Montagnani (iD https://orcid.org/0000-0003-2957-9071 Mikel Moriana-Armendariz (D) https://orcid.org/0000-0001-8251-1338 Umberto Morra di Cella (D) https://orcid.org/0000-0003-4250-9705 Martin Mörsdorf (D) https://orcid.org/0000-0002-3903-2021 Jonathan R. Mosedale (D) https://orcid.org/0000-0001-9008-5439 Lena Muffler (D) https://orcid.org/0000-0001-8227-7297 Miriam Muñoz-Rojas (D) https://orcid.org/0000-0002-9746-5191 Jonathan A. Myers (D) https://orcid.org/0000-0002-2058-8468 Isla H. Myers-Smith (D) https://orcid.org/0000-0002-8417-6112 Marianna Nardino (D) https://orcid.org/0000-0001-9466-8340 Ilona Naujokaitis-Lewis (D) https://orcid.org/0000-0001-9504-4484 Lena Nicklas (D) https://orcid.org/0000-0002-9337-4153 Georg Niedrist (D) https://orcid.org/0000-0002-7511-6273 Mats B. Nilsson (D) https://orcid.org/0000-0003-3765-6399 Signe Normand (D) https://orcid.org/0000-0002-8782-4154 Marcelo D. Nosetto (D) https://orcid.org/0000-0002-9428-490X Yann Nouvellon (D) https://orcid.org/0000-0003-1920-3847 Martin A. Nuñez (D) https://orcid.org/0000-0003-0324-5479 Romà Ogaya (D) https://orcid.org/0000-0003-4927-8479 Jérôme Ogée (D) https://orcid.org/0000-0002-3365-8584 Joseph Okello (D) https://orcid.org/0000-0003-4462-3923 Janusz Olejnik (D) https://orcid.org/0000-0001-5305-1045
Jørgen Eivind Olesen (D) https://orcid.org/0000-0002-6639-1273 Øystein H. Opedal (D) https://orcid.org/0000-0002-7841-6933 Simone Orsenigo (D) https://orcid.org/0000-0003-0348-9115 Andrej Palaj (iD https://orcid.org/0000-0001-7054-4183 Timo Pampuch (D) https://orcid.org/0000-0002-6290-9661 Meelis Pärtel (D) https://orcid.org/0000-0002-5874-0138 Ada Pastor (D) https://orcid.org/0000-0002-7114-770X Aníbal Pauchard (D) https://orcid.org/0000-0003-1284-3163 Harald Pauli (D) https://orcid.org/0000-0002-9842-9934 Marian Pavelka (D) https://orcid.org/0000-0002-7339-3410 William D. Pearse (D) https://orcid.org/0000-0002-6241-3164 Matthias Peichl (D) https://orcid.org/0000-0002-9940-5846 Rachel M. Penczykowski (D) https://orcid.org/0000-0003-4559-0609 Josep Penuelas (D) https://orcid.org/0000-0002-7215-0150 Matteo Petit Bon (D) https://orcid.org/0000-0001-9829-8324 Alessandro Petraglia (D) https://orcid.org/0000-0003-4632-2251 Shyam S. Phartyal (D) https://orcid.org/0000-0003-3266-6619 Gareth K. Phoenix (D) https://orcid.org/0000-0002-0911-8107 Casimiro Pio (D) https://orcid.org/0000-0002-3531-8620 Andrea Pitacco (D) https://orcid.org/0000-0002-7260-6242 Camille Pitteloud (D) https://orcid.org/0000-0002-4731-0079 Roman Plichta (D) https://orcid.org/0000-0003-2442-8522 Francesco Porro (D) https://orcid.org/0000-0001-9855-2468 Miguel Portillo-Estrada (D) https://orcid.org/0000-0002-0348-7446 Jérôme Poulenard (D) https://orcid.org/0000-0003-0810-0308 Rafael Poyatos (D) https://orcid.org/0000-0003-0521-2523 Anatoly S. Prokushkin (D) https://orcid.org/0000-0001-8721-2142 Radoslaw Puchalka (D) https://orcid.org/0000-0002-4764-0705 Mihai Pușcaș (D) https://orcid.org/0000-0002-2632-640X Dajana Radujković (D) https://orcid.org/0000-0003-4981-5879 Krystal Randall (D) https://orcid.org/0000-0003-2507-1000 Amanda Ratier Backes (iD https://orcid.org/0000-0002-7229-578X David Renault (D) https://orcid.org/0000-0003-3644-1759 Anita C. Risch (D) https://orcid.org/0000-0003-0531-8336 Christian Rixen (D) https://orcid.org/0000-0002-2486-9988 Sharon A. Robinson (D) https://orcid.org/0000-0002-7130-9617 Bjorn J. M. Robroek (D) https://orcid.org/0000-0002-6714-0652 Adrian V. Rocha (D) https://orcid.org/0000-0002-4618-2407 Graziano Rossi (D) https://orcid.org/0000-0002-5102-5019 Olivier Roupsard (ID) https://orcid.org/0000-0002-1319-142X Alexey V. Rubtsov (D) https://orcid.org/0000-0002-9663-4344 Patrick Saccone (D) https://orcid.org/0000-0001-8820-593X Jhonatan Sallo Bravo (D) https://orcid.org/0000-0001-9007-4959 Cinthya C. Santos (D) https://orcid.org/0000-0001-7042-5993 Judith M. Sarneel (D) https://orcid.org/0000-0001-6187-499X Tobias Scharnweber (ID) https://orcid.org/0000-0002-4933-5296 Marius Schmidt (D) https://orcid.org/0000-0001-5292-7092 Thomas Scholten (D) https://orcid.org/0000-0002-4875-2602 Max Schuchardt (D) https://orcid.org/0000-0003-3103-8063 Tony Scott (D) https://orcid.org/0000-0002-6631-0672 Julia Seeber (D) https://orcid.org/0000-0003-0189-7377 Tim Seipel (D) https://orcid.org/0000-0001-6472-2975 Philipp Semenchuk (D) https://orcid.org/0000-0002-1949-6427 
Rebecca A. Senior (D) https://orcid.org/0000-0002-8208-736X Josep M. Serra-Diaz (D) https://orcid.org/0000-0003-1988-1154 Piotr Sewerniak (D) https://orcid.org/0000-0002-3071-3963 Ankit Shekhar (D) https://orcid.org/0000-0003-0802-2821 Laura Siegwart Collier (D) https://orcid.org/0000-0003-0985-9615 Elizabeth Simpson (D) https://orcid.org/0000-0002-6107-0286 David P. Siqueira (D) https://orcid.org/0000-0002-0756-0153 Zuzana Sitková (D) https://orcid.org/0000-0001-6354-6105 Johan Six (D) https://orcid.org/0000-0001-9336-4185 Marko Smiljanic (D) https://orcid.org/0000-0002-2324-0723 Stuart W. Smith (D) https://orcid.org/0000-0001-9396-6610 Ben Somers (D) https://orcid.org/0000-0002-7875-107X José João L. L. Souza (D) https://orcid.org/0000-0003-4670-6626 Bartolomeu Israel Souza (D) https://orcid.org/0000-0003-2173-8314 Arildo Souza Dias (D) https://orcid.org/0000-0002-5495-3435 Marko J. Spasojevic (D) https://orcid.org/0000-0003-1808-0048 James D. M. Speed (D) https://orcid.org/0000-0002-0633-5595 Fabien Spicher (D) https://orcid.org/0000-0002-9999-955X Angela Stanisci (D) https://orcid.org/0000-0002-5302-0932 Klaus Steinbauer (D) https://orcid.org/0000-0002-3730-9920 Rainer Steinbrecher (D) https://orcid.org/0000-0002-5931-4210 Michael Steinwandter (D) https://orcid.org/0000-0001-8545-6047 Michael Stemkovski (D) https://orcid.org/0000-0002-9854-887X Jörg G. Stephan (D) https://orcid.org/0000-0001-6195-7867 Christian Stiegler (D) https://orcid.org/0000-0002-0130-2401 Stefan Stoll (D) https://orcid.org/0000-0002-3656-417X Martin Svátek (1D) https://orcid.org/0000-0003-2328-4627 Miroslav Svoboda (D) https://orcid.org/0000-0003-4050-3422 Torbern Tagesson (D) https://orcid.org/0000-0003-3011-1775 Andrew J. Tanentzap (D) https://orcid.org/0000-0002-2883-1901 Franziska Tanneberger (D) https://orcid.org/0000-0002-4184-9671 Jean-Paul Theurillat (D) https://orcid.org/0000-0002-1843-5809 Haydn J. D. Thomas (D) https://orcid.org/0000-0001-9099-6304 Andrew D. Thomas (D) https://orcid.org/0000-0002-1360-1687 Marcello Tomaselli (D) https://orcid.org/0000-0003-4208-3433 Urs Albert Treier (D) https://orcid.org/0000-0003-4027-739X Mario Trouillier (D) https://orcid.org/0000-0001-9151-7686 Pavel Dan Turtureanu (D) https://orcid.org/0000-0002-7422-3106 Vilna A. Tyystjärvi (D) https://orcid.org/0000-0002-1175-5463 Masahito Ueyama (D) https://orcid.org/0000-0002-4000-4888 Karol Ujházy (D) https://orcid.org/0000-0002-0228-1737 Mariana Ujházyová (D) https://orcid.org/0000-0002-5546-1547 Domas Uogintas (D) https://orcid.org/0000-0002-3937-1218 Josef Urban (D) https://orcid.org/0000-0003-1730-947X Marek Urbaniak (D) https://orcid.org/0000-0002-1225-9170 Tudor-Mihai Ursu (D) https://orcid.org/0000-0002-4898-6345 Francesco Primo Vaccari (D) https://orcid.org/0000-0002-5253-2135 Stijn Van de Vondel (D) https://orcid.org/0000-0002-0223-7330 Liesbeth van den Brink (D) https://orcid.org/0000-0003-0313-8147 Maarten Van Geel (D) https://orcid.org/0000-0001-8688-6225 Vigdis Vandvik (D) https://orcid.org/0000-0003-4651-4798 Pieter Vangansbeke (D) https://orcid.org/0000-0002-6356-2858 Andrej Varlagin (D) https://orcid.org/0000-0002-2549-5236
G. F. Veen (D) https://orcid.org/0000-0001-7736-9998 Elmar Veenendaal (D) https://orcid.org/0000-0001-8230-2501 Susanna E. Venn (D) https://orcid.org/0000-0002-7433-0120 Hans Verbeeck (D) https://orcid.org/0000-0003-1490-0168 Erik Verbrugggen (D) https://orcid.org/0000-0001-7015-1515 Frank G. A. Verheijen (D) https://orcid.org/0000-0001-6741-4249 Luca Vitale (D) https://orcid.org/0000-0002-7637-264X Pascal Vittoz (D) https://orcid.org/0000-0003-4218-4517 Maria Vives-Ingla (D) https://orcid.org/0000-0003-4887-8392 Jonathan von Oppen (D) https://orcid.org/0000-0001-6346-2964 Josefine Walz (D) https://orcid.org/0000-0002-0715-8738 Runxi Wang (D) https://orcid.org/0000-0003-4902-169X Yifeng Wang (D) https://orcid.org/0000-0003-2660-7874 Robert G. Way (D) https://orcid.org/0000-0003-4763-7685 Ronja E. M. Wedegärtner (D) https://orcid.org/0000-0003-4633-755X Robert Weigel (D) https://orcid.org/0000-0001-9685-6783 Jan Wild (D) https://orcid.org/0000-0003-3007-4070 Matthew Wilkinson (D) https://orcid.org/0000-0002-3858-553X Martin Wilmking (iD https://orcid.org/0000-0003-4964-2402 Lisa Wingate (D) https://orcid.org/0000-0003-1921-1556 Manuela Winkler (D) https://orcid.org/0000-0002-8655-9555 Sonja Wipf (iD https://orcid.org/0000-0002-3492-1399 Georg Wohlfahrt (D) https://orcid.org/0000-0003-3080-6702 Georgios Xenakis (D) https://orcid.org/0000-0002-2950-4101 Yan Yang (D) https://orcid.org/0000-0003-0858-7603 Zicheng Yu (D) https://orcid.org/0000-0003-2358-2712 Kailiang Yu (D) https://orcid.org/0000-0003-4223-5169 Florian Zellweger (1D) https://orcid.org/0000-0003-1265-9147 Jian Zhang (D) https://orcid.org/0000-0003-0589-6267 Peng Zhao (D) https://orcid.org/0000-0003-3289-5067 Klaudia Ziemblińska (D) https://orcid.org/0000-0003-4070-6553 Reiner Zimmermann (iD https://orcid.org/0000-0002-8724-941X Shengwei Zong (D) https://orcid.org/0000-0002-3583-6110 Viacheslav I. Zyryanov (D) https://orcid.org/0000-0002-1748-4801 Ivan Nijs (iD https://orcid.org/0000-0003-3111-680X Jonathan Lenoir (D) https://orcid.org/0000-0003-0638-9582

\section{REFERENCES}

Abatzoglou, J. T., Dobrowski, S. Z., Parks, S. A., \& Hegewisch, K. C. (2018). TerraClimate, a high-resolution global dataset of monthly climate and climatic water balance from 1958-2015. Scientific Data, 5, 170191. https://doi.org/10.1038/sdata.2017.191

Amatulli, G., Domisch, S., Tuanmu, M.-N., Parmentier, B., Ranipeta, A., Malczyk, J., \& Jetz, W. (2018). A suite of global, cross-scale topographic variables for environmental and biodiversity modeling. Scientific Data, 5, 180040. https://doi.org/10.1038/sdata.2018.40

Antão, L. H., Bates, A. E., Blowes, S. A., Waldock, C., Supp, S. R., Magurran, A. E., Dornelas, M., \& Schipper, A. M. (2020). Temperature-related biodiversity change across temperate marine and terrestrial systems. Nature Ecology and Evolution, 4, 927-933. https://doi. org/10.1038/s41559-020-1185-7

Ashcroft, M. B., Cavanagh, M., Eldridge, M. D. B., \& Gollan, J. R. (2014). Testing the ability of topoclimatic grids of extreme temperatures to explain the distribution of the endangered brush-tailed rock-wallaby (Petrogale penicillata). Journal of Biogeography, 41, 1402-1413. 
Ashcroft, M. B., Chisholm, L. A., \& French, K. O. (2008). The effect of exposure on landscape scale soil surface temperatures and species distribution models. Landscape Ecology, 23, 211-225. https://doi. org/10.1007/s10980-007-9181-8

Ashcroft, M. B., \& Gollan, J. R. (2012). Fine-resolution (25 m) topoclimatic grids of near-surface $(5 \mathrm{~cm})$ extreme temperatures and humidities across various habitats in a large $(200 \times 300 \mathrm{~km})$ and diverse region. International Journal of Climatology, 32, 2134-2148.

Barnes, R., Sahr, K., Evenden, G., Johnson, A. \& Warmerdam, F. (2017). dggridR: discrete global grids for R. R package version 0.1.12.

Bergstrom, D. M., Wienecke, B. C., Hoff, J., Hughes, L., Lindenmayer, D. B., Ainsworth, T. D., Baker, C. M., Bland, L., Bowman, D. M. J. S., Brooks, S. T., Canadell, J. G., Constable, A. J., Dafforn, K. A., Depledge, M. H., Dickson, C. R., Duke, N. C., Helmstedt, K. J., Holz, A., Johnson, C. R., ... Shaw, J. D. (2021). Combating ecosystem collapse from the tropics to the Antarctic. Global Change Biology, 27, 1692-1703. https://doi.org/10.1111/gcb.15539

Berner, L. T., Massey, R., Jantz, P., Forbes, B. C., Macias-Fauria, M., MyersSmith, I., Kumpula, T., Gauthier, G., Andreu-Hayles, L., Gaglioti, B. V., Burns, P., Zetterberg, P., D'Arrigo, R., \& Goetz, S. J. (2020). Summer warming explains widespread but not uniform greening in the Arctic tundra biome. Nature Communications, 11, 1-12. https:// doi.org/10.1038/s41467-020-18479-5

Bond-Lamberty, B., \& Thomson, A. (2018). A Global Database of Soil Respiration Data, Version 4.0. ORNL DAAC.

Booth, T. H., Nix, H. A., Busby, J. R., \& Hutchinson, M. F. (2014). BIOCLIM: the first species distribution modelling package, its early applications and relevance to most current MAXENT studies. Diversity and Distributions, 20, 1-9.

Bramer, I., Anderson, B., Bennie, J., Bladon, A., De Frenne, P., Hemming, D., Hill, R. A., Kearney, M. R., Körner, C., Korstjens, A. H., Lenoir, J., Maclean, I. M. D., Marsh, C. D., Morecroft, M. D., Ohlemüller, R., Slater, H. D., Suggitt, A. J., Zellweger, F., \& Gillingham, P. K. (2018). Advances in monitoring and modelling climate at ecologically relevant scales. Advances in Ecological Research, 58, 101-161.

Breiman, L. (2001). Random forests. Machine Learning, 45, 5-32.

Bruelheide, H., Dengler, J., Purschke, O., Lenoir, J., Jiménez-Alfaro, B., Hennekens, S. M., Botta-Dukát, Z., Chytrý, M., Field, R., Jansen, F., Kattge, J., Pillar, V. D., Schrodt, F., Mahecha, M. D., Peet, R. K., Sandel, B., van Bodegom, P., Altman, J., Alvarez-Dávila, E., ... Jandt U. (2018). Global trait-environment relationships of plant communities. Nature Ecology and Evolution, 2, 1906. https://doi.org/10.1038/ s41559-018-0699-8

Bütikofer, L., Anderson, K., Bebber, D. P., Bennie, J. J., Early, R. I., \& Maclean, I. M. (2020). The problem of scale in predicting biological responses to climate. Global Change Biology, 26, 6657-6666. https://doi.org/10.1111/gcb.15358

Chen, L., Aalto, J., \& Luoto, M. (2021). Significant shallow-depth soil warming over Russia during the past 40 years. Global and Planetary Change, 197, 103394.

Cooper, E. J. (2014). Warmer shorter winters disrupt Arctic terrestrial ecosystems. Annual Review of Ecology, Evolution, and Systematics, 45, 271295. https://doi.org/10.1146/annurev-ecolsys-120213-091620

Copernicus Climate Change Service (C3s). (2019). C3S ERA5-Land reanalysis. (ed Copernicus Climate Change Service).

Coûteaux, M.-M., Bottner, P., \& Berg, B. (1995). Litter decomposition, climate and litter quality. Trends in Ecology and Evolution, 10 63-66.

Crowther, T. W., Todd-Brown, K. E. O., Rowe, C. W., Wieder, W. R., Carey, J. C., Machmuller, M. B., Snoek, B. L., Fang, S., Zhou, G., Allison, S D., Blair, J. M., Bridgham, S. D., Burton, A. J., Carrillo, Y., Reich, P. B. Clark, J. S., Classen, A. T., Dijkstra, F. A., Elberling, B., ... Bradford, M. A. (2016). Quantifying global soil carbon losses in response to warming. Nature, 540, 104-108. https://doi.org/10.1038/natur e20150
Daly, C. (2006). Guidelines for assessing the suitability of spatial climate data sets. International Journal of Climatology, 26, 707-721. https:// doi.org/10.1002/joc.1322

Davis, E., Trant, A., Hermanutz, L., Way, R. G., Lewkowicz, A. G., Collier, L. S., Cuerrier, A., \& Whitaker, D. (2020). Plant-environment interactions in the low arctic torngat mountains of labrador. Ecosystems, 1-21.

De Frenne, P., Lenoir, J., Luoto, M., Scheffers, B. R., Zellweger, F., Aalto, J., Ashcroft, M., Christiansen, D., Decocq, G., De Pauw, K., Govaert, S., Greiser, C., Gril, E., Hampe, A., Jucker, T., Klinges, D., Koelemeijer, I., Lembrechts, J., Marrec, R., ... Hylander, K. (2021). Forest microclimates and climate change: Importance, drivers and future research agenda. Global Change Biology, 27(11), 2279-2297. https://doi. org/10.1111/gcb.15569

De Frenne, P., Rodriguez-Sanchez, F., Coomes, D. A., Baeten, L., Verstraeten, G., Vellend, M., Bernhardt-Romermann, M., Brown, C. D., Brunet, J., Cornelis, J., Decocq, G. M., Dierschke, H., Eriksson, O., Gilliam, F. S., Hedl, R., Heinken, T., Hermy, M., Hommel, P., Jenkins, M. A., ... Verheyen, K. (2013). Microclimate moderates plant responses to macroclimate warming. Proceedings of the National Academy of Sciences of the United States of America, 110, 18561-18565. https://doi.org/10.1073/pnas.1311190110

De Frenne, P., Zellweger, F., Rodríguez-Sánchez, F., Scheffers, B. R., Hylander, K., Luoto, M., Vellend, M., Verheyen, K., \& Lenoir, J. (2019). Global buffering of temperatures under forest canopies. Nature Ecology and Evolution, 3, 744-749. https://doi.org/10.1038/ s41559-019-0842-1

Dinerstein, E., Olson, D., Joshi, A., Vynne, C., Burgess, N. D., Wikramanayake, E., Hahn, N., Palminteri, S., Hedao, P., Noss, R., Hansen, M., Locke, H., Ellis, E. C., Jones, B., Barber, C. V., Hayes, R., Kormos, C., Martin, V., Crist, E., ... Saleem, M. (2017). An ecoregionbased approach to protecting half the terrestrial realm. BioScience, 67, 534-545. https://doi.org/10.1093/biosci/bix014

Du, E., Terrer, C., Pellegrini, A. F., Ahlström, A., Van Lissa, C. J., Zhao, X., Xia, N., Wu, X., \& Jackson, R. B. (2020). Global patterns of terrestrial nitrogen and phosphorus limitation. Nature Geoscience, 13, 221-226. https://doi.org/10.1038/s41561-019-0530-4

Fick, S. E., \& Hijmans, R. J. (2017). WorldClim 2: New 1-km spatial resolution climate surfaces for global land areas. International Journal of Climatology, 37, 4302-4315. https://doi.org/10.1002/joc.5086

Geiger, R. (1950). The climate near the ground. Harvard University Press.

Gistemp Team. (2021). GISS surface temperature analysis (GISTEMP), version 4. NASA Goddard Institute for Space Studies.

Gorelick, N., Hancher, M., Dixon, M., Ilyushchenko, S., Thau, D., \& Moore, R. (2017). Google earth engine: Planetary-scale geospatial analysis for everyone. Remote Sensing of Environment, 202, 18-27. https:// doi.org/10.1016/j.rse.2017.06.031

Gottschall, F., Davids, S., Newiger-Dous, T. E., Auge, H., Cesarz, S., \& Eisenhauer, N. (2019). Tree species identity determines wood decomposition via microclimatic effects. Ecology and Evolution, 9, 12113-12127. https://doi.org/10.1002/ece3.5665

Graae, B. J., Vandvik, V., Armbruster, W. S., Eiserhardt, W. L., Svenning, J.-C., Hylander, K., Ehrlén, J., Speed, J. D., Klanderud, K., Bråthen, K. A., Milbau, A., Opedal, O. H., Alsos, I. G., Ejrnaes, R., Bruun, H. H., Birks, H. J. B., Westergaard, K. B., Birks, H. H., \& Lenoir, J. (2018). Stay or go-how topographic complexity influences alpine plant population and community responses to climate change. Perspectives in Plant Ecology, Evolution and Systematics, 30, 41-50. https://doi.org/10.1016/j.ppees.2017.09.008

Greiser, C., Meineri, E., Luoto, M., Ehrlén, J., \& Hylander, K. (2018). Monthly microclimate models in a managed boreal forest landscape. Agricultural and Forest Meteorology, 250, 147-158. https:// doi.org/10.1016/j.agrformet.2017.12.252

Grünberg, I., Wilcox, E. J., Zwieback, S., Marsh, P., \& Boike, J. (2020). Linking tundra vegetation, snow, soil temperature, and permafrost. Biogeosciences, 17, 4261-4279. https://doi.org/10.5194/ bg-17-4261-2020 
Grundstein, A., Todhunter, P., \& Mote, T. (2005). Snowpack control over the thermal offset of air and soil temperatures in eastern North Dakota. Geophysical Research Letters, 32. https://doi. org/10.1029/2005GL022532

Hall, D. K., Riggs, G. A., Salomonson, V. V., Digirolamo, N. E., \& Bayr, K. J. (2002). MODIS snow-cover products. Remote Sensing of Environment, 83, 181-194. https://doi.org/10.1016/S0034-4257(02)00095-0

Hengl, T., Mendes de Jesus, J., Heuvelink, G. B. M., Ruiperez Gonzalez, M., Kilibarda, M., Blagotić, A., Shangguan, W., Wright, M. N., Geng, X., Bauer-Marschallinger, B., Guevara, M. A., Vargas, R., MacMillan, R. A., Batjes, N. H., Leenaars, J. G. B., Ribeiro, E., Wheeler, I., Mantel, S., \& Kempen, B. (2017). SoilGrids250m: Global gridded soil information based on machine learning. PLoS One, 12, e0169748. https://doi.org/10.1371/journal.pone.0169748

Hengl, T., Nussbaum, M., Wright, M. N., Heuvelink, G. B., \& Gräler, B. (2018). Random forest as a generic framework for predictive modeling of spatial and spatio-temporal variables. PeerJ, 6, e5518. https://doi.org/10.7717/peerj.5518

Hennon, P. E., D'amore, D. V., Witter, D. T., \& Lamb, M. B. (2010) Influence of forest canopy and snow on microclimate in a declining yellow-cedar forest of Southeast Alaska. Northwest Science, 84, 7387. https://doi.org/10.3955/046.084.0108

Holden, Z. A., Klene, A. E., Keefe, R. F., \& Moisen, G. G. (2013). Design and evaluation of an inexpensive radiation shield for monitoring surface air temperatures. Agricultural and Forest Meteorology, 180, 281-286. https://doi.org/10.1016/j.agrformet.2013.06.011

Hursh, A., Ballantyne, A., Cooper, L., Maneta, M., Kimball, J., \& Watts, J. (2017). The sensitivity of soil respiration to soil temperature, moisture, and carbon supply at the global scale. Global Change Biology, 23, 2090-2103. https://doi.org/10.1111/gcb.13489

Jian, J., Steele, M. K., Zhang, L., Bailey, V. L., Zheng, J., Patel, K. F., \& Bond-Lamberty, B. P. (2021). On the use of air temperature and precipitation as surrogate predictors in soil respiration modelling. European Journal of Soil Science. https://doi.org/10.1111/ejss.13149

Johnston, A. S. A., Meade, A., Ardö, J., Arriga, N., Black, A., Blanken, P. D., Bonal, D., Brümmer, C., Cescatti, A., Dušek, J., Graf, A., Gioli, B., Goded, I., Gough, C. M., Ikawa, H., Jassal, R., Kobayashi, H., Magliulo, V., Manca, G., ... Venditti, C. (2021). Temperature thresholds of ecosystem respiration at a global scale. Nature Ecology and Evolution, 5, 487-494. https://doi.org/10.1038/s41559-021-01398-z

Karger, D. N., Conrad, O., Böhner, J., Kawohl, T., Kreft, H., Soria-Auza, R. W., Zimmermann, N. E., Linder, H. P., \& Kessler, M. (2017a). Climatologies at high resolution for the earth's land surface areas. Scientific Data, 4, 170122. https://doi.org/10.1038/sdata.2017.122

Karger, D. N., Conrad, O., Böhner, J., Kawohl, T., Kreft, H., Soria-Auza, R. W., Zimmermann, N. E., Linder, H. P. \& Kessler, M. (2017b). Data from: Climatologies at high resolution for the earth's land surface areas. https://doi.org/10.5061/dryad.kd1d4

Kattge, J., Bönisch, G., Díaz, S., Lavorel, S., Prentice, I. C., Leadley, P., Tautenhahn, S., Werner, G. D. A., Aakala, T., Abedi, M., Acosta, A. T. R., Adamidis, G. C., Adamson, K., Aiba, M., Albert, C. H., Alcántara, J. M., Alcázar C, C., Aleixo, I., Ali, H., ... Wirth, C. (2019). TRY plant trait database-enhanced coverage and open access. Global Change Biology, 26, 119-188. https://doi.org/10.1111/gcb.14904

Kearney, M. R., Gillingham, P. K., Bramer, I., Duffy, J. P., \& Maclean, I. M. (2019). A method for computing hourly, historical, terrain-corrected microclimate anywhere on Earth. Methods in Ecology and Evolution, 11, 38-43. https://doi.org/10.1111/2041-210X.13330

Kearney, M., \& Porter, W. (2009). Mechanistic niche modelling: Combining physiological and spatial data to predict species' ranges. Ecology Letters, 12, 334-350. https://doi.org/10.1111/j.1461-0248.2008.01277.x

Kearney, M., Shine, R., \& Porter, W. P. (2009). The potential for behavioral thermoregulation to buffer "cold-blooded" animals against climate warming. Proceedings of the National Academy of Sciences of the
United States of America, 106, 3835-3840. https://doi.org/10.1073/ pnas.0808913106

Kissling, W. D., Walls, R., Bowser, A., Jones, M. O., Kattge, J., Agosti, D. Amengual, J., Basset, A., van Bodegom, P. M., Cornelissen, J. H. C., Denny, E. G., Deudero, S., Egloff, W., Elmendorf, S. C., Alonso García, E., Jones, K. D., Jones, O. R., Lavorel, S., Lear, D., ... Guralnick, R. P. (2018). Towards global data products of essential biodiversity variables on species traits. Nature Ecology and Evolution, 2, 15311540. https://doi.org/10.1038/s41559-018-0667-3

Körner, C., \& Hiltbrunner, E. (2018). The 90 ways to describe plant temperature. Perspectives in Plant Ecology, Evolution and Systematics, 30, 16-21. https://doi.org/10.1016/j.ppees.2017.04.004

Körner, C., \& Paulsen, J. (2004). A world-wide study of high altitude treeline temperatures. Journal of Biogeography, 31, 713-732. https://doi.org/10.1111/j.1365-2699.2003.01043.x

Lembrechts, J., Aalto, J., Ashcroft, M., De Frenne, P., Kopecký, M., Lenoir, J., Luoto, M., Maclean, I. M., ... Nijs, I. (2020). SoilTemp: Call for data for a global database of near-surface temperature. Global Change Biology, 26, 6616-6629.

Lembrechts, J. J., \& Lenoir, J. (2020). Microclimatic conditions anywhere at any time! Global Change Biology, 26(2), 337-339. https://doi. org/10.1111/gcb.14942

Lembrechts, J. J., Lenoir, J., Roth, N., Hattab, T., Milbau, A., Haider, S., Pellissier, L., Pauchard, A., Ratier Backes, A., Dimarco, R. D., Nuñez, M. A., Aalto, J., \& Nijs, I. (2019). Comparing temperature data sources for use in species distribution models: From in-situ logging to remote sensing. Global Ecology and Biogeography, 28, 1578-1596. https://doi.org/10.1111/geb.12974

Lembrechts, J., Lenoir, J., Scheffers, B. R., \& De Frenne, P. (2021). Designing countrywide and regional microclimate networks. Global Ecology and Biogeography, 30(6), 1168-1174.

Lembrechts, J. J., \& Nijs, I. (2020). Microclimate shifts in a dynamic world. Science, 368, 711-712. https://doi.org/10.1126/science.abc1245

Lenoir, J., Bertrand, R., Comte, L., Bourgeaud, L., Hattab, T., Murienne, J., \& Grenouillet, G. (2020). Species better track climate warming in the oceans than on land. Nature Ecology and Evolution, 4, 10441059. https://doi.org/10.1038/s41559-020-1198-2

Luojus, K., Pulliainen, J., Takala, M., Derksen, C., Rott, H., Nagler, T., Solberg, R., Wiesmann, A., Metsamaki, S., \& Malnes, E. (2010). Investigating the feasibility of the GlobSnow snow water equivalent data for climate research purposes. In: 2010 IEEE international geoscience and remote sensing symposium. IEEE.

Maclean, I. M., Duffy, J. P., Haesen, S., Govaert, S., De Frenne, P., Vanneste, T., Lenoir, J., Lembrechts, J. J., Rhodes, M. W., \& Van Meerbeek, K. (2021). On the measurement of microclimate. Methods in Ecology and Evolution, 12(8), 1397-1410. https://doi. org/10.1111/2041-210X.13627

Maclean, I. M., \& Klinges, D. H. (2021). Microclimc: A mechanistic model of above, below and within-canopy microclimate. Ecological Modelling, 451, 109567. https://doi.org/10.1016/j.ecolmodel.2021.109567

Maclean, I. M., Mosedale, J. R., \& Bennie, J. J. (2019). Microclima: An r package for modelling meso-and microclimate. Methods in Ecology and Evolution, 10, 280-290.

Myers-Smith, I. H., Kerby, J. T., Phoenix, G. K., Bjerke, J. W., Epstein, H. E., Assmann, J. J., John, C., Andreu-Hayles, L., Angers-Blondin, S., Beck, P. S. A., Berner, L. T., Bhatt, U. S., Bjorkman, A. D., Blok, D., Bryn, A., Christiansen, C. T., Cornelissen, J. H. C., Cunliffe, A. M., Elmendorf, S. C., ... Wipf, S. (2020). Complexity revealed in the greening of the Arctic. Nature Climate Change, 10, 106-117. https:// doi.org/10.1038/s41558-019-0688-1

Niittynen, P., Heikkinen, R. K., Aalto, J., Guisan, A., Kemppinen, J., \& Luoto, M. (2020). Fine-scale tundra vegetation patterns are strongly related to winter thermal conditions. Nature Climate Change, 10, 1143-1148. https://doi.org/10.1038/s41558-020-00916-4 
Niittynen, P., \& Luoto, M. (2018). The importance of snow in species distribution models of arctic vegetation. Ecography, 41, 1024-1037. https://doi.org/10.1111/ecog.03348

Obu, J., Westermann, S., Bartsch, A., Berdnikov, N., Christiansen, H. H., Dashtseren, A., Delaloye, R., Elberling, B., Etzelmüller, B., \& Kholodov, A. (2019). Northern Hemisphere permafrost map based on TTOP modelling for $2000-2016$ at $1 \mathrm{~km} 2$ scale. Earth-Science Reviews, 193, 299-316.

O'donnell, M. S., \& Ignizio, D. A. (2012). Bioclimatic predictors for supporting ecological applications in the conterminous United States. US Geological Survey Data Series, 691, 4-9.

Olden, J. D., Lawler, J. J., \& Poff, N. L. (2008). Machine learning methods without tears: A primer for ecologists. The Quarterly Review of Biology, 83, 171-193. https://doi.org/10.1086/587826

Opedal, O. H., Armbruster, W. S., \& Graae, B. J. (2015). Linking smallscale topography with microclimate, plant species diversity and intra-specific trait variation in an alpine landscape. Plant Ecology and Diversity, 8, 305-315. https://doi.org/10.1080/17550 874.2014.987330

Overland, J. E., Wang, M., Walsh, J. E., \& Stroeve, J. C. (2014). Future Arctic climate changes: Adaptation and mitigation time scales. Earth's Future, 2, 68-74. https://doi.org/10.1002/2013EF000162

Pastorello, G., Papale, D., Chu, H., Trotta, C., Agarwal, D., Canfora, E., Baldocchi, D., \& Torn, M. (2017). A new data set to keep a sharper eye on land-air exchanges. Eos, Transactions American Geophysical Union (Online), 98.

Perera-Castro, A. V., Waterman, M. J., Turnbull, J. D., Ashcroft, M. B., McKinley, E., Watling, J. R., Bramley-Alves, J., Casanova-Katny, A., Zuniga, G., Flexas, J., \& Robinson, S. A. (2020). It is hot in the sun: Antarctic mosses have high temperature optima for photosynthesis despite cold climate. Frontiers in Plant Science, 11, 1178. https://doi. org/10.3389/fpls.2020.01178

Pincebourde, S., Murdock, C. C., Vickers, M., \& Sears, M. W. (2016). Finescale microclimatic variation can shape the responses of organisms to global change in both natural and urban environments. Integrative and Comparative Biology, 56, 45-61. https://doi.org/10.1093/icb/ icw016

Pleim, J. E., \& Gilliam, R. (2009). An indirect data assimilation scheme for deep soil temperature in the Pleim-Xiu land surface model. Journal of Applied Meteorology and Climatology, 48, 1362-1376. https://doi. org/10.1175/2009JAMC2053.1

Portillo-Estrada, M., Pihlatie, M., Korhonen, J. F. J., Levula, J., Frumau, A. K. F., Ibrom, A., Lembrechts, J. J., Morillas, L., Horvath, L., Jones, S. K., \& Niinemets, U. (2016). Climatic controls on leaf litter decomposition across European forests and grasslands revealed by reciprocal litter transplantation experiments. Biogeosciences, 13, 16211633. https://doi.org/10.5194/bg-13-1621-2016

Potter, K. A., Woods, H. A., \& Pincebourde, S. (2013). Microclimatic challenges in global change biology. Global Change Biology, 19, 29322939. https://doi.org/10.1111/gcb.12257

R Core Team. (2020). R: a language and environment for statistical computing. R Foundation for Statistical Computing.

Richardson, L. F. (1922). Weather prediction by numerical process. Cambridge University Press.

Rosenberg, N. J., Kimball, B., Martin, P., \& Cooper, C. (1990). From climate and $\mathrm{CO}_{2}$ enrichment to evapotranspiration. Climate change and US water resources (pp. 151-175). CABI.

Santoro, M. (2018). GlobBiomass-Global datasets of forest biomass. PANGAEA10, 1594.

Scherrer, D., Schmid, S., \& Körner, C. (2011). Elevational species shifts in a warmer climate are overestimated when based on weather station data. International Journal of Biometeorology, 55, 645-654. https://doi.org/10.1007/s00484-010-0364-7

Schimel, D. S., Braswell, B., Mckeown, R., Ojima, D. S., Parton, W., \& Pulliam, W. (1996). Climate and nitrogen controls on the geography and timescales of terrestrial biogeochemical cycling. Global
Biogeochemical Cycles, 10, 677-692. https://doi.org/10.1029/96GBO 1524

Schimel, J. P., Bilbrough, C., \& Welker, J. M. (2004). Increased snow depth affects microbial activity and nitrogen mineralization in two Arctic tundra communities. Soil Biology and Biochemistry, 36, 217-227. https://doi.org/10.1016/j.soilbio.2003.09.008

Senior, R. A., Hill, J. K., \& Edwards, D. P. (2019). Global loss of climate connectivity in tropical forests. Nature Climate Change, 9, 623-626. https://doi.org/10.1038/s41558-019-0529-2

Smith, M., \& Riseborough, D. (1996). Permafrost monitoring and detection of climate change. Permafrost and Periglacial Processes, 7, 301-309. https://doi.org/10.1002/(SICI)1099-1530(19961 0)7:4<301:AID-PPP231>3.0.CO;2-R

Smith, M., \& Riseborough, D. (2002). Climate and the limits of permafrost: a zonal analysis. Permafrost and Periglacial Processes, 13, 1-15. https://doi.org/10.1002/ppp.410

Soudzilovskaia, N. A., Douma, J. C., Akhmetzhanova, A. A., Van Bodegom, P. M., Cornwell, W. K., Moens, E. J., Treseder, K. K., Tibbett, M., Wang, Y. P., \& Cornelissen, J. H. (2015). Global patterns of plant root colonization intensity by mycorrhizal fungi explained by climate and soil chemistry. Global Ecology and Biogeography, 24, 371382. https://doi.org/10.1111/geb.12272

Speak, A., Montagnani, L., Wellstein, C., \& Zerbe, S. (2020). The influence of tree traits on urban ground surface shade cooling. Landscape and Urban Planning, 197, 103748.

Stefan, V. \& Levin, S. (2018). Plotbiomes: Plot Whittaker biomes with ggplot2. R package version 0.0. 0.9001.

Steidinger, B. S., Crowther, T. W., Liang, J., Van Nuland, M. E., Werner, G. D. A., Reich, P. B., Nabuurs, G. J., de-Miguel, S., Zhou, M., Picard, N., Herault, B., Zhao, X., Zhang, C., Routh, D., \& Peay, K. G. (2019). Climatic controls of decomposition drive the global biogeography of forest-tree symbioses. Nature, 569, 404-408. https://doi. org/10.1038/s41586-019-1128-0

Terando, A. J., Youngsteadt, E., Meineke, E. K., \& Prado, S. G. (2017). Ad hoc instrumentation methods in ecological studies produce highly biased temperature measurements. Ecology and Evolution, 7, 98909904. https://doi.org/10.1002/ece3.3499

van den Hoogen, J., Geisen, S., Routh, D., Ferris, H., Traunspurger, W., Wardle, D. A., de Goede, R. G. M., Adams, B. J., Ahmad, W., Andriuzzi, W. S., Bardgett, R. D., Bonkowski, M., Campos-Herrera, R., Cares, J. E., Caruso, T., de Brito Caixeta, L., Chen, X., Costa, S. R., Creamer, R., ... Crowther, T. W. (2019). Soil nematode abundance and functional group composition at a global scale. Nature, 572, 194-198. https://doi.org/10.1038/s41586-019-1418-6

van den Hoogen, J., Robmann, N., Routh, D., Lauber, T., Van Tiel, N., Danylo, O., \& Crowther, T. W. (2021). A geospatial mapping pipeline for ecologists. bioRxiv. https://doi.org/10.1101/2021.07.07.451145

Wang, K., \& Dickinson, R. E. (2012). A review of global terrestrial evapotranspiration: Observation, modeling, climatology, and climatic variability. Reviews of Geophysics, 50. https://doi.org/10.1029/2011RG000373

Way, R. G., \& Lewkowicz, A. G. (2018). Environmental controls on ground temperature and permafrost in Labrador, northeast Canada. Permafrost and Periglacial Processes, 29, 73-85. https://doi. org/10.1002/ppp.1972

White, H. J., León-Sánchez, L., Burton, V. J., Cameron, E. K., Caruso, T., Cunha, L., Dirilgen, T., Jurburg, S. D., Kelly, R., Kumaresan, D., Ochoa-Hueso, R., Ordonez, A., Phillips, H. R. P., Prieto, I., Schmidt, O., \& Caplat, P. (2020). Methods and approaches to advance soil macroecology. Global Ecology and Biogeography, 29, 1674-1690. https://doi.org/10.1111/geb.13156

Whiteman, C. D. (1982). Breakup of temperature inversions in deep mountain valleys: Part I. Observations. Journal of Applied Meteorology, 21, 270-289. https://doi.org/10.1175/15200450(1982)021<0270:BOTIID>2.0.CO;2

Wild, J., Kopecký, M., Macek, M., Šanda, M., Jankovec, J., \& Haase, T. (2019). Climate at ecologically relevant scales: A new temperature 
and soil moisture logger for long-term microclimate measurement. Agricultural and Forest Meteorology, 268, 40-47. https://doi. org/10.1016/j.agrformet.2018.12.018

Wood, S. (2012). mgcv: Mixed GAM Computation Vehicle with GCV/ AIC/REML smoothness estimation. http://cran.r-project.org/web/ packages/mgcv/index.html

World Meteorological Organization. (2008). Guide to meteorological instruments and methods of observation, Geneva, WMO-No. 8.

Xu, T., \& Hutchinson, M. (2011). ANUCLIMversion 6.1 userguide. The Australian National University, Fenner School of Environment and Society.

Xu, Y., Ramanathan, V., \& Victor, D. G. (2018). Global warming will happen faster than we think. Nature. https://doi.org/10.1038/d4158 6-018-07586-5

Zellweger, F., De Frenne, P., Lenoir, J., Vangansbeke, P., Verheyen, K., Bernhardt-Römermann, M., Baeten, L., Hédl, R., Berki, I., Brunet, J., Van Calster, H., Chudomelová, M., Decocq, G., Dirnböck, T., Durak, T., Heinken, T., Jaroszewicz, B., Kopecký, M., Malis, F., ... Coomes, D. (2020). Forest microclimate dynamics drive plant responses to warming. Science, 368, 772-775. https://doi.org/10.1126/scien ce.aba6880

Zhang, Y., Sherstiukov, A. B., Qian, B., Kokelj, S. V., \& Lantz, T. C. (2018). Impacts of snow on soil temperature observed across the circumpolar north. Environmental Research Letters, 13, 044012. https:// doi.org/10.1088/1748-9326/aab1e7

Zhang, Y., Wang, S., Barr, A. G., \& Black, T. (2008). Impact of snow cover on soil temperature and its simulation in a boreal aspen forest. Cold Regions Science and Technology, 52, 355-370. https://doi. org/10.1016/j.coldregions.2007.07.001
Zhou, S., Williams, A. P., Lintner, B. R., Berg, A. M., Zhang, Y., Keenan, T. F., Cook, B. I., Hagemann, S., Seneviratne, S. I., \& Gentine, P. (2021). Soil moisture-atmosphere feedbacks mitigate declining water availability in drylands. Nature Climate Change, 11(1), 38-44. https://doi.org/10.1038/s41558-020-00945-z

Zomer, R. J., Trabucco, A., Bossio, D. A., \& Verchot, L. V. (2008). Climate change mitigation: A spatial analysis of global land suitability for clean development mechanism afforestation and reforestation. Agriculture, Ecosystems and Environment, 126, 67-80. https://doi. org/10.1016/j.agee.2008.01.014

\section{SUPPORTING INFORMATION}

Additional supporting information may be found in the online version of the article at the publisher's website.

How to cite this article: Lembrechts, J. J., van den Hoogen, J., Aalto, J., Ashcroft, M. B., De Frenne, P., Kemppinen, J., Kopecký, M., Luoto, M., Maclean, I. M. D., Crowther, T. W., Bailey, J. J., Haesen, S., Klinges, D. H., Niittynen, P., Scheffers, B. R., Van Meerbeek, K., Aartsma, P., Abdalaze, O., Abedi, M., ... Lenoir, J. (2021). Global maps of soil temperature. Global Change Biology, 00, 1-35. https://doi.org/10.1111/gcb.16060 